\title{
Exploring the Meaning of Sustainability within Three Selected Institutions of the Graphic Design Field: A Phenomenological Study
}

Szilvia Kadas

Follow this and additional works at: https://researchrepository.wvu.edu/etd

\section{Recommended Citation}

Kadas, Szilvia, "Exploring the Meaning of Sustainability within Three Selected Institutions of the Graphic Design Field: A Phenomenological Study" (2018). Graduate Theses, Dissertations, and Problem Reports. 7194.

https://researchrepository.wvu.edu/etd/7194

This Dissertation is protected by copyright and/or related rights. It has been brought to you by the The Research Repository @ WVU with permission from the rights-holder(s). You are free to use this Dissertation in any way that is permitted by the copyright and related rights legislation that applies to your use. For other uses you must obtain permission from the rights-holder(s) directly, unless additional rights are indicated by a Creative Commons license in the record and/ or on the work itself. This Dissertation has been accepted for inclusion in WVU Graduate Theses, Dissertations, and Problem Reports collection by an authorized administrator of The Research Repository @ WVU.

For more information, please contact researchrepository@mail.wvu.edu. 
Exploring the Meaning of Sustainability within Three Selected Institutions of the Graphic Design Field:

A Phenomenological Study

\author{
Szilvia Kadas \\ Dissertation submitted \\ to the Davis College of Agriculture, \\ Natural Resources and Design, School of \\ Design and Community Development \\ at West Virginia University \\ in partial fulfillment of the requirements \\ for the degree of \\ Doctor of Philosophy in \\ Human and Community Development
}

\begin{abstract}
Katie Baker-Jones, Ph.D., Committee Chairperson
Robert G. Britten, Ph.D.

Ron Dulaney Jr, M. Arch

Kerry S. Odell, Ph.D.

School of Design and Community Development
\end{abstract}

Morgantown, West Virginia

2018

Keywords: Graphic Design Research, Sustainable Design, Design Ethics, Phenomenology, Socially and Environmentally Responsible Design

Copyright 2018 Szilvia Kadas 


\title{
ABSTRACT \\ Exploring the Meaning of Sustainability within Three Selected Institutions of the Graphic Design Field: A Phenomenological Study
}

\author{
Szilvia Kadas
}

This qualitative study builds on existing literature that identified a delayed shift toward sustainable practices in the commercial graphic design industry. A lack of consensus about what sustainability and sustainable practices mean in the context of graphic design could be one of the reasons for this delayed shift. Because institutions are a major contributor in shaping the implementation of sustainable practices (Alexander, 2006), this study explored the co-constructed meaning of the concept of sustainability in selected graphic design institutions. The overarching research question was asked: How does the collective voice of selected graphic design institutions conceptualize sustainability? The three selected graphic design institutions were (a) the most broadly circulated graphic design professional trade magazines, (b) the primary professional organization of graphic designers, and (c) graphic design higher educational programs. This dissertation applied a phenomenological approach to conduct document analysis on the textual content produced by these selected institutions. All data was collected and analyzed in the fall of 2017. After coding and analyzing the data, this study brought to surface some reoccurring themes that occupied the discourse within the selected institutions regarding sustainable design. The main themes for the overarching research question yield that within the examined datasets, when sustainability was mentioned, 46 percent of the texts referred to the challenges of working sustainably, 36 percent of the texts projected sustainable graphic design as a vehicle to change the mainstream culture to a more sustainable lifestyle, and 18 percent of the texts referenced sustainability as a relevant and actionable concept in graphic design. The analysis aimed to identify the main themes of the underlying values concerning sustainability to establish an up-to-date assessment of the common meaning of sustainability in the three selected graphic design institutions. This research was conducted in hopes of furthering the discourse of sustainability within the graphic design field. 


\section{DEDICATION}

To my grandfather, Dr. Uhr Győzö. For his compassion, wisdom, and strength in life. 


\section{ACKNOWLEDGMENTS}

First, I wish to express my gratitude to my supportive dissertation committee: to my chair Dr. Katie Baker Jones (fashion, dress \& merchandising) and committee members Professor Ron Dulaney (interior design), Dr. Bob Britten (journalism and news design), and Dr. Kerry S. Odell (agricultural and extension education) for all the helpful guidance they provided during my research. I am very grateful to my multidisciplinary doctoral program and committee for encouraging me to learn and apply empirical research methods to my practical graphic design skills and examine my design discipline from a new perspective.

I would like to say thank you to the Davis College of Agriculture, Natural Resources \& Design and the Gradate Education Office at West Virginia University, who awarded me the Outstanding Merit Scholarship for Continuing Doctoral Students. This fellowship allowed me to focus my efforts fully on researching and writing my dissertation in the academic year of 2017-2018.

I also would like to express my appreciation to my supportive family. I am forever grateful for them for always believing in me and encouraging me to work hard to live a life filled with meaning. For me this meaning manifested in my devotion to teaching graphic design and my dedication to discovering my responsibilities as a graphic designer toward the environment and the greater society. 
TABLE OF CONTENTS

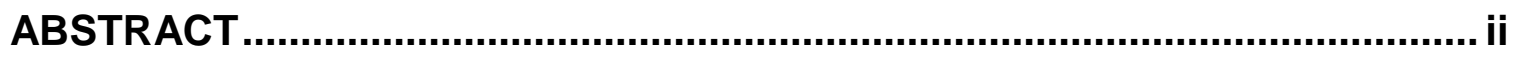

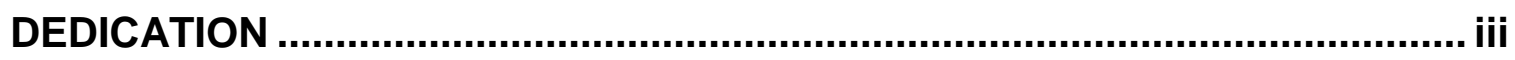

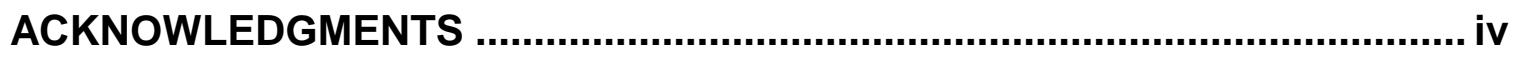

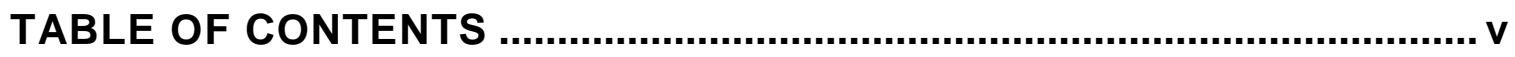

LIST OF FIGURES .................................................................................... vii

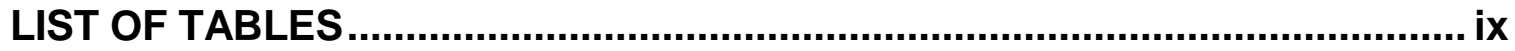

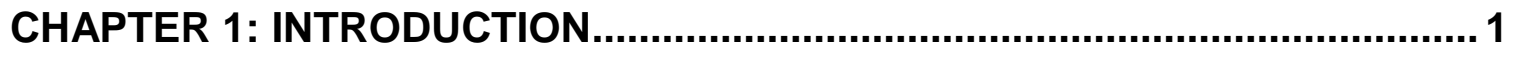

Problem Statement ................................................................................. 14

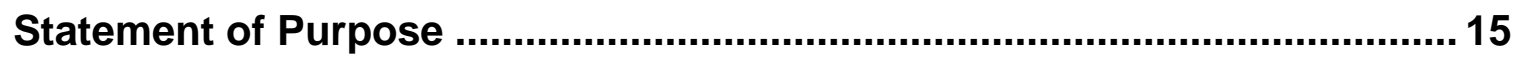

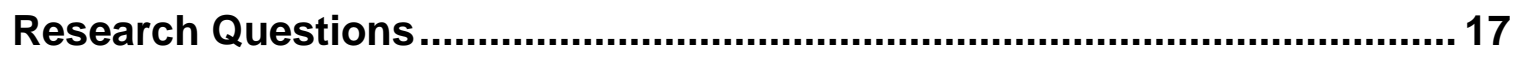

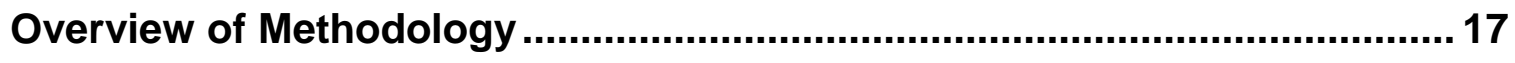

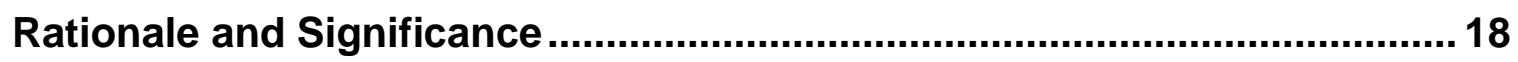

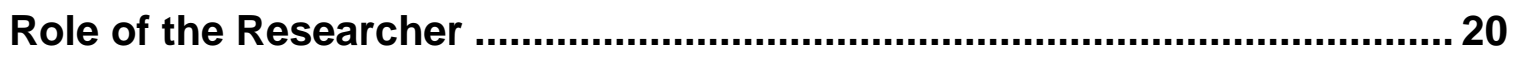

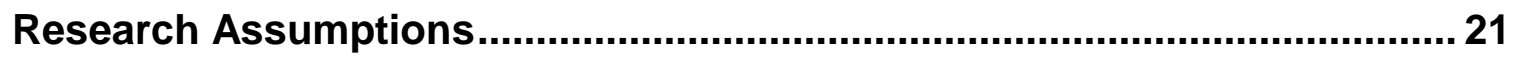

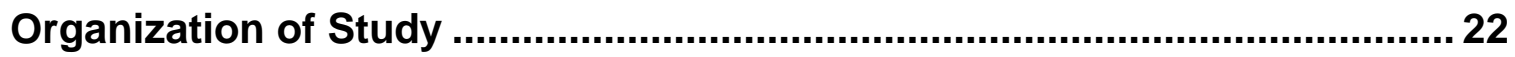

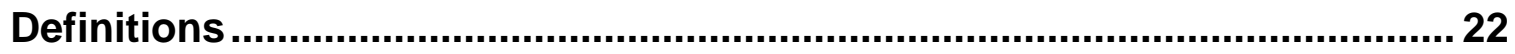

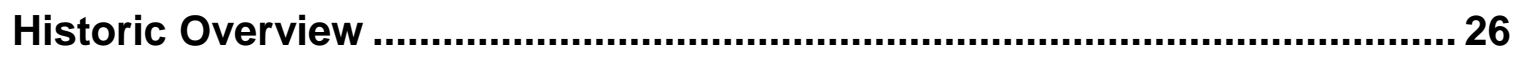

Sustainable Models in the Graphic Design Field....................................... 37

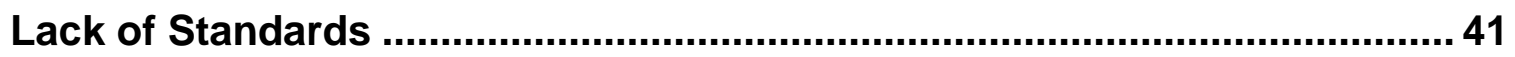


Current Resources and Approaches Supporting Sustainable Initiatives.... 47

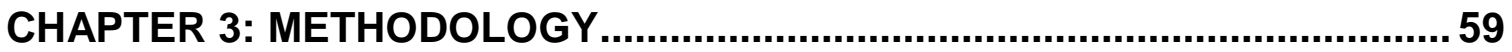

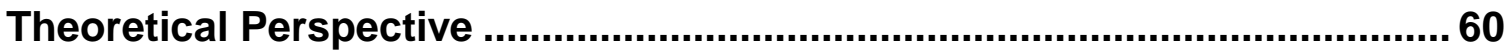

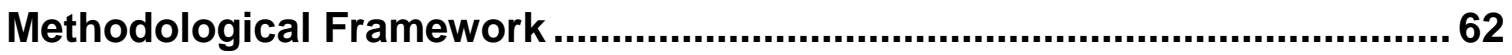

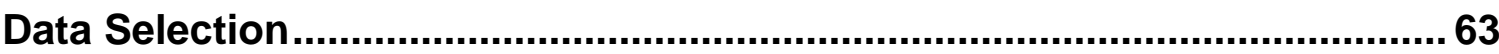

Data Collection Method.................................................................................. 71

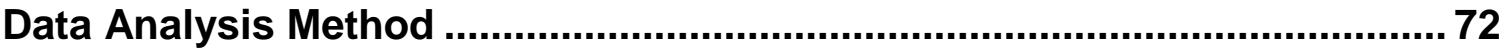

Research Procedure

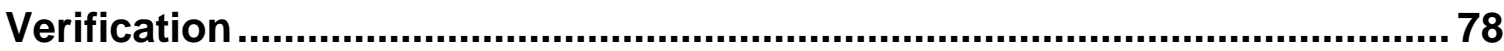

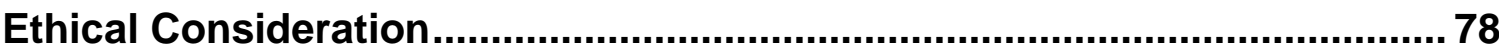

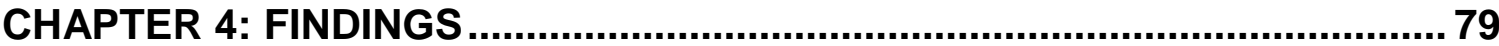

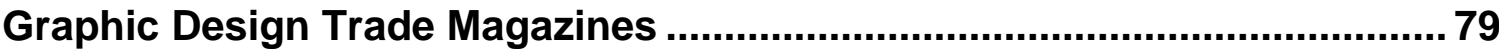

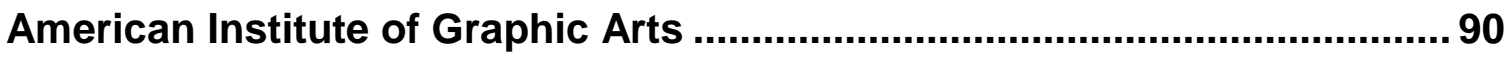

Graphic Design Higher Educational Programs........................................... 96

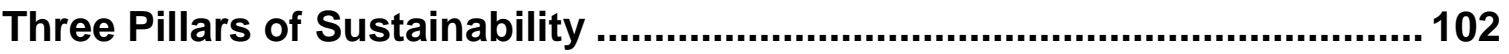

Overview and Discussion of Sustainability within the Data .......................106

Visual Representation of Sustainability .................................................112

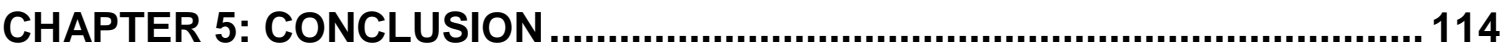

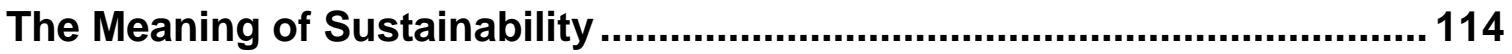

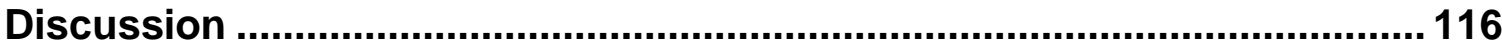


Contribution

Opportunities for Future Research ............................................................ 118

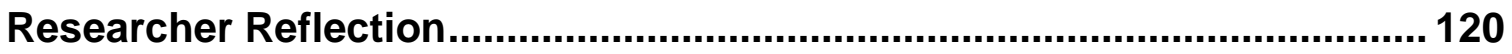

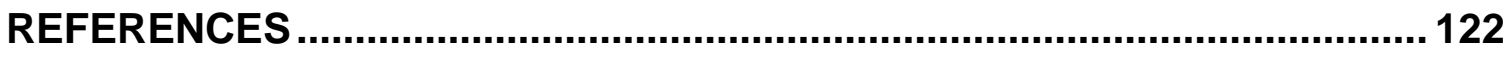

VITA 


\section{LIST OF FIGURES}

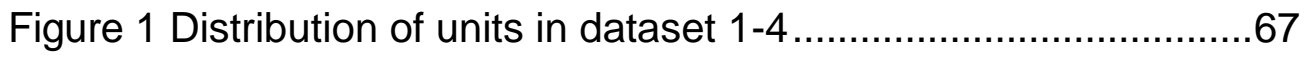

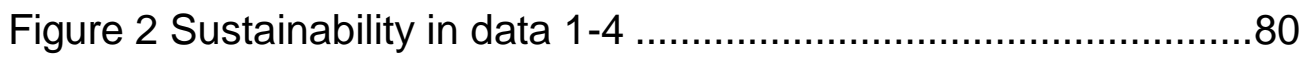

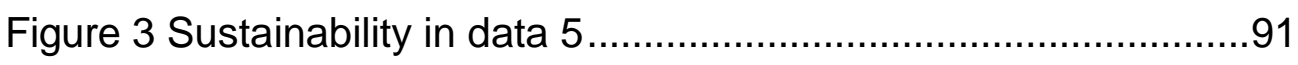

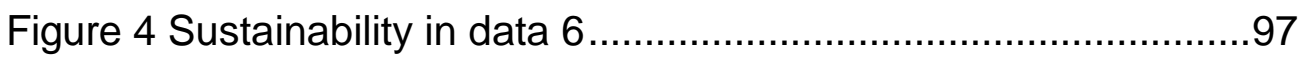

Figure 5 Distribution of codes within the academic programs ............98

Figure 6 Three pillars of sustainability ..........................................102

Figure 7 Model of sustainability within the data ..............................104

Figure 8 Concept of sustainability within the data............................107 


\section{LIST OF TABLES}

Table 1 Main attributes of the four magazines ...................................64

Table 2 Attributes of the units from the AIGA website..........................68

Table 3 Attributes of the academic programs .....................................69

Table 4 Four research questions in connection with the datasets .......70

Table 5 In Vivo coding method-process ............................................76 


\section{CHAPTER 1: INTRODUCTION}

Today, many companies and trades are making efforts to reduce their negative impact on the environment and society, taking initiatives to re-think the way they design and integrate sustainable development into their business models (Verghese, Lewis, \& Fitzpatrick, 2012). Their goals include commitments to tackle poverty, end inequalities, and mitigate climate change. A recent study showed that in 2016 corporate sustainability became mainstream, as many corporate executives reported that sustainability was on their company's agenda (Kiron, Unruh, \& Kruschwitz, et. al., 2017). This means that these companies need manufacturers and service providers who can support these sustainable efforts. Graphic design is one of the service sectors within the market that connects production and consumption by providing visual communication for businesses (Davis, 2012). Therefore, mainstream graphic designers have a key function in the production chain; they are one of the connecting links "between client and producer, and raw materials and the manufacturer" (Sherin, 2013, p. 10).

There are growing interests and initiatives in sustainable graphic design (Benson \& Perullo, 2017; Carroll 2012; Dritz 2014; Gavos, 2012; Jedlička 2009a, b; Perkins, 2006; and Sherin, 2013), but the graphic design profession has not yet come to a consensus on a clear definition or set of criteria to assure consistent standards for sustainable design (Dritz, 2014). Dritz cautioned the design profession that "this has created misunderstanding and potentially missed opportunities for graphic designers and the business they serve" (2014, p. 46). Furthermore, Anne Chick (2011) stated "contemporary design professionals have 
been struggling with the challenges posed by addressing the core concept of sustainability development in earnest for over thirty years" (p. 52). Alastair FuadLuke (2009) pointed out that "sustainability has many flexible definitions, depending on its context and the field of study" (p. 23). Dresner (2002) commented that the problem with the concept of sustainability is not that it is meaningless, but that it is an adverb or qualifier that has different meanings to different people, therefore "it is a contestable concept like liberty and justice" ( $p$. 2). Therefore, this study examined what sustainability means to the collective voice of graphic design institutions, and analyzed the most common values and beliefs that currently occupy the graphic design selected institutions regarding sustainability.

In spring 2017 a pilot study was conducted (Kadas \& Britten, 2017) to examine the language used to communicate the concept of sustainability to designers within the single issue of GD USA 2016 October trade magazine. The research methodology and method of analysis was identical to this phenomenological study, only the scope of data was limited to a single issue. The pilot study revealed that similar concepts to sustainability such as environmental responsibility and social responsibility, design for good or for positive change, socially conscious and green design were often blurred and merged into "responsible design." Gordon Kaye, the editor of the GD USA magazine stated: It has come to feel anachronistic to invite design firms to participate in a traditional 'green' issue because sustainable design and socially responsible design are so intertwined (p. 28). The publication sets the tone for 
these ambiguous terms by stating that this section was once called "green design," but after weeks of "soul searching," they landed on the still unsatisfying name of "responsible design" (Responsible Design, 2016, p. 28).

The magazine's editor Gordon Kaye, clarified that "in the early days, the focus was well-meaning but narrow," but over time designers broadened their spectrum and "moved beyond asking questions about their specific area of design and production expertise, and sought to align sustainability with the client's brands, mission, processes, and practices in ways that are real, verifiable, transparent, commonsensical" (p. 28). Also, the editor explained that the name "responsible design" was more suitable than "sustainable design", because it merged together these similar ideas: "blurring or erasing the lines between...concepts [like] environmental responsibility and social responsibility, design for good and for positive change" (p. 28).

Observing this new trend within the graphic design discourse, the special issue reflected the changing understanding of "green design," and "sustainable design" which the editors argued no longer focused solely on materials, but incorporated a more holistic understanding of the designer's role in making a societal difference. As each case is different, the editors noted, "designing responsibly matters no matter how you label it or what you call it" (p. 28). This sentence reflected a perceived need to keep an open mind about the many different approaches designers take on sustainability, but it may also give the impression that sustainability is an unclear, indefinable or even unreachable concept. This pilot study identified three recurring themes within the issue: 
choosing the right client, mission-driven design, and materials choice. Because of this pilot study I wanted to further investigate the meaning of sustainability and examine if this ambiguity exists when the scope of the research is broadened. Therefore, this dissertation set out to study how the concept of sustainability was communicated within the four most broadly circulated graphic design trade magazines. To triangulate my data, two other data sources were also included. These additional institutional sources were the primary professional organization of graphic designers' website and ten academic graphic design programs' mission statements. These academic graphic design programs were selected from an alphabetically ranked list of the GDUSA's 2017 article of the top graphic design schools in the United States. All three datasets were collected during fall 2017. These three data sources are a representative sample of the collective voice of the graphic design institutions that dictate, but also reflect the collective views and beliefs of the graphic design profession.

Institutions play a key role in setting professional standards, and this is especially true in the case of planning for sustainable development: "Institutions are the rules of the game in society" (Alexander, 2006, p. 2). Institutions are a major contributor in shaping and encouraging the implementation of sustainable practices (Alexander, 2006). Therefore, this research examined how graphic design as a collective voice conceptualized the three pillars of sustainability and similar concepts that are mentioned within the textual output of the three selected graphic design institutions. 
The graphic design field and its responsibilities. Graphic design is a collective term to refer to the diverse field of creative expression that uses visual problem-solving techniques to integrate text and images conveying ideas and messages to a targeted audience. Graphic design emerged from the graphic arts and become a distinct discipline by the mid-1900s (Cramsie, 2010). Patrick Cramsie (2010) noted that there were several aspects that differentiated graphic design from fine arts. For instance, the fact that graphic design was functional, "it was either selling or informing, or sometimes doing it both" (p. 9) and it's aspect of "reproduction is what distinguishes graphic design from most forms of art" ( $p$. 11). Cramsie defined graphic designers as a "service provider" (2010, p. 9), which also differentiated them from the autonomy of the artists. Also, graphic design has a direct link to consumer culture, and Davis (2012) brought to attention that "design and mass media are essential to capitalist economic system that assign social value to the consumption of material goods" (p. 98).

Cramsie (2010) further explained that graphic designers became worthy of study and being included in art history only in the last three decades. This lack of attention was due to "graphic design's role as a service provider [as it] masked whatever artistic merit it might have possessed" (p. 9). Graphic design occupies a creative realm that lays in-between the two poles of the high arts and the applied arts. It contains both aspects at the same time, which made it difficult for art historians to classify graphic design. Graphic design cannot be completely utilitarian nor can it be completely symbolic. If it is the former, then it becomes solely pragmatic, and if it is the latter, then it becomes autonomous art. 
Furthermore, this little attention was also due to the "lack of clarity about the status of graphic design [which] has been compounded by its ephemeral nature" (2010, p. 9). Graphic design includes different creative activities such as typography, identity design, magazine and book illustration, art-direction, packaging design, branding, interactive design, game design, and advertisement. The various forms of media application may also create challenges to view graphic design as a unified field. Graphic designers may use many different media for conveying messages, such as print and digital, screen-based media. A single graphic designer regularly engages in various types of projects, which requires most graphic designers to be familiar with a multitude of work areas across media and different applications (Jedlička, 2009b).

Still, it is fair to say that the collective focus of graphic design is neither the media nor the tools used in its production. Rather, it is on the creative methods that treat words and images on a two, - three, - or even four-dimensional surface and use reproduction (and often mass-production) to communicate ideas to society. Graphic designers' work exists in a social context and often has material consequences. This means that they bear a social and environmental responsibility for the material on which their designs are printed or the messages their designs convey to the public. The outcome of the design has an impact on society and the environment whether disseminated in print or digital media. Designers working in the digital media are increasingly concerned with their ethical responsibility. In September 2017 at a technological design conference 
called Techfest, designers declared and signed the The Copenhagen Letter, in which they manifested:

It is time to take responsibility for the world we are creating. Time to put humans before business. Time to replace the empty rhetoric of building a better world with a commitment to real action. It is time to organize, and to hold each other accountable. (n.p.)

This letter is the manifesto for a transparent society, a call for action to bring clarity and structure to the inherent chaos of the postmodern world in which ultimately business is put first.

The negative impacts of graphic design. Graphic design has a significant influence on society, the environment, and the economy. Research showed that currently brand identities and logos are more recognizable by the public than common animal species (Assadourian, 2010). Graphic designers create these brand identities and, thus, influence consumer ideologies. Design is a powerful tool for shaping the world and how we live in "marketing and advertising shapes consumer culture, including the self-image and personal values of buyers" (Perkins, 2006, n.p.). Davis (2012) stated that advertising "define[s] who we are and what we believe..." (p. 99). In this way, design may negatively influence consumer behaviors and practices, or not take advantage of the potential to positively influence consumers. For instance, The U.S. Environmental Protection Agency (EPA) urged American households and businesses to implement sustainable materials management (SMM) and 
embrace a system approach of the concept of Reduce, Reuse, and Recycle (EPA, 2016).

Today the main emphasis in packaging is placed on developing the sustainable supply chain by refining efficiency of the used materials to reduce the materials' environmental impacts (Dominic, Östlund, Buffington, \& Masoud, 2015). However, the visual communication on the packaging or elsewhere that would inspire, motivate, and inform consumers to recycle has not yet been realized effectively (Nordin \& Selke, 2010). Still more than 50 percent of municipal solid waste (MSW) in the U.S. ends up in landfills (EPA, 2016). The Sustainable Development Commission analysis confirmed that labels providing data about the ecological advantages or disadvantages of the products were unsuccessful in getting more shoppers to buy the more sustainable products (Maniates, 2010).

Nordin and Selke (2010) emphasized the need to differentiate the two distinct kinds of the social factors of sustainability: social equity and the consumer awareness and perceptions factor. Visual designers may have potential to motivate consumers with visual design to inspire sustainable consumer behavior change in this critical stage of the products' life (Jedlička et al., 2009). Ultimately the success of the full implementation of recycling is subject to the consumers' comprehension and sustainable action (Nordin \& Selke, 2010; Oki \& Sasaki, 2000).

However, the unsustainable practices of the graphic design profession go beyond the ideological negative or lack of positive influence it may have on 
society. The material products of graphic design have a large impact on the environment as well: packaging, advertisements, flyers, magazines, and other mass-produced ephemera (Scalin, 2017). In 2014 total municipal solid waste (MSW) in the USA was 258 million tons that included durable goods (furniture), nondurable goods (paper, clothing and packaging,) and other items such as food (EPA, 2016). To talk about the negative impact of print is also relevant, because surveys showed that the majority of graphic designers still identified print as their main area of practice (Gavos, 2012). Over half of the annual waste discarded into the United States landfills is printed material (Northwest Product Stewardship Council, 2015). Besides generating solid waste, the print industry also pollutes water and air. Further, the global print industry is charged with raw material depletion and high-energy consumption related to non-renewable energies (Jedlička et al., 2009). Paper creates the highest concern of all printed materials, as the U.S. produces almost 69 million tons of paper per year (EPA, 2016). It is thus important for designers to realize that their work contributes to a global system that requires sustainable practices.

To research the institutionalized design ethical guidelines in regard to sustainability is both timely and pressing. Empirical research in graphic design is still at its infancy as "traditionally graphic design theory has privileged intuition and creativity over empirical research" (Bennett, 2006, p. 14). Additionally, graphic designers argued that calculating the impact of their design work would only bring even more restrictions on their creative process (Bennett, 2006). However, I argue that measuring the potential negative impact of graphic 
designers and mitigating the harm of the designed object and service on society and the environment would elevate rather than limit the significance of graphic design work.

Graphic design profession in relation to the medium. The graphic design profession may include multiple different media and skills, which makes the graphic design field and training specialized and nuanced. The primary media graphic designers may use are print and digital which may include web and broadcast. According to Adrian Shaughnessy (2005) what ultimately defines the profession is the overarching goal to create a unique visual language, which brings balance between text (typography) and image (photography or illustration), and content and form. Marshall McLuhan (1964) gave voice to the power of the medium in which a designer chooses to produce their work:

In a culture like ours, long accustomed to splitting and dividing all things as a means of control, it is sometimes a bit of a shock to be reminded that, in operational and practical fact, the medium is the message. This is merely to say that the personal and social consequences of any medium — that is, of any extension of ourselves—result from the new scale that is introduced into our affairs by each extension of ourselves, or by any new technology. (p. 7)

Furthermore, W.J.T. Mitchell (2005) indicated that "a medium is more than the materials of which it is composed. It is... a social practice, a set of skills, habits, techniques, tool codes, and conventions" (p. 10). 
As there are many media involved in the graphic design profession it is important to acknowledge that the social, ecological, and economic footprint of the media the graphic designer is applying to communicate their ideas. While the print media may have both large social and ecological footprints, the digital media may have less direct negative footprint on the environment but still have enormous social and environmental responsibility that is necessary in order to practice ethically. When discussing print media specifically, the term is understood as print design in this document and is applied throughout the manuscript.

There are many specialized design career options for a graphic designer depending on the focus of the technological skillset, media, and methods of problem-solving that is acquired through their education and work experience. A graphic designer may work as an art director, advertising designer, book and magazine designer, illustrator, creative director, environmental graphics designer, interaction designer, motion designer, package designer, user experience designer (UX), user interface designer (UI), visual designer, or web designer which all have very specific attributes.

According to the recent US Department of Labor report, Occupational Outlook Handbook (2018), though most graphic designers are employed in publishing houses, public relations departments, advertising agencies, independent design studios, or as in-house graphic designers in larger corporations, in 2016 about 1 in 5 graphic designers were self-employed freelancers. This may be because while the most common work environment for 
a graphic designer is to be an in-house graphic designer, several companies may outsource their graphic design projects to freelancers or independent design studios. Today, in the midst of the technological and ecological transition, the public and therefore the market is increasingly responsive to social and environmental issues. Thus, it directly affects the demand and requirements graphic designers may face in their career. As such, there is a demand for designing sustainable services in each medium.

\section{The status of sustainability in graphic design education and} professional practice. The National Association of Schools of Art and Design (NASAD) and the American Institute of Graphic Arts (AIGA) are both institutional bodies that mention sustainability as a standard and essential design practice for their members. For instance, the NASAD guidelines recommended discussing matters of lifespan and sustainability in the classroom. Specifically, it mentioned that undergraduate design students should have the "ability to justify the use of resources and identify long-term consequences of design action in their solutions to problems" (NASAD Handbook 2017-18, 2017, p. 116). The document endorsed all three pillars of sustainability as a fundamental foundation of good practice. It drew attention to the importance of exercising "critical judgment about the student's own design and the design of others with regard to usefulness, usability, desirability, technological feasibility, economic viability, and sustainability in terms of long-term consequences" (NASAD Handbook 2017-18, 2017, p. 120). Furthermore, the NASAD Handbook 2017-18 (2017) also suggested developing students' "functional knowledge of ...ethics, intellectual 
property, labor issues, and decisions associated with ecological and social responsibility and sustainability" (p. 122). These guidelines firmly demonstrate NASAD's strong commitment to a comprehensive design education that includes the core principles of sustainable design.

The American Institute of Graphic Arts (AIGA) encourages graphic designers to take ownership of their ethical obligations. In 2010 the AIGA published its Standards of Professional Practice, in which it outlines some of the main ethical obligations of its members. Item 7.3 , added in 2011 , declared the designer's responsibility to society and the environment: "A professional designer shall consider environmental, economic, social, and cultural implications of his or her work and minimize the adverse impacts" (AIGA, 2010, n. p.). While the guideline does not explicitly use the word sustainability, it does refer specifically to the three pillars of sustainability, which are the social, environmental, and economic systems in our interconnected world (Elkington, 1998). However, this point does not go into any further standards or details for implementation of sustainable practices. It is the responsibility of the graphic design practitioner to apply their judgment to interpret this guideline into her practice.

Some graphic designers are searching to reduce their negative impact on society and the environment. However, Thomas Russ (2010) also posed the question, "as the designer undertakes a design that is intended to meet some degree of sustainability but that has no objective standard on which to rely, what will guide the process?" (p. 67). Russ (2010) argued professional institutions must take the lead and define its ethics regarding sustainability. Therefore, this 
research examined how graphic design as an institution conceptualizes the three pillars of sustainability (social, environmental, and ecological) in three selected graphic design institutions: (1) professional trade publications, (2) the primary professional organization of graphic designers, and (3) academic graphic design departments.

\section{Problem Statement}

Research has shown that consumers prefer sustainable products and services and therefore businesses have adapted to these changing consumer demands (Kiron, Unruh, \& Kruschwitz, et. al., 2017). The global market is in transition to operationalize sustainable practices in production chains. Also, given that graphic designers' work may directly influence consumer behavior and values on a large scale, they not only need to be aware of the effectiveness of their work for their clients, but also of the implications of their work for the greater society and the environment (Jedlička, 2009a, b). Despite this need, the graphic design industry is lagging behind adopting specific sustainable guidelines to help lead the graphic design practices (Benson \& Perullo, 2017; Carroll 2012; Dritz 2014; Gavos, 2012; Jedlička 2009a, b; and Perkins, 2006).

Institutions create "cognitive, normative, and regulative structures and activities that provide stability and meaning to social behavior" (Scott, 1995, p. 33) and therefore shape the norms and values of a profession. Thus, it is necessary to examine the state of the institutionalization of sustainability within the graphic design profession. Failing to adopt sustainable theories and practices into the graphic design institutions will produce an unsustainable graphic design 
profession. This may result in aspects of the graphic design industries falling behind in the global marketplace.

\section{Statement of Purpose}

Through this research, a systematic analysis of the phenomena of sustainability within three representative graphic design institutions was conducted. To understand the meaning of sustainability within the cultural context at hand, textual document analysis was conducted on the concept of sustainability in the content produced by three selected institutions: (a) professional trade publications, (b) the primary professional organization of graphic designers, the American Institute of Graphic Arts (AIGA), and (c) academic graphic design departments. The analysis identified main themes that might help explain how sustainability was manifested within the cultural context of these institutions.

After analyzing the constructed meaning of the concept of sustainability within the institution of the graphic design profession, the main themes that were most dominant in the representation of sustainability within its core institutions were identified. Additionally the most common focus of the concept of sustainability was identified by dividing sustainability into its three pillars. Because of the 2017 pilot study, I furthermore included similar words and phrases synonymous to sustainable design such as design for good and responsible design. It was necessary to include similar words and phrases because graphic design institutions interpret sustainability in many different ways. There is no one definition or consensus of what sustainability means in 
graphic design. This investigation of the meaning of sustainability seeks to understand the challenges that the mainstream graphic design field faces in adopting the concept of sustainability. This research points out the current gap in the graphic design discourse on how to solve the adoption of sustainability into the mainstream graphic design institutions. The purpose of this analysis is therefore to help the graphic design field move toward a consensus about what sustainability is by assessing how it is currently communicated to graphic designers. The analysis may bring to light underlying issues that could be improved to stimulate a more sustainable graphic design profession.

I examined the phenomena of sustainable design with qualitative empirical research because of my eagerness to document the sustainability gap in the graphic design industry that goes beyond my own professional practice. I believe that mass-produced ephemera, generated by graphic designers may have a negative impact on society and the environment, and empirical research may help practice to mitigate these negative impacts. Therefore, this research created an interdisciplinary inquiry that integrates social research into the field of design. I find the role of empirical research as a systematic and rigorous tool essential in closing the gap of sustainability in an effective manner. I therefore advocate for a greater presence of a clearly defined knowledge that can provide responsible leadership to graphic designers in our complex and interconnected society, environment, and the economy. 


\section{Research Questions}

To understand the meaning of sustainability within the cultural context at hand, the overarching research question posed was: How does the collective voice of selected graphic design institutions conceptualize sustainability? To assess this question, this research was divided into three sub-questions: (RQ1) How have contemporary mainstream graphic design trade magazines articulated the concept of sustainability? (RQ2) How has the American Institute of Graphic Arts (AIGA) communicated the concept of sustainability to their members? (RQ3) How have the mission statements and web textual content of graphic design higher education departments conceived of sustainability? (RQ4) In what ways were the three pillars of sustainability (social, environmental, and economic) presented within the data?

\section{Overview of Methodology}

This research is grounded in the epistemological stance of constructionism. Because "meaning is not discovered, but constructed," (Crotty, 1998, p. 9) the meaning of sustainability is neither objective nor subjective, but rather created by the collective voice of institutions that shape the values and beliefs of society and consequently the individuals. Although the graphic design institutions may be constituted of individual graphic design educators and practitioners who write about their profession, this research looks at the collective goals and missions of the selected institutions. To study sustainability within the field of graphic design from an "institutionalist" (Scott, 1995, p. ix.) perspective is vital, because the institution is "[...] a crystallization of meanings" at its purest 
sense (Berger \& Kellner, 1981, p. 31). Thus, the way these graphic design institutions discuss and project sustainability to their primary audiences can have far reaching affects. It affects the values and beliefs of the graphic designers, and it bears an ideological effect on the general public's understanding and conception of sustainability.

The phenomenological approach is applied in this study because phenomenology examines the "common meaning [...] of a concept or a phenomenon" (Creswell, 2013, p. 76). Specifically, the hermeneutic approach of phenomenology is chosen to conduct this study, as the primary focus of this research is to understand the essence of the phenomenon of sustainability from textual descriptions (content produced by graphic design institutions).

"[Texts]...are means of transmitting meaning—experience, beliefs, values—from one person or community to another. Hermeneutics assumes a link between the two that makes the exercise feasible" (Crotty, 1998, p. 91). This methodology is further discussed in-depth in Chapter Three.

\section{Rationale and Significance}

The growing demands for sustainable services from consumers and businesses created a stage for the graphic design field to incorporate sustainability into the mainstream design practice. To achieve that, sustainability must be represented and communicated in core graphic design institutions. The way graphic design institutions present the concept of sustainability shape and effect the perception of their audiences about the sustainable graphic design. Therefore, this study sets out to examine textual content produced by the three 
main graphic design institutions regarding sustainability. Institutional attitudes toward sustainability matter, because these attitudes filter into the professional values and beliefs of individual graphic designers. Through their work they influence ideologically the perception of the public. Because literature indicated the absence of a specific criteria, and the subjectivity of the concept of sustainability within the graphic design field, an interpretive approach of the phenomenology was chosen to understand what sustainability means in the graphic design institutions, and how it is projected to graphic design practitioners.

D'Andrade (1984) explained that rules of a culture directly influence values and behaviors of individuals, and "in the cognitive paradigm, what a creature does is, in large part, a function of the creature's internal representation of its environment" (p. 88). Institutions stand on three distinct foundations: "regulative," "normative," and "cognitive" elements (Scott, 1995, p. 35). Thus, for graphic designers to embody sustainable practices, designers need to be informed, trained, motivated, and regulated by its key professional institutions.

As a gateway and first step to further social research and ultimately help standardize sustainable solutions, my dissertation sets out to understand where the mainstream graphic design institutions position themselves regarding sustainability. I will focus my qualitative analyses from an "institutionalist" (Scott, 1995, p. ix) standpoint, examining the way core institutions communicate the concept of sustainability to future and contemporary graphic designers. Thus, I will provide a systematic analysis to identify main themes and patterns that are 
most common in graphic design professional trade communications regarding the three pillars of sustainability (society, environment, and economy).

\section{Role of the Researcher}

In qualitative research the researcher is the instrument of the study (Ary, Jacobs, \& Sorensen, 2006). In this study, the researcher played a dominant role in sample selection, coding, analysis, and interpretation of the data. The axiology of the qualitative research rejects the notion of an objective or neutral researcher and argues "we always bring certain beliefs and philosophical assumptions to our research" (Creswell, 2013, p. 15). Therefore, I believe in a transparent reflection of my worldview, philosophical beliefs, and assumptions, including my professional and cultural values.

My role as a social researcher may bring an unusual perspective into the graphic design industry, as currently the field of graphic design predominantly builds its theories on anecdotes and visual precedence as its method of inquiry (Bennett, 2006). As a graphic designer and as a member of the graphic design community, I respect and appreciate the creative visual process, and reject any rigid restrictions on this predominantly intuitive practice. However, I believe that graphic design can be more effective when combining intuition with research. Analyzing the graphic design profession through empirical research is one way to identify challenges encountered by the field around the adoption of sustainable practices. My goal is to identify the main themes that occupy sustainability discourse within the textual content of the selected institutions. This analysis may 
point to specific issues that hold back the graphic design profession from moving forward with its sustainability efforts.

\section{Research Assumptions}

This research builds on a central assumption that the graphic design industry has not yet came to consensus on the concept of sustainability, and therefore the industry has been slow to provide sustainable graphic design services to the market. This assumption is derived from the literature (Benson \& Perullo, 2017; Carroll 2012; Dritz 2014; Gavos, 2012; Jedlička 2009a, b; Perkins, 2006; and Sherin, 2013) and my experience as a graphic designer. Because professional institutions hold the power to influence the values and beliefs of practitioners, I therefore will investigate the concept of sustainability within selected institutions that represent the profession.

The Standards of Professional Practice demonstrated that sustainability is part of the AIGA ethical standard. Also, the National Association of Schools of Art and Design (NASAD), which accredits higher educational institutions in art and design, provides extensive recommendations on sustainable design goals and educational practices (NASAD Handbook, 2018, n.p.). Therefore, this research is building on the assumption that sustainability is part of the institutional culture both on the professional and educational level. This research is set to investigate how sustainability is presented within the textual communication of the institutional platforms of trade magazines, the AIGA's website, and in ten academic graphic design program mission statements. 


\section{Organization of Study}

Chapter two presents a review of the literature surrounding sustainability in graphic design. First, I will present a historical overview of the development of sustainable design and introduce current challenges and barriers that the industry faces. Then I will review current resources and approaches available to graphic designers that support sustainable initiatives. Finally, I will demonstrate how my research will fill these gaps in knowledge revealed through the literature review.

Chapter three outlines this study's theoretical perspective, methodological foundations, and a description of data selection and analysis. In chapter four I share my research findings by identifying the main discovered themes within the textual content of the selected three institutional platforms. Chapter five evaluates its findings and compares these themes across the examined institutional domains by finding underlying similarities within the discourse of sustainability. Chapter five offers a conclusion along with an in-depth discussion on significance of this research, pointing toward further implications.

\section{Definitions}

Below, the terms and key concepts used in this document are introduced and shall have the following meanings.

Environmental design. The term environmental design shall not be confused with environmentally friendly design. 
Environmental design is the field of developing physical, spatial environments (interiors and/or exteriors) to solve a particular need or create a specific experience. The field of Environmental Design could include Architecture, Urban Planning, Landscape Design, Interior Design, Exhibit Design and, sometimes, Event Design. (“Sustainable Design Dictionary," 2017, n.p.).

Institutions. In this study, graphic design institutions shall mean any establishment where a unified voice or agenda is carried out in order to instruct and guide graphic design students and professionals. "Institutions consist of cognitive, normative, and regulative structures and activities that provide stability and meaning to social behavior. Institutions are transported by various carrierscultures, structures, and routines—and they operate at multiple levels of jurisdiction" (Scott, 1995, p. 33).

Graphic design(er). The United States Department of Labor (2018) defined the graphic design profession as a collective term to refer to graphic design professionals who "create visual concepts, using computer software or by hand, to communicate ideas that inspire, inform, and captivate consumers. They develop the overall layout and production design for various applications such as advertisements, brochures, magazines, and corporate reports" (n.p.).

Sustainable development. The term sustainable development was coined in 1987 in the Our Common Future, also known as the Brundtland Report. This document defined the term as "The ability to make development sustainable to ensure that it meets the needs of the present without compromising the ability 
of future generations to meet their own needs" (UN World Commission, 1987, p. 16).

Sustainable graphic design. "The process of developing products, services, and organizations that comply with the principles of economic, social, and ecological sustainability. There are many principles of sustainable design, including a customer-centric approach, dematerialization, transmaterialization, and biomimicry." ("Sustainable Design Dictionary," 2017, n. p.).

Sustainable design. Sustainable design as the NASAD handbook stated, is "The consequences of design in interdependent systems, lifespan of designed objects, and use and disposal of resources (NASAD Handbook 2017-18, p. 116).

Sustainable packaging. The following outlines the sustainable definition from the two-main industry-based sustainable packaging organizations. Both sustainable packaging organizations developed a vocabulary to define what is responsible and sustainable packaging and both operate simultaneously to transform the packaging industry to a sustainable one. The Sustainable Packaging Coalition $\AA$ (SPC) is a project of GreenBlue $\AA^{\circledR}$, based in the United States. SPC is working to form an industry-and science-based sustainable vision of packaging. SPC put together a list of qualities that describe a common ground in understanding what sustainable packaging means. According to their definition, a package is sustainable if it:

1. Is beneficial, safe \& healthy for individuals and communities throughout its life cycle;

2. Meets market criteria for both performance and cost; 
3. Is sourced, manufactured, transported, and recycled using renewable energy;

4. Optimizes the use of renewable or recycled source materials;

5. Is manufactured using clean production technologies and best practices;

6. Is made from materials healthy throughout the life cycle;

7. Is physically designed to optimize materials and energy;

8. Is effectively recovered and utilized in biological and/or industrial closed loop cycles. (www.sustainablepackaging.org).

The Australian-based Sustainable Packaging Alliance (SPA) similarly to SPC, distributes worldwide tools, such as $\mathrm{PIQET}^{\circledR}$ (discussed later in the review), and other resources in order to help assess the environmental impact of packaging. SPA is building its foundation on the following four sustainability principles. Sustainable packaging design must be

1. effective (offer social and economic benefits)

2. efficient in its use of materials, energy, and water;

3. cyclic (create a closed loop system where products are recoverable through industrial or natural processes);

4. safe (SPA, 2015).

Both models attempt to capture the key principles of sustainable packaging to serve as a model for adoption in the industry. Although these definitions have been clarified for industry professionals, they have not been communicated on the packaging. The consumer may know that packaging contains some recycled 
or recyclable materials, but has no way of knowing if other elements of sustainable packaging were part of the production and design process. These elements of sustainability are rarely communicated to the consumer.

\section{CHAPTER 2: REVIEW OF LITERATURE}

This chapter surveys the topic of sustainable, ethical, responsible, and socially conscious graphic design found within literature. First, I will present the history of ethical considerations and sustainability in graphic design. This historical overview will provide an outline of the adoption of the triple bottom line of sustainable development into the field of graphic design and demonstrate the different types of sustainable graphic design models conceptualized by contemporary graphic designers. Next, I will reveal challenges and barriers toward sustainability identified within the literature. Further, sustainable solutions for graphic designers offered in the literature are explored. This literature review aims to articulate the existing theories and practices surrounding sustainability in graphic design and then compare them with the concept of sustainability constructed by the prevailing graphic design institutions.

\section{Historic Overview}

\section{Ethical considerations and sustainability in graphic design. When}

graphic designers discuss the need to integrate ethical considerations into design practice, three main writings come to the surface: First Things First: A Manifesto by Ken Garland (1964), its later revision, First Things First Manifesto 2000 by Tibor Kalman, and The Road to Hell by Milton Glaser (2002). First Things First: A Manifesto (1964) - written by graphic designer Ken Garland and signed by 
twenty-two contemporary visual communicators - was a call for a more ethical practice in the field of graphic design. It pointed out some of the ethical challenges mainstream graphic designers face while working for commerce. The manifesto advocated for an educational reform, and to place larger public focus on cause related services that would improve greater society. The 1964 manifesto was significant, because graphic designers for the first time publicly demonstrated awareness of the ramifications of their designs. Garland was driven by his social convictions, in which he disagreed with graphic design's entanglement with consumer and corporate culture. Garland (1964) wrote:

We do not advocate the abolition of high pressure consumer advertising: this is not feasible. Nor do we want to take any of the fun out of life. But we are proposing a reversal of priorities in favor of the more useful and more lasting forms of communication. (n.p.)

Garland's vision for graphic design was to embrace social and political issues and create meaningful designs that went beyond the tricks and gimmicks of a salesperson.

In The Road to Hell, Milton Glaser (2002) published a list of twelve common graphic design activities that required designers to misrepresent or to bend the truth in their everyday practice. Glaser (2002) used the metaphor of Dante's Hell to describe the graphic design profession. He explained that if graphic designers wanted to get to purgatory instead of hell, they must at least acknowledge their works' falsification. Although these writings brought awareness on the moral shortcomings of the commercial graphic design 
profession, they remained in the realm of the personal moral pursuit of activism. I argue that the only way graphic designers will be able to move toward a sustainable design is through institutionalizing main ethical professional standards in regard to social, environmental, cultural, and economic impacts. This may require future collaborations between different design disciplines, creative practice, manufacturing, and empirical research.

Furthermore, Shaughnessy (2005) wrote in her book How to be a Graphic Designer, Without Losing Your Soul that "Integrity in design is a bit like obesity in ballet dancers- you don't often see it" (p. 25). She explained that the reason for this is not because "designers lack honesty and decency; quite the opposite. Rather it is because preserving integrity in the remorseless climate of modern business is difficult" (p. 25). This statement again takes us back to the preliminary argument that graphic designers serve commerce, and therefore they should obey the needs and wants of the clients even if that is not in the best interest of the public or conflicts with their own personal moral values. The lack of autonomy graphic designers may feel over the design decisions they make may cause a detachment from the social and environmental responsibility their work carries.

Shaughnessy (2005) argued that the solution is for graphic designers to start standing up for the moral values and start negotiating ethical solutions with their clients: "By standing up for yourself, by having beliefs (creative and ethical), and perhaps most importantly of all, by questioning what you are asked to do as a designer, you can acquire self-respect, which is the first step on the path to 
earning the respect of clients and other designers" (p. 27). When Shaughnessy (2005) interviewed the famous contemporary graphic designer Neville Brody, about the necessity of integrating ethical considerations into the graphic design profession, Brody replied that integrity in design is what differentiates the good from the bad" (p. 27). That brings up the following question: are there historic precedents of any relationship between moral responsibility with the arts and design?

Tolstoy (1995) explained that Alexander Gottlieb Baumgarten (1714- 62), the founder of aesthetics believed that man perceives beauty through its senses in nature, therefore the mission of art is to imitate and mimic nature. Other philosophers such as Moses Mendelssohn (1729-86), and Ludwig Schütz (18381901) however, argued that the main goal of art is not only beauty but it is to achieve moral perfection, as good is the moral will of man. Another aesthetic philosopher who contradicted this belief was Immanuel Kant (1724-1804). Kant's aesthetics were based on the premise that humans perceive themselves outside of the natural world; therefore all their creations are artificial. This viewpoint created a duality not only between man and nature, but also between nature and art. Schiller (Tolstoy, 1995), one of Kant's followers, defined the purpose of fine art as the pursuit of beauty, without regard for usefulness. This short overview of aesthetics was necessary to understand the capstone relations of nature, art and design. These conflicting beliefs illustrate the manifold philosophical grounds upon which art can be perceived. However, as graphic design originates from the fine arts, the debate whether design has a moral obligation to do good in the 
world is relevant. Because many graphic designers serve commerce, some graphic designers may feel morally isolated as the underpinning of graphic design is in the arts and not business.

\section{Development of sustainable design and concepts, such as green}

design, ecological design. Design became aware of its environmental footprint in the late 1960s. Despite the awareness of the negative impacts of design, the scale of natural environment exploitation and pollution has been only growing. Brown and Schmidt (2014) wrote: "Human activity is changing the earth at a global scale... Of course, humans have been altering the earth to our advantage for thousands of years, but the planetary scale and influence of our impact is unprecedented" (p. 64). Theologian Thomas Berry suggested an ecozoic approach based on a "mutual -enhancing human-Earth relationship," rather than maintaining our current technozoic lifestyle that consumes its surroundings (Brown \& Schmidt, 2014).

The environmental limit of human intervention into nature has been puzzling over the years. For instance, the Radical Environmentalism and Deep Ecology ideological movements of the 1960 s rejected any intervention into "nature," as they believed that any minor alteration of nature would cause irrecoverable harm to the ecosystem (Chiapponi, 1998, p. 109). To understand the connection between ecology and design, I will first review the three terms often attached to design: green, ecological, and sustainable. In the following, I examine the meaning behind each term. It is important to mention that these terms are used in all sorts of design areas, not specifically graphic design. The 
three terms appeared around the late ' 60 s as the public became environmentally conscious due to scientific data reports showing the significant impact humans were having on the Earth's ecosystem by the current consumerist lifestyle.

Pauline Madge (1997) summed up the meaning of the three terms, which are often used interchangeably in graphic design. The ideology of "green design" (p. 329) dates to the late 1960s, but it was not until 1980 that the media popularized the issue. Increased media interest raised public awareness on green topics. The color green became a mainstream token and an advertising strategy. Green design did not reject either consumerism or the industrialized world. On the contrary, it boosted consumption under the new slogan: green. In 1988, John Elkington and Julia Hailes published the Green Consumer Guide. "Light green" became the political term of green consumerism, which raised opposition in many who believed in a more radical "dark green" approach of solving environmental problems. There was an urge to step beyond "Green Consumerism" (Madge, 1997, p. 330).

According to Madge (1997) the term "ecological design" (p. 331) was used from the late '60s onward. In the 1990s there were many governmentally supported steps taken to reinforce global environmental standards and to include them into national policies. One of the examples of this was the European Union's Eureka program, where in 1991 a group of designers developed methods and processes to operationalize Eco-design. Furthermore, in the United Kingdom and the Netherlands multidisciplinary research began to unify 
institutions with industry to develop and integrate life cycle models into the production chain.

The term sustainability nourished the idea of a system that helped to keep up a healthy well-being on Earth. In the context of design, sustainability considers the entire life cycle of products, which re-introduced the idea of longlife and durable products moving beyond recycling (Madge, 1997). Jedlička (2009b), stated that the definition of sustainable development, which was coined by the World Commission on Environment and Development in 1987, is still wildly accepted and currently in use: "A sustainable development is development that meets the needs of the present without compromising the ability of future generations to meet their own ends" (p. 12). The various adoptions of the model of sustainable development into the graphic design field follow.

Today, sustainable development has become one of the primary concerns and efforts of the United Nations. In September 2015, 193 world leaders signed the 17 Global Sustainable Development Goals (SDGs) of the 2030 Agenda for Sustainable Development at the historic United Nations Summit in New York (Transforming Our World: The 2030 Agenda for Sustainable Development, 2015). The document called for global investment and effort toward improving the life of all people, tackling climate change, and providing prosperity and peace by working in partnership with one another.

Graphic design ties with commerce. Graphic design from the beginning was concerned with promoting ideas in a visual manner. Graphic design - also referred to as visual communication - is a modified continuation of the traditional 
graphic arts, therefore the history of the traditional graphic design is as old as human beings. The cave paintings from Lascaux c. $15,000-10,000$ B.C. are considered the earliest graphic art works (Meggs, 1998). The borderline between graphic design and art even today is elusive. Graphic arts gradually branched off from the other fine arts forms. As fine art was concerned with artistic expression, graphic art's concern was solving communication problems with visuals. As the printing press was adopted widely across Europe in the mid-1400s (Eskilson, 2012), graphic arts became a more functional tool, bringing information to the wider public.

However, the pivotal historical event and social change that started the process of bringing to life the graphic design profession was the British Industrial Revolution at the end of the 1800 s and the early-1900s. Industrialization and mass production inflated material consumption to a greater scale (Assadourian, 2010). As Adams (2014) described, suddenly large quantities of identical products and services were available. The industrial revolution created an abundance of mass-produced items. In the overcrowded marketplace manufacturers needed graphic artists to create visual-identities that made these similar mass-produced products immediately recognizable, memorable, and desirable to the public. Also, the industrial revolution brought many technological developments, notably for designers the 1875 Robert Barclay patent for the offset lithographic printing press that enabled printing on tin and metal plates. This paved the way for the development of packaging design (Meggs, 1998). 
It is fair to say, that the graphic design profession not only has a link with the consumer culture, but also it is directly tied to the technological developments that accrue over time. Therefore, graphic design is a constantly evolving discipline that is highly responsive to new technology. This creates another contrast with other fine art forms, which may be more conservative with the adoption of new technology and more likely to practice and preserve traditional techniques than graphic design.

Among many who criticized the new emerging commercial arts and technical revolution was the British art historian John Ruskin (1819-1900), who wrote:

All the stamped metals, and artificial stones, and imitation woods and bronze, over the invention of which we hear daily exultation-all the short, and cheap, and easy ways of doing that whose difficulty is its honour-are just so many new obstacles in our already encumbered road. They will not make us happier or wiser-they will extend neither the pride of judgement nor the privilege of enjoyment. They will only make us shallower in our understanding, colder in our hearts, and feebler in our wits. (Cramsie, 1998, p. 139).

According to Cramsie (1998) in this cultural climate of Britain, a successful British artist and designer William Morris (1834-1896) formed an opposite pole, by creating a new style; the Arts and Crafts movement. Many consider Morris's movement to be the forerunner of late 20th century environmental art and design. Morris recognized the high demand for mass-advertisement but advocated for art 
and design to keep its stylistic visual languages as hand-made, organic, and traditional arts and crafts. Morris created multi-disciplinary new stylistic principles for the arts called Art Nouveau. Jules Cheret (1836-1932), Leonetto Cappiello (1875-1942), Henri de Toulouse-Lautrec (1864-1901), Theophile Steinlen (18591923), Eugene Grasset (1841-1917), Alphonse Mucha (1860-1939), and Lucian Bernhard (1883-1972) were among the first celebrated designers who gained fame in Western society by creating a popular visual culture for the masses (Cramsie, 2010 and Eskilson, 2012).

The First World War changed the landscape of Europe and its economy. Graphic design became a tool to communicate propaganda during wartime. James Flagg's (1877-1960) famous I want YOU for U.S Army (1917) and Howard Christy's (1873-1952) well known recruiting poster Gee!! I Wish I Were a Man (1917) illustrates the political temper of the era during which the posters were created. Between the first and second world wars, many styles emerged, such as Cubism, Dada, De Stijl, Purism, Russian Constructivism, Art Deco, Secession, and German Expressionism (Cramsie, 1998).

A significant milestone in the development of the graphic design history was 1919 when Herbert Bayer and László Moholy-Nagy (1895-1946) started to teach typography at the Bauhaus School in Weimar, Germany. The typography workshop became focused on brand identity, advertisement, and visual communication. The Bauhaus attempted to systematically connect the industry with the arts and design. German Expressionism continued to be the governing force in graphic design. Under the leadership of Walter Gropius (1983-1969), 
Johannes Ittens (1888-1967), Lyonel Feininger (1871-1956), Moholy-Nagy (1895-1946), Marcel Breuer (1902-1981), and Joost Schmidt (1893-1948) were among the many modern artists who taught at the modern school of Bauhaus.

The term graphic design was created by the book and type designer William Addison Dwiggins (1880-1956) in 1922. From the 1920s, graphic designers and art directors were coordinating most of the design work (text and images) in publishing and advertising agencies. In 1920 the advertising industry in the United States grew rapidly. "Between 1914 and 1929, the annual dollar volume of advertising rose from $\$ 600,000$ to nearly $\$ 3$ billion" (Eskilson, 2012, p. 242). In the United States many magazines appeared such as Vogue, Seventeen, Vanity Fair, and Fortune that enhanced the role of graphic designers in the consumer society. However, the political agenda was still a dominant aspect of the graphic design industry.

After the Second World War, economic prosperity allowed the focus of graphic design to shift from the war to corporate identities. Many companies wanted to create a unified visual look for their corporation to be more recognizable among the public. Saul Bass (1920-1996), Paul Rand (1914-1996), and Tom Geismar (b.1931-) were among the first graphic designers to create corporate identities. These designs were created in the dominant style of the post - war era: the international style. The 1960s was the golden age of corporate identity and logo design.

In the United States the international style was quickly followed by postmodernism. The postmodern style allowed designers to borrow from different 
styles and to combine them in an eclectic manner. In the early 2000 s there was a major shift in graphic design. As technology advanced, computer-based design emerged. Designs for print were created by computers, and manual applications were taken over by computer software (Photoshop, Freehand); therefore, the aesthetics of graphic design became a more digital aesthetics. However, the Digital Revolution, which created a new field in graphic design (digital and broadcast), only arrived after the late '90s (Eskilson, 2012). This historic overview shows how visual communication changed throughout human history, and how the tools and technologies used in the era shaped the development of the graphic design industry.

\section{Sustainable Models in the Graphic Design Field}

Modeling sustainable development helps professionals conceptualize and integrate sustainability into their practices. Most professions beyond graphic design model sustainability as residing at the balanced intersection of the three spheres of society, environment, and economy, with interdependent relationship in between these different spheres. These three spheres are often referred to as the "triple bottom line of sustainable development" (Elkington, 1998, p. 72). Elkington (1998) wrote about the importance of the share zones, an interdependent relationship in which "[s]ociety depends on the economy-and the economy depends on the global ecosystem, whose health represents the ultimate bottom line" (p. 73).

According to Cook (2008) all designed artifacts are embedded in a social environment, as they are the imperious work of humans, using raw materials 
from the natural environment. All three systems are interconnected and are dependent on each other's stability. Cook (2008) clarified that sustainability requires an understanding that artifacts are not natural systems, but human systems and therefore need clear ethical guidelines that avoid interfering with either the natural or the human systems. "Counterfeit naturalism" (Cook, 2008, p. 265) is when artifacts are treated as natural systems and therefore dealt with in ways that deny the ethical responsibilities of the designer.

Aaris Sherin (2008) modeled the concept of the triple bottom line as a series of overlapping spheres. While Elkington (1998) and Cook (2008) placed emphasis on the stability and interdependent relation between these spheres, Sherin's pointed out in her model that sustainability only occurs where Elkington's three principles intersect. Therefore, Sherin's model depicted the three pillars of sustainability as distinct spheres, and the overlapping area as sustainable practice.

Wendy Jedlička $(2009$ a,b) built her theory of sustainability on the triple bottom line as well, however she organized the three different areas in a new relation. Jedlička explained that sustainable design requires "system thinking" (McNamara, 2009, p. 133). System thinking stresses the adoption of concepts of interconnectedness and interrelatedness of the world. A design, whether it is a book, a poster, or packaging, is a part of a single system, which is the environment. Jedlička's model presented the interconnected and interdependent nature of design. What the designer creates is by all means connected to an economic system, to the society, and to the environment. A designed product 
cannot be disconnected from the environment to be sustainable. A designed product goes through these three layers at some point in its life cycle; therefore, a product must be satisfactory to all three layers of the system. For example, "A toxic material might appear to have a nice loop within the economic system yet affect workers in the societal system and have negative impacts on the environment" (Jedlička et al., 2009b, p. 158).

Jedlička's model contrasts the sustainable theory of Cook (2008). According to Jedlička (2009), the human system must be part of the natural environment to be sustainable. From this theoretical perspective, many natural design concepts emerged such as the cradle to cradle (McDonough \& Braungart 2002) and biomimicry (Benyus, 1997). These concepts embrace the idea of the philosopher Mendelssohn and its followers, in which art is part of the natural world.

The Living Principles, the sustainability division of the American Institute of Graphic Arts (AIGA), further refined this sustainability model. The Living Principles added "culture" as the fourth layer of sustainability. These sustainable principles—environment, people, economy, and culture-may guide the decisionmaking process of sustainability-conscious designers. The environmental layer includes moving away from production and manufacturing that impacts the natural environment and interrupts the eco-systems. It embraces eliminating activities from practices that may contribute to climate change or produce a large carbon footprint. 
At the same time, it is important to engage in practices that will encourage preservation and restoration of natural resources. The social layer at AIGA focused on building a fair community for people, highlighting "poverty, violence, injustice, education, healthcare, safe housing, labor and human rights" (livingprinciples.org, n.p.). The third layer is the economy. This layer focused on profitability and monetary success, with emphasis on meeting humanity's basic needs. The fourth and last layer involved issues of culture. This layer is significant as any design product must be a product of its culture. Through culture the identity of the community and place is articulated. Traditions and historic artifacts of a community are part of the cultural value of our society. According to AIGA it is important to preserve cultural diversity in order to sustain human character.

While there are minor differences between these theoretical frameworks, they all rely on system thinking and a holistic view of production. Recognizing the need of considering multiple layers of interaction in design, this study will build on the theoretical framework of the concept of the triple-bottom-line model of sustainability as conceived by Jedlička. Comparing Jedlička's with Sherin's model it becomes evident that in Sherin's model the three areas-the environmental, the economic, and the social-have independent existences that merely intersect. However, in Jedlička's model these three areas cannot exist individually or separately —rather they are part of each other and dependent upon each other to function as a system. Furthermore, both Jedlička and Sherin's model considered three pillars of sustainability, while the AIGA's Living 
Principle model took more areas into consideration (such as the role of the individual, the planet, or businesses). This may obscure the relationship between the core pillars of sustainability (environment, society, and economy). Jedlička, by making clear the completely overlapping relationship between the elements, also defines the role of sustainable graphic designers within this system.

\section{Lack of Standards}

Dritz (2014) suggested that the core problem regarding sustainability in the graphic design industry derives from the absence of standards. Although "graphic designers are ready for a change" (Dritz, 2014, p. 36), there is lack of consistency in sustainable practices. Additionally, she mentioned that there is a shortage of sustainable education and information available for designers:

The graphic design industry as a whole has not come to any consensus on the definition or expectation of the role of the sustainable graphic designer. This has created misunderstanding and potentially missed opportunities for graphic designers and the business they serve. (Dritz, 2014, p. 46).

Gavos (2012) surveyed graphic designers to ask them if a LEED Green Building type of certification in graphic design would be beneficial for them to move toward sustainable practices. Gavos' survey disclosed an overwhelming interest in LEED type education and certification in the field of graphic design. In line with Gavos, Carr (2009) advocated for introducing similar standards as LEED, provided by the U.S. Green Building Council (USGBC), to architecture. Carr (2009) also claimed that one of the main reasons for lack of standards in 
graphic design is that it does not "operate under a system of accreditation" (p. 1). Although LEED is a value-added credential, which is administered by the USGBC, this suggests that the graphics design industry might incorporate third party licensure in order to establish some measure of accountability.

Autonomy deficit as service providers. As the literature indicated that graphic designers are "service providers" (Cramsie, 2010) rather than autonomous artists, their sovereignty in decision-making is limited. The mainstream design studios may accept work that benefits corporate clients but is not always in alignment with societal and ecological needs. The AIGA noted that "Private profit making is often at odds with public good" (Perkins, 2006, n.p.). If designers want to realize the power of their work and their position then they must have objective tools to negotiate sustainability in the intersections between corporations, the consumer, and the global impact of the designed work. While the AIGA encourages designers to "ask questions, express doubts, and propose alternatives. [They might do so by performing inquiries such as] is the message truthful? Is the service beneficial? Is the product useful, made well and produced in a sustainable way?" (Perkins, 2006, n.p.). Asking subjective questions without objective standards could jeopardize the client-designer relationship since the designer is a service provider for the large corporation. Thus, standards could help designers avoid conflicts because the concepts are already accepted by large professional design organizations.

Without standards it becomes a difficult and personal process to determine which clients to accept and which to reject. This can become 
problematic for designers on several fronts. Designers might not want to seem overly critical of prospective clients and rejecting clients can have a huge economic impact on design firms. By suggesting that designers can be either profitable or principled, the AIGA implies that one cannot be both:

Some designers consciously shift their activities away from for-profit clients and into the not-for-profit realm, into activism and cause-related marketing. Many designers have taken the leap to developing their own, non-commissioned projects. Design entrepreneurs working at a small scale have more latitude to explore new business models and practices (Perkins, 2006, n.p.).

This suggests that designers who work for commission in the corporate global market can never fully be balanced between their ethical obligation and their professional duties.

Serving business and alternatives. The global market demands brand identities for consumers to be able to differentiate similar products and consumers are exposed to hundreds of advertisements, brands, and logos every day. AIGA recognizes that graphic design is directly linked to corporate consumerism and, thus, unsustainable consumption. Advertising can change behavior and the values of consumers. The AIGA debated the position designers hold within the consumer market they serve and noted, "Our involvement in materialism and conspicuous consumption may even extend to the creation of artificial needs and the promotion of unnecessary products through advertising and marketing messages that are manipulative or deceptive" (Perkins, 2006, 
n.p.). Perkins' (2006) remark aligns with Garland's (1964), Kalman's (2000), and Glaser's (2002) critique regarding the ethical barriers of graphic design profession because it serves business.

The entanglement with consumer culture is also detected throughout the historical evolution of other design disciplines. The main goal of design was to create the illusion of happiness and well-being and associate it with a specific brand and product. Assadourian (2010) explained, "In most countries today people are exposed to hundreds if not thousands of consumerist symbols every day. Logos, jingles, slogans... all these symbols of different brands routinely bombard people, influencing behavior even at unconscious levels" (pp. 8-9). The goal of graphic designers is to convince consumers to buy the product. Can graphic designers as visual communicators contribute to change current consumer behaviors to a sustainable consumer culture? Among many designers, Brian Dougherty (2008) urged his colleagues to do their share in transforming the industry into a sustainable one. Dougherty (2008) strongly believed communication must encourage the cultural shift for a sustainable life.

Yet, to transform the consumer culture we must investigate more about how human cultures form and how they shape human behavior. Assadourian (2010) explained that all humans are "embedded in a cultural system" (p. 3). Human beings grow into a range of "values, beliefs, customs, traditions, symbols, norms, and institutions" that becomes their "cultural reality," which people experience as a "natural" behavior (p. 3). Human norms, values, and traditions differ all around the globe. Cultures transform throughout history as well; they 
adjust to new circumstances. Assadourian (2010) insisted that cultures can change and the culture of consumerism must change fundamentally for the sake of sustaining life on earth. He points out in his essay that:

Transforming cultures is no small task. It will require decades of effort in which cultural pioneers - those who can step out of their cultural realities enough to critically examine them-work tirelessly to redirect key cultureshaping institutions: education, business, government, and the media, as well as social movements and long-standing human traditions. (p. 4) According to Assadourian (2010), the solution would shift values, norms, and habits toward eco-system reconstruction. In addition, he argued that humans must reduce mainstream consumption to a minimum level. The remaining minimal consumption needs to be either durably or cradle to cradle designed. McDonough and Braungart (2002) modeled their cradle to cradle (C2C) design approach after cyclical ecological systems, in which organisms decompose after death to provide nourishment for the creation of new life, closing the loop of the environment (Jedlička, 2009b, p. 235). This strategy opposed linear systems, or cradle to grave, where cradle is the birth of the design and the grave is the end of use, or the landfill.

The cradle to cradle approach of design thus suggested that materials must be either durable, transformable to different uses, or decomposable. In this way, it is modeled on natural systems that do not produce waste. One of the strategies of the cradle to cradle approach is biomimicry, which means to stimulate nature in the approach of design; bio refers to life, and mimesis refers 
to modeling or simulating. Both Assadourian (2010) and McDonough and Braungart (2002) clash with Chiappolini (1998), and Cook's (2008) ideas that considered design inherently artificial, therefore they did not believe that making design nature-like would provide a sustainable solution.

The Sustainable Development Commission confirmed that government and producer initiatives in the "choice editing" process affected consumer behaviors (Maniates, 2010, p. 119). Choice editing means to change the mainstream marketplace to a sustainable one by offering only sustainable choices for customers and therefore moving consumers to a more sustainable consumption (Maniates, 2010). This requires advocating changes from the key players who influence mass consumption. Although the main driver of consumption is economic, media, government, and education systems also have a great impact on consumers. For example, the government has a key role in applying tax and policies to motivate consumer behavior to a certain orientation. Governmental choice editing has occurred by considering safety factors and performance standards (Maniates, 2010). If sustainability is encoded at the institutional level, then it would not be left to the ethical choice or subjectivity of the individual graphic designer.

\section{Lack of design ethics in higher educational curricula. Although}

NASAD has demonstrated a clear commitment to sustainable values in art and design education, standards for integrating sustainability into the design curriculum have yet to fully take shape. As a result, universal integration of sustainability oriented standards and accreditation in design programs merits 
additional research. Also, as higher education institutions are gradually cycling toward accreditation review it may take time to integrate sustainable developments in design curriculum. Alain Findeli (2001) argued that most design schools lack courses that deal with design theoretical issues, teaching design with no philosophical, ethical, and sustainable approach. This has resulted in artists and designers lacking the sufficient knowledge, responsibility, and insight for making ethical and sustainable artifacts. Also, as each division of manufacturing is so specialized and segmented, the design industry has lacked the vocabulary, knowledge, and, therefore, the ability and initiatives to collaborate within these separate but interconnected areas of the supply chain. David Orr (2002) argued that all current ecological issues are ramifications of design failures. Orr (2002) urged designers to view design from a completely new perspective and advocated for educational reform in the field of design toward a sustainably designed world. Similarly, Susan S. Szenasy (2012), an educator of design history and design ethics, also advocated for more sustainable practices in the design profession.

\section{Current Resources and Approaches Supporting Sustainable Initiatives}

Findeli (1994) researched the threshold of significance, in which he examined what differentiates the banal and the utopian objects from designed artifacts. He introduced the space of artifacts model, in which Findeli presented two different poles of the designed object spectrum: one pole was "purely instrumental" and the opposite was "purely symbolic" (Findeli, 1994, pp. 49-68). The threshold of significance includes the aesthetics, ethical responsibilities, and 
social, cultural, and environmental context of an object. According to Findeli (1994), there are two conditions of an artifact. First, a designed object's value must be greater than the "threshold of significance" (p. 53). Everything below this line is considered an object of "banality or uselessness" (p. 54)" The second condition is the budgetary and technological limitation of a design project. Everything above that is a utopian object. Therefore, to make an ethical design decision, a designer should evaluate the potential significance and ecological impact of a designed object (Findeli, 1994).

Medardo Chiappolini (1998) stated that: "The concept of nature has, since ancient times, always been connected to the idea of a monolithic and immutable genitive principle, which being outside and above human actions has therefore determined it" (p. 109). Which follows the philosophical view of Kant. According to Chiappolini (1998), the duality of a natural and artificial environment is inaccurate, as they are one entity. The technological development, just as human society, is a segment of the environment. Therefore, he opposed the concept of radical environmentalism and deep ecology since every human activity would alter the surroundings on some level. Chiappolini (1998) argued technology is not the cause of our environmental problems. He speculated that designers have detached their work from reality and the environment by over simplifying a complex system:

As every designer knows, the tools to formalize reality, the model, the simulation, and the interventions on reality must be as simple as possible. There are apparently unsolved contradictions between the complexities of 
the environment regarded as system and the simplicity intrinsic to the design process. (p. 111)

To solve the artificiality of the design industry, it is necessary to look at design as part of an interconnected system. Life Cycle Assessment (LCA) measures sustainable effectiveness throughout the entire life cycle of a designed product. LCA gives credibility to the design, in that designers become accountable for their work as its impacts become measurable. Chiappolini (1998) urged designers to broaden their perspectives and methods in which they work by integrating knowledge and collaboration between segmented work phases of their products. LCA is the only way to track the environmental impact of design; therefore, it must be incorporated into the design process.

Russ (2010) urged design professionals to move the design industry toward a sustainable one. At the same time, he acknowledged a current lack of accurate data about sustainable materials and manufacturing for designers to work with. He wrote: "There are many definitions of sustainability and sustainable design; few are very satisfactory when it comes to actual applications" (Russ, 2010, p. 105). Russ further explained "While there is objective knowledge of human impacts on the environment and examples of design that has minimalized such impact, there is no objective "toolbox" on which designers may rely" (Russ, 2010, p. 67).

In the following I will outline some of the main ongoing discussions regarding sustainability both in theory and practice in the field of graphic design. Many designers identified sustainable materials and best practices in the field of 
graphic design (Benson \& Perullo, 2017; Boylston 2009; Dougherty, 2008; Chick \& Micklethwaite 2011; and Sherin, 2008), and encouraged a more holistic system thinking that is rooted in the core of the ethical approaches of the profession (Fine, 2016; Jedlička, 2009a, b; and Sherin, 2013). Thus, they joined the broad ethical and sustainable discourse across deign disciplines (Benyus, 1997; Braungart \& McDonough, 2002; Findeli 2001; Fry, 2009, Manzini, 2014; Russ, 2010; and Walker \& Giard, 2013). Along with sustainable design, other approaches have emerged from design ethics such as human centered design and socially conscious design (Buchanan, 2001; Heller \& Vienne, 2003; Resnick, 2016; Scalin, 2012; Shea, 2012; and Simmons, 2011).

Chick \& Micklethwaite (2011) explored methods to use design thinking and entrepreneurship to solve sustainability problems. They encouraged designers to solve these problems arguing designers must embrace a greater consciousness regarding their work's social and environmental impacts when designing new products and services. Chick \& Micklethwaite (2011) developed a comprehensive method for sustainable designers to carve out a space in the global marketplace.

Sustainable toolkits. Graphic design practitioners have been developing environmentally friendly methods to reduce their ecological footprint. This section introduces these latest methods. Undoubtedly, there is still a lot to be done, but there are some initiatives that are already in place to help navigate through the sustainable design working process. These developments have addressed some of the main practical issues when adopting sustainable techniques into the 
graphic design practice. What follows is a review of published materials that have helped establish sustainable graphic design practices, such as toolkits, charts, and resources available today for designers who seek to work sustainably.

Since most designers are still employed in print (Gavos, 2012), and most environmental impact is due to the print industry, this section examines the most common manufacturing processes and materials graphic designers use in the print industry. The review showcases extant scholarship relating to the printing process from an environmental perspective, and studies on materials such as paper and inks; it also lists currently available resources for graphic designers.

The O2 International Network for Sustainable Design was founded in 1988 in Milan, Italy to advocate for nontoxic manufacturing and materials. Since then it has grown into an international network, partnering with over 70 countries. The O2 International Network organizes events, lectures, and workshops to teach sustainable design worldwide. Additionally, the AIGA has promoted sustainability by setting up a website that allows designers to locate and identify sustainable resources (livingprinciples.org, n.p.). The Paper Finder Tools, Renourish Paper Finder Tool, Re-Nourish Green Printer Tool, Living Principles Scorecard, and the Celery Design Sustainability Scorecard are among some of the helpful tools that assist designers toward sustainable design processes and products.

The latest progress includes work from Eric Benson and Yvette Perullo, co-founders and partners of Renourich, a non-profit organization. This project began as Benson's MFA Thesis, but it has since grown into an online resource that lets designers calculate in advance how they can reduce some of their 
negative impacts on the environment. Furthermore, Benson and Perullo (2017) published Design to Renourish: Sustainable Graphic Design in Practice, which instructed designers on integrating sustainability into their practice. However, these suggestions and calculations are far from being comprehensive since most current sustainability initiatives lack interdisciplinary input from other relevant sectors and industries.

Dougherty, a graphic designer and the creator of Celery Design Collaborative, wrote Green Graphic Design (2008), which helped put theory in practice. He argued that the main problem in the print industry is that its products are disposed in the landfill rather than the recycling facility. Additionally, its manufacturing process requires a large amount of natural resources. Dougherty attempted to target and eliminate all materials from the graphic design industry that are destined to have a dead end. He suggested designers work exclusively with design materials and processes that have a sustainable profile. Dougherty introduced a chart, originally created by Michael S. Brown, called the "Sustainability Toolkit and Scorecard" (Dougherty, 2008, p. 186). His chart aimed to help graphic designers to choose the right materials for their work and determine the ultimate destinations of those materials. The scorecard is easy to use and defined materials from an ecological perspective. These measurements presented segments of the process that concern the environmental impact of the materials, but it failed to reveal the full impact of the entire design process. To have a more integral view on the sustainable impacts, graphic designers might 
create a holistic chart that measures the environmental impact of every work phase involved in the process of the product and service lifecycle.

Sustainable paper and paper mills. Dougherty (2008) posited that the graphic design industry is one of the major consumers of paper. Although paper is a renewable resource and can be recycled or composted, paper consumption leads to deforestation and cutting down ancient forests. Paper also uses a lot of energy, consumes and pollutes a large quantity of water, and creates solid waste (Dougherty, 2008). Even though fifty percent of North American paper is recycled, it is responsible for more than half of the trees harvested (Jedlička, 2009b). However, there are ways to cut paper consumption if graphic designers pay attention. They can use post-consumer recycled (PCR) fibers, sustainably harvested virgin fiber, or use tree-free alternative fibers such as bamboo, kenaf, hemp, and agricultural-pulp/residue, which are all great fiber alternatives. PCR fiber production requires 42 percent less water than virgin fiber production. Boylston (2009) noted that one ton of 100 percent of recycled paperboard protects 14 trees and conserves more than 1.500 liters of oils, as its production is much more energy efficient (p. 32).

There are many non-profit organizations that encourage and advocate responsible forest management and sustainable paper use. The five main certifications for a sustainable paper are: The Forest Stewardship Council (FSC) certificate, the Ancient Forest Friendly certificate, the Rainforest Alliance Certified papers certificate, and the Programme for the Endorsement of Forest Certification (PEFC) Schemes certificate. The duty of these independent, non- 
profit organizations is to protect endangered forests and advocate for responsible forest management around the world (Jedlička, 2009b).

Recycling paper is important because its fibers can be used to create post-consumer paper and it prevents paper-releasing methane while decomposing in landfills. Still, recycling is not entirely harmless. In some cases, the de-inking process utilizes toxic chemicals. The recycling symbol alone stands for a paper that can be recycled, but it is not from recycled fibers (Dougherty, 2008). All recyclable labels must come "with a qualifying statement regarding the availability of recycling programs in a substantial majority of communities for product or community" (Jedlička, 2009b, p. 281). When a paper is from postconsumer recycled fibers, there is a number next to the logo indicating the percentage of the recycled fibers in the paper. There is a similar logo for postconsumer paperboards that is used by many in sustainable packaging today.

Paper production also requires a large quantity of energy and water (Dougherty, 2008). In order to reduce the environmental damage, today many sustainable paper mills are using closed-loop systems. According to regulations, bleached paper fibers in Europe and North America must use a Chlorine Free Process (PCF) or Total Chlorine Free (TCF) fibers to achieve the different shades of white paper. TCF refers to a totally chlorine-free virgin paper, while $\mathrm{PCH}$ stands for processed chlorine-free recycled paper, which demands a content that consists of more than 30 percent post-consumer paper. Jedlička (2009b) explained that bleaching with chlorine is not only harmful to the natural environment, but research shows that being exposed to chlorine can cause 
sickness in humans as well. TCF and PCF are two symbols that help distinguish paper that is chlorine free from other paper mills, which still uses this toxic bleaching process. Graphic designers can reduce their carbon-footprint by strictly working with fibers that are from renewable energy certified resources, such as: Renewable Energy Certificate and Verifiable Emissions Reductions paper mills. The sustainable goal for the print design industry is to contract carbon neutral manufacturers for their work.

Sustainable ink. Dougherty (2008) wrote at length about the importance of choosing sustainable inks when creating print projects. The two principal components of inks are the medium and the pigment. The medium helps the pigment stay on the printing roll, but when the pigment is transferred on to the paper, the medium must evaporate fast so the pigment absorbs into the paper. Putting volatile organic compounds (VOCs) into the medium helps the medium evaporate. Standard inks usually contain up to 35 percent VOCs. To reduce the environmental footprint of the printing process, designers can use low VOCs or VOC-free inks. Designers can also use vegetable-based inks instead of petroleum-based inks when printing. Furthermore, instead of using oil-based inks that needs solvent-based solutions to clean, water-washable inks are now available.

When applying ink, it not only affects the eco-effectiveness of the printing process phase, but also affects the de-inking process once it arrives at the recycling facility or in the landfill. Metals such as cooper, zinc, and barium in the pigments can contaminate water if leached from the landfills and can generate 
hazardous waste when going through the de-inking process at the recycling facility. Cobalt added into the inks as a drying component is highly toxic to the environment as well. To simplify the nontoxic ink-selection process, Pantone introduced a new color pallet system called Goe ${ }^{\mathrm{TM}}$, which offers a less complicated search Dougherty (2008).

Sustainable printing manufacturing. One of the biggest problems in the print design industry today is that there is a disconnect between designers and manufacturers. In most cases the designer creates print projects with no regard to how it is going to be manufactured. Dougherty (2008) urged designers to work together with printers and inquire about the size of their press sheet.

Understanding and planning manufacturing processes is necessary for designers to get eco-efficient results out of printing to avoid unnecessary waste. Designing the press sheet before sending the design to the manufacturer is the key strategy. Designers may calculate their maximum project size by deducting from the given press sheet size a half inch margin and a quarter inch trim mark.

The total impression of printing determines which printing method is chosen. The quantity of total impressions, or print run, can be categorized in three groups. Short runs print between 1-1,000 impressions. For these jobs, digital printing is the most sustainable printing method. When setting up the digital print it does not produce as much pre-consumer paper waste, the process consumes less energy, and there is no need to clean with toxic solvents. However, digital printing has many limitations including color use restrictions and post-consumer recycled paper options, as it demands an explicit surface quality. 
Medium scale printing jobs run between 1,000-50,000 impressions. For these print jobs, conventional offset lithography printing is most suitable. The offset printing technique is based on the repulsion of oil and water. It uses a large quantity of energy and water. However, PCR fibers are widely available for offset printing. Print jobs that run over 50,000 impressions are considered large print jobs. Here, web offset presses are recommended (Dougherty, 2008).

Conclusion. This literature review on the field of sustainable graphic design demonstrates the efforts of graphic designers to take responsibility and mitigate negative impacts on society and the environment. However, this review also revealed that ethical and sustainable theories in graphic design rely heavily on anecdotes rather than systematic empirical studies. Graphic design is still lacking methods to systematically measure its negative impact on society and the environment. Therefore, it is difficult to establish clear guidelines and standards for sustainability. Today, sustainability is left to the moral judgment of the individual designer and viewed as activism. Even though some graphic design institutions have regulative power, such as NASAD, they have not yet established guidelines. However, I argue that without institutionalizing sustainability, sustainable values and objective guidelines, sustainability will not create a paradigm shift in the collective mainstream graphic design industry.

The literature also illuminated that there are many innovative approaches for sustainability in the context of graphic design. However, these options were largely promoted through individual activist publications, which may not reach an audience of mainstream graphic designers. Because institutions mediate the 
values of the mainstream profession, it is necessary to examine whether and how graphic design institutions promote responsible and intelligent professional activities to current and future graphic designers. As the literature review indicated there has not been a significant amount of empirical research made in graphic design and therefore there is no clear standards established in the field. However, many professionals have pointed out that there is a need to create interdisciplinary work that crosses design and empirical studies. The literature also emphasized the significant role of education, manufacturing practices, and policy makers in shifting towards sustainability in the graphic design industry.

Because sustainability acknowledges the interconnected nature of the world, recognizing the multiple sectors and stakeholders involved and the different interests of each constituency is not an easy task. Solving the sustainability crisis in the graphic design industry is not a singular task. Working collaboratively together in a multidisciplinary team effort, investing in empirical and creative research may be the way to develop strategies to create sustainable standards for the graphic design industry. To that end, this research offers a first step to provide empirical evidence that future research may build upon. 


\section{CHAPTER 3: METHODOLOGY}

Today mainstream businesses are moving toward a sustainable supply chain, and many corporate executives recognize sustainability as an important mission of their company (Kiron, Unruh, \& Kruschwitz, et al., 2017). Studies showed (Dritz, 2014; Gavos, 2012) that mainstream graphic designers are ready for a change and would be interested in obtaining a LEED type certification, yet the collective graphic design profession has still not created standards or any consensus on what sustainable graphic design actually means. Inconsistent or absent standards regarding sustainability in graphic design may create confusion and prevent the profession from keeping up with the sustainable initiatives of the mainstream business (Dritz, 2014). Because the graphic design profession is composed of many dispersed individual practitioners, professional institutions play a key role in shaping a cohesive voice of the profession. Therefore, this research will explore how the concept of sustainability manifests in the textual productions of three representative graphic design institutions: (a) the four most popular contemporary graphic design trade magazines, (b) in the AIGA website, and in (c) the mission statements of ten higher-educational graphic design programs.

Magazines are public records that reflect the culture and fundamental norms of a group (Altheide, 1996), so this research will examine how sustainable values are communicated and negotiated in the editorial textual content of contemporary, mainstream graphic design trade publications. Scott (1995) indicated that professional organizations have a significant role in shaping the 
beliefs and values of the practice because "as distinct from unions, professional occupations have sought to exercise control not only over the condition of work (pay, benefits, and safety) but over the definitions of the work itself" (p. x). Thus, it is important to survey the messages that AIGA publishes on its website to understand the profession's collective voice and position toward the pillars of sustainability. Higher education implants ethical standards in whole generations of designers (Findeli, 2001), therefore it is necessary to investigate how the concept of sustainability manifests in the mission statements of university graphic design departments. Examination of these three domains reveals the state of the core institutional values of graphic design regarding sustainability.

\section{Theoretical Perspective}

Because "all research is interpretive: guided by a set of beliefs and feelings about the world and how it should be understood and studied" (Denzin \& Lincoln, 2013, p. 13) it is important to acknowledge the epistemological stance of the researcher. This research is grounded in the constructionist epistemology paradigm, which rejects the notion of the "truth" "simply as objective" or "simply as subjective" (Crotty, 1998, p. 43). Rather, meaning is constructed "by human beings as they engage with the world they are interpreting" (Crotty, 1998, p. 43). Social constructionism argues that culture is the foundation of governing rules in the individuals' meaning-making process. Crotty (1998) positioned culture as a "source rather than a result of human thought and behavior" (p. 53). Phenomena therefore are "constructed and sustained by the observation of the social rules" 
(Greenwood, 1994, p. 85), which implies that practitioners create meaning from the rules and values culture presents to them.

Graphic design practitioners are influenced by the gatekeepers of their culture who set the rules of the design community. The gatekeepers of a culture are the collective voice of practitioners who unify under one cohesive voice of the institution. Scott (1995) indicated that "[i]ndividuals do construct and continuously negotiate social reality in everyday life, but they do so within the context of wider, preexisting cultural systems: symbolic frameworks [...] that provide orientation and guidance" (p. 41). Thus, investigating the values and behaviors that the representative institutions communicate is necessary as they are shaping the norms and beliefs of their community.

If meaning is shaped, what is the meaning of sustainability within the culture of the mainstream graphic design institutions? Specifically, this research will analyze the written content that key institutions produce. To this end I propose three sites of research: (a) four most broadly circulated professional graphic design trade magazines editorial content published in 2017; (b) the textual content of the American Institute of Graphic Arts webpage; and (c) ten graphic design higher education's mission statements. From this analysis, I will formulate an understanding of the dominating values regarding sustainability projected to individuals within the culture - specifically, practicing graphic designers. 


\section{Methodological Framework}

The phenomenological approach was chosen to best investigate the meaning of sustainability as it appears within the commercial graphic design institutions' textual content. The word phenomenology comes from the Greek

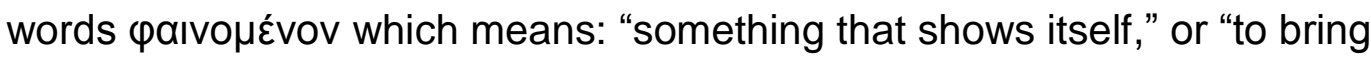

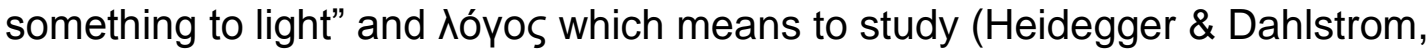
2005 , p. 4). Phenomenology is more of an analytical approach than a theory, which investigates the thing as it appears or shows itself (Ram \& Houston, 2015). This philosophical approach was chosen also because phenomenology concerns itself with "what all participants have in common" with the collective or "the universal essence" (Creswell, 2013, p. 76). Thus, this approach deals with the core substance of a phenomenon and seeks commonalities within the descriptions of a phenomenon (Merriam, 2009).

Specifically, the hermeneutic approach of phenomenology is applied in this study because it emphasizes the meaning that the text carries and the interpretation of the phenomena with the means of textual document analysis. "Everything that is said and is there in the text stands under anticipations" (Gadamer, 1976, p. 121), which means that text is a testimony and evidence of the phenomena as it appears. In this research, texts produced by professional institutions will be examined as such a vehicle for transmitting meaning within a community.

The hermeneutic approach this research follows the work of Martin Heidegger, Hans-Georg Gadamer and Max van Manen. Although van Manen 
(1990) does not recommend applying a set of rules when conducting hermeneutic phenomenological research, he suggested researchers identify a general "abiding" concern (p. 31). Then, the researcher discovers essential schemes within the text. In the case of this study this general concern is the lack of consensus on what sustainability means in the field of commercial graphic design. Following this identification of schemes, van Manen (1990) suggested concluding with a thick description of the detected essence of the phenomena found within the text.

\section{Data Selection}

Analyzing "[o]rganizational and institutional documents have been a staple in qualitative research for many years" (Bowen, 2009, p. 27). Professional institutions such as trade magazines, work associations, academic institutions, academic journals and conferences are the main channels where the graphic design profession communicates and therefore influences the values and beliefs of its members or audiences. To triangulate my data, three different discourse sites were selected: (a) the AIGA website, (b) contemporary graphic design trade magazines, and (c) higher-educational graphic design programs. All "relevant text" (Saldaña, 2016, p. 18) was coded and analyzed on the selected datasets. For the purpose of this research, a text was considered relevant if it responds to the "analytic lens" of sustainability (Saldaña, 2016, p. 7). Ultimately, the aim was to arrive to data saturation, which ensured that "no new properties, dimensions, conditions" came to surface (Strauss \& Corbin, 1998, p. 136). 
To assess the first research question (RQ1) how have contemporary mainstream graphic design trade magazines articulated the concept of sustainability, the four highest circulation number graphic design trade magazines were selected from SRDS Media Solutions Database (see Table 1).

Table 1

Main Attributes of the Four Magazines

\begin{tabular}{|c|c|c|c|c|}
\hline Data-set & $\begin{array}{c}\text { Trade } \\
\text { Publication }\end{array}$ & Unit & Frequency & $\begin{array}{c}\text { Total } \\
\text { Circulation } \\
\text { (Sworn) }\end{array}$ \\
\hline 1 & $\begin{array}{l}\text { Graphic Design } \\
\text { USA, October } \\
2017\end{array}$ & $\begin{array}{l}1- \\
17 \mathrm{a} / \mathrm{b}\end{array}$ & Bimonthly & $20,537^{*}$ \\
\hline 2 & $\begin{array}{l}\text { Communication } \\
\text { Arts, Annual } \\
58,2017 \\
\text { September- } \\
\text { October }\end{array}$ & $\begin{array}{l}18- \\
37\end{array}$ & Bimonthly & $30,899^{*}$ \\
\hline 3 & How, fall 2017 & $\begin{array}{l}38- \\
44\end{array}$ & Bi-monthly & $11,672^{*}$ \\
\hline 4 & $\begin{array}{l}\text { Print Magazine, } \\
\text { fall } 2017\end{array}$ & $\begin{array}{l}45- \\
56\end{array}$ & Bi-monthly & $10,556^{*}$ \\
\hline
\end{tabular}

Note. *Source: (SRDS, 2017, n.p.).

Altogether, four fall 2017 issues of these magazines were analyzed through the lens of sustainability. Each individual issue consisted of approximately 6- 20 units (articles and vignettes) that were coded and analyzed. The data selection included the following trade publications: Graphic Design USA (GDUSA), Communication Arts, How, and Print. I treated these magazines as a unified voice without mentioning individual contributors, as many times there was no specific indication of the individual writers' bylines. 
Specifically, the GDUSA, October 2017 issue was selected for my first dataset. In the entire trade issue's editorial content, I identified and coded 18 units that mentioned sustainability (unit $1-17 \mathrm{a} / \mathrm{b}$ ). The GDUSA trade magazine targets graphic design professionals who design and produce advertising and communication products and services. It is important to mention that the analyzed units were located in the "Responsible Design" section of the magazine, which was sponsored by Rolland Enterprises based in Saint-Jerome, Quebec, Canada. Rolland is one of the most environment-friendly paper producers in North America, and a leading offset and digital printing company.

The Communication Arts, September/October 2017 issue contributed my second dataset, and I identified and coded 19 units (unit 18-37) that mentioned sustainability. Communication Arts overall is edited for designers, art directors, design firms, corporate design departments, advertising agencies, interactive designers, illustrators and photographers, everyone involved in visual communication. Communication Arts offers new ideas and informs design practitioners about the highest professional standards of the industry.

The fall 2017 issue of How, a graphic design trade magazine, was my third dataset, which consisted of six (6) coded units (Unit 38-44). How magazine offers the latest and in-depth insights for graphic designers on topics such as creativity, business, and technology. The magazine's targeted audience consists of individual/freelance graphic designers, students, and design studios and firms. How also displays the most current design precedents from around the world. The magazine also provides professional development online courses led by 
professional graphic designers. How sets out to inspire designers to achieve the best quality and most technically advanced approaches to the graphic design profession. The magazine suspended its hard copy publications in Spring 2018 but persists in a digital format accessible online.

The fall 2017 issue of Print Magazine was my fourth dataset. I identified and analyzed 12 units (Unit 45-56) within this dataset. Print Magazine was founded in 1940 and is one of the oldest graphic design trade magazines. Since Winter 2017 the magazine suspended all its printed publications and it is only available online. The magazine informs graphic designers on current trends and issues regarding the global graphic design industry. The magazine is edited and written by top graphic design professionals and design thinkers such as Zachary Petit, Steven Heller, Debbie Millman, Ellen Shapiro, Paul Shaw, and Jude Stewart. In the fall 2017 issue Scott Boylston, prominent sustainable design educator and designer wrote the article entitled "Graphic Design and the Anthropocene- an Argument for more Sustainable Design Thinking - and thus a more sustainable world" (Unit 56) that advocated for a sustainability paradigm shift of the mainstream graphic design industry. 


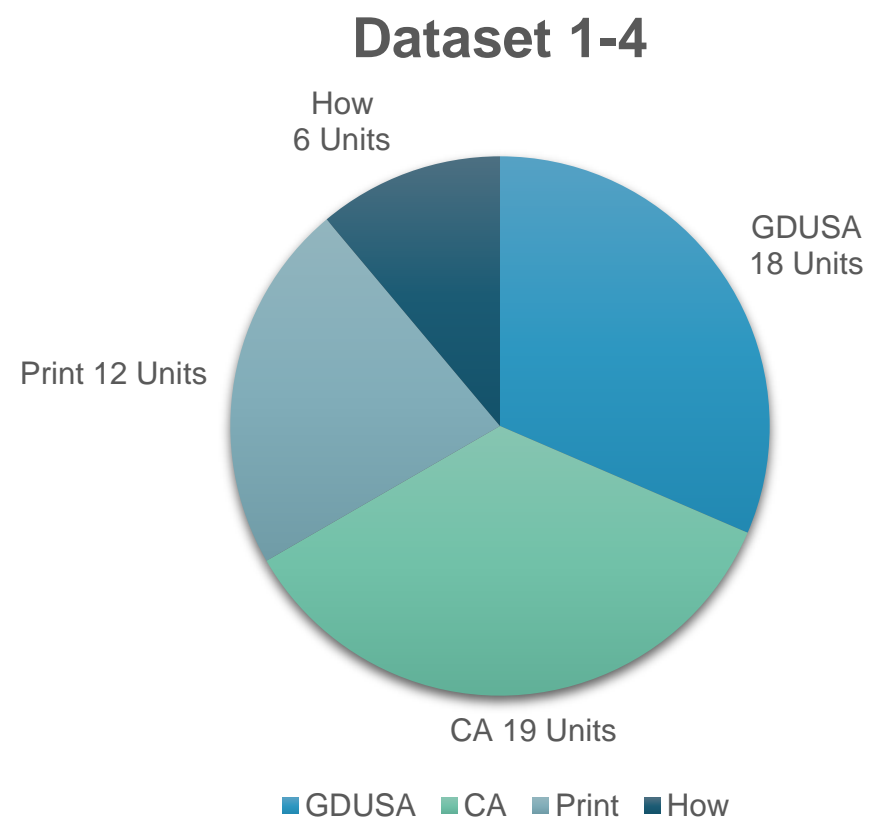

Figure 1. Distribution of Units in Dataset 1-4. All together 55 units were analyzed in Dataset 1-4. These units were identified as sustainable in each individual issue of the graphic design magazines.

Next, I analyzed the textual content of the online communication platform produced by the AIGA professional association to investigate (RQ2) How has the American Institute of Graphic Arts (AIGA) communicated the concept of sustainability to its members? Public documents can reflect cultural norms and values at a time of history. They can be a rich and valuable source to track communication of a culture and society. Altheide (2000) emphasized the link between document analysis and discourse tracking, arguing that this data collection strategy is a way to observe the development of discourse. I identified five units as sustainable within dataset five. All units were retrieved from: https://www.aiga.org. Only units that were tagged as sustainable by the AIGA were coded and analyzed including the offshoot website of AIGA's sustainable 
resources, which was retrieved from https://www.aiga.org/the-living-principlesfor-design.

Table 2

Attributes of the Units from the AIGA website

\begin{tabular}{|c|c|c|}
\hline Dataset & Website & Unit \\
\hline 5 & http://aiga.orgretrieved in 2017 & $57-62$ \\
\hline
\end{tabular}

To understand (RQ3) How have the mission statements and web textual content of graphic design higher education departments conceived of sustainability? In order to answer this question, ten academic graphic design programs were selected from an alphabetically ranked list of the GDUSA's 2017 article of the top graphic design schools in the United States. All three datasets were collected during fall 2017. These schools were listed in Table 3. I divided this dataset into 10 units. Each unit represented one distinct academic program. 
Table 3

Attributes of the Academic Programs

\begin{tabular}{|c|c|c|c|c|c|}
\hline Data-set & Graphic Design Programs & Unit & Location & Student Population & Control \\
\hline \multirow[t]{10}{*}{6} & Academy of Art University & 63 & San Francisco, CA & 15,212 & Private for-profit \\
\hline & Art Center College of Design & 64 & Pasadena CA & 2,045 & Private not-for-profit \\
\hline & Auburn University & 65 & Auburn, AL & 25,912 & Public \\
\hline & $\begin{array}{l}\text { Boston University College of } \\
\text { Fine Arts }\end{array}$ & 66 & Boston, MA & $\begin{array}{c}\text { 32,112 (entire Boston } \\
\text { University) }\end{array}$ & Private not-for-profit \\
\hline & California College of Arts & 67 & Oakland, CA & 1,998 & Private not-for-profit \\
\hline & $\begin{array}{l}\text { California Institution of the } \\
\text { Arts (CalArts) }\end{array}$ & 68 & Valencia, CA & 1,459 * & Private $^{*}$ \\
\hline & $\begin{array}{l}\text { Carnegie Mellon School of } \\
\text { Design }\end{array}$ & 69 & Pittsburgh, PA & $\begin{array}{l}\text { 12,587 (entire Carnegie } \\
\text { Mellon University) }\end{array}$ & Private not-for-profit \\
\hline & College for Creative Studies & 70 & Detroit, MI & 1,459 & Private not-for-profit \\
\hline & Cooper Union School of Art & 71 & New York, NY & 966 & Private not-for-profit \\
\hline & Cranbrook Academy of Art & 72 & Bloomfield Hills, MI & 156 & Private not-for-profit \\
\hline
\end{tabular}

Note. Data retrieved from the Carnegie Classification of Institutions of Higher Education (2017). ${ }^{*}$ Retrieved from https://calarts.edu 
Table 4

Four Research Questions in Connection with the Datasets

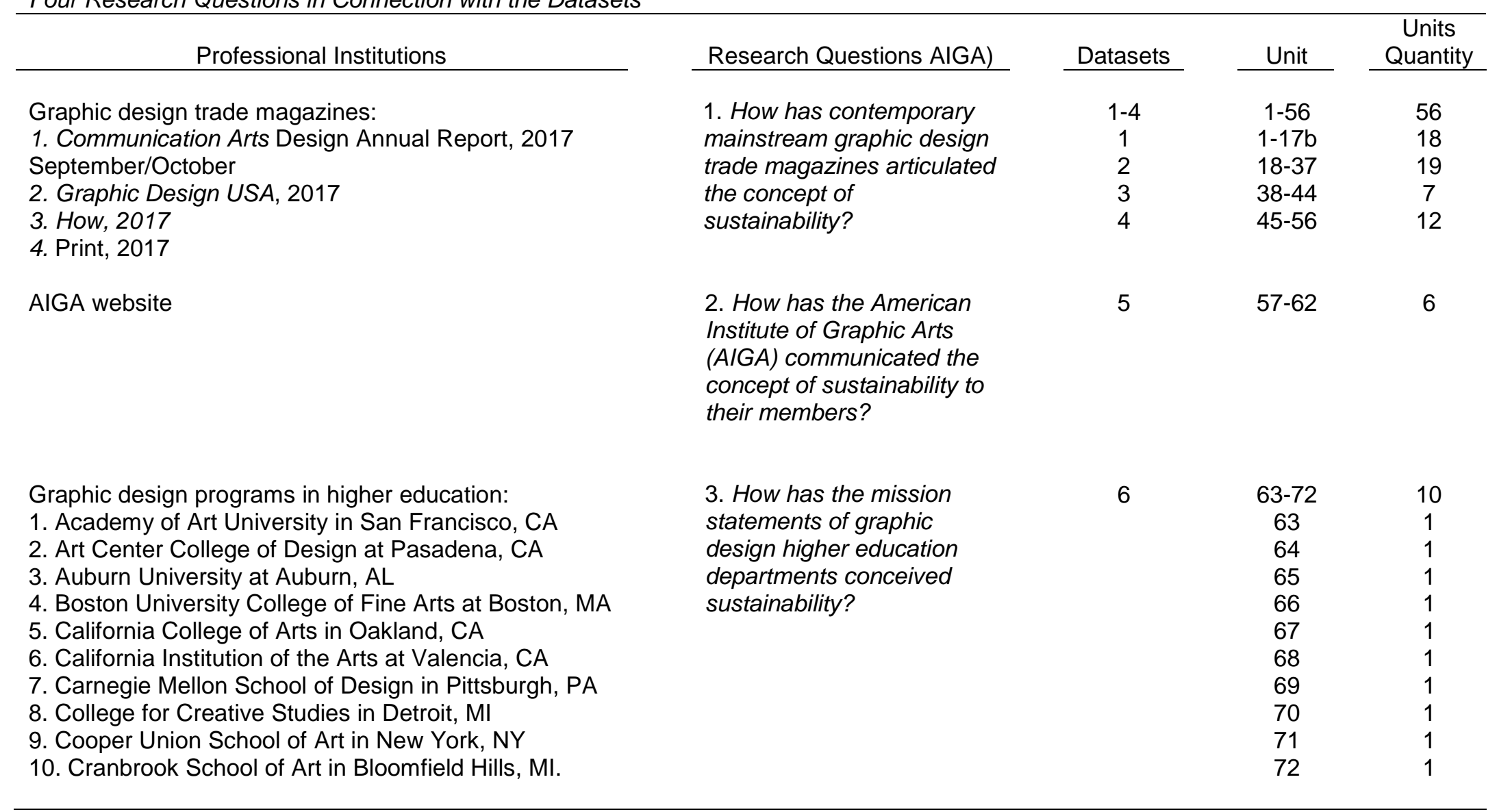




\section{Data Collection Method}

To best investigate the phenomenon of sustainability within the selected graphic design institutions, textual document analysis was selected to explore discursive practice in the field. According to Bowen (2009) the method of document analysis can be used as the only data source in the case of hermeneutic inquiry, historical, and cross-cultural studies. May (2011) described documents as "sedimentations of social practices that have the potential to inform and structure the decisions which people make on a daily and long-term basis" (p. 198). Documents as a data source may yield information on cultural context and reflect on how a culture and a community make sense of a phenomenon (Bogdan \& Biklen, 1998; Coffey, 2013; May, 2011; Lee, 2002).

Document analysis, therefore, allows the researcher to explore the status of how graphic designers in the selected sites made sense of sustainability. Textual content produced by the selected institutions offered a rich source of data to assess the professional discourse within the graphic design field.

Merriam (2009) explained that documents embrace a wide range of primary and secondary sources such as public records, popular culture documents, visual documents, and artifacts. In this regard, the textual content that these institutions produce may be categorized both as public record (mass media) and popular culture document. They reflect the culture, while they also reveal the fundamental beliefs and norms of a society (Altheide, 1996).

Documents - as a data source - may yield information on cultural context and reflect on how a culture and a community make sense of a phenomenon 
(Bogdan \& Biklen, 1998; Coffey, 2013; May, 2011; Lee, 2002). Document analysis, therefore allowed me to explore how graphic design institutions made sense of sustainability and may reveal underlying values of the selected graphic design institutions regarding sustainability.

As the aim of this research was to explore how sustainability is presented to graphic design practitioners, the study needed a discussion platform where communication could be tracked about sustainability that was constant data and not produced for the sake of this research. Coffey (2013) draws attention to the difference between 'found' documents produced for a purpose before the research at hand and between documents that were made for the specific research purposes at hand. For this study, it was important to remove the researcher's influence on the subject.

\section{Data Analysis Method}

In Vivo coding (please note, different from NVivo Qualitative Data Analysis Software) was applied for the analysis because it was necessary to label codes with the exact language the writers used in these units (Saldaña, 2016, p. 105). Saldaña (2016) explained "[a]s you read interview transcripts or other documents that feature participant voice, attune yourself to words and phrases that seem to call for bolding, underlining, italicizing, highlighting, or vocal emphasis if spoken aloud" (p. 106). In Vivo Coding allowed detection of the different ways the lexicon emerged. With this coding method, the research focused only on the concept of sustainability and highlighted words and phrases used by the writers to describe their sustainable practice. My themes therefore, emerged from my collapsed 
most common codes. Therefore, the themes that I deliver in my findings reflect the lexicon that emerged directly from the analyzed data.

This data analysis approach was useful for synthesizing the data into meaningful information and helped identify critical links and patterns in the data. Charmaz (2001) defined coding as the "critical link between data collection and their explanation of meaning" (Saldaña 2016, p. 3). In addition, analytical memos helped me reflect on meaning making with the data and to develop codes. This theoretical framework provided an opportunity to examine the selected institutions textual content through the specific lens of sustainability.

\section{Research Procedure}

Data collection began in October 2017 and ended on November 2017. The most recent magazine issues and web content were included in the data. Next, the entire textual content of the selected institutions was hermeneutically read with relevant content divided into units. Then, units that showed evidence of the three pillars of sustainability were marked for further analysis. Because sustainability is still considered a subjective and ambiguous term in graphic design, sustainability often appeared mixed with similar terms such as "responsible design" and "design for good." However, the analysis only considered a unit sustainable if it specifically mentioned the term sustainable or referred to it by the holistic approach of the triple bottom line, as demonstrated by Jedlička (2009a). This decision was made, due to the purpose of the current study, which was to understand what sustainability means when the selected institutions used the actual term. 
Coding commenced, identifying recurring themes. In Vivo Coding (Elemental Methods) were used for the first cycle coding. For the second cycle coding method, Focused Coding condensed codes into broader themes. Finally, themes were linked together and interpreted while connecting back to the literature review and theory at hand. Synthesizing data into useful information was essential to find patterns within the data.

Sustainability as an explicit concept and the three individual domains (social, environmental, and economical) were incorporated into the development of codes. Any sentence that mentioned or referred to the concept of sustainability was coded and analyzed. Some authors used terms as explicit synonyms for sustainability, such as ethical, social, green, responsible, and design for good; these sentences were also included. When sustainability and its three pillars were detected within the selected data, the sentence was underlined, and tagged as social, environmental, economic, or sustainable. This tagging method gave me further indication of which pillar was mentioned in the underlined sentence. I tagged the underlined sentence sustainable, only when sustainability was explicitly mentioned, or all three pillars were included in the same sentence, or in some cases, when sustainability was clearly understood from the textual context of the sentence.

Next, I entered all underlined sentences into Excel sheets, labeled with each tag (social, environmental, economic, and sustainable). Table 5 illustrates my tagging process. Table 5 demonstrates how codes emerged from the actual textual content of the data. For example, in Table 5 the first sentence consists of 
a sentence explicitly mentioning sustainability. However, the second (Unit 4) and fourth (Unit 4) sentences did not mention the term sustainability. Still, we know that the writer referred to sustainability because the sentence before and after in the same unit explicitly mentioned sustainability: "but the need for sustainable innovation is very much alive" (Unit 4). This is an example for using textual context in tagging. The seventh sentence (Unit 69) gives another example of my tagging method, for the case when the term sustainability was not explicitly mentioned, but the writer listed all three pillars of sustainability in his/her sentence (social, environmental, and economic), and therefore I tagged sustainable. 
Table 5

In Vivo Coding Method- Process

\begin{tabular}{|c|c|c|c|c|c|}
\hline Unit & Quotes & In Vivo Code 1. & In Vivo Code 2. & Focused Code & Tag \\
\hline 1 & $\begin{array}{l}\text { I believe design has the power to } \\
\text { lead the way for positive change, to } \\
\text { shift consumer behavior and lifestyle } \\
\text { aspirations toward a healthier and } \\
\text { sustainable future. }\end{array}$ & $\begin{array}{l}\text { Design has power } \\
\text { for positive change } \\
\text { sustainable future }\end{array}$ & $\begin{array}{l}\text { design for } \\
\text { change }\end{array}$ & $\begin{array}{l}\text { Design for } \\
\text { sustainable change }\end{array}$ & Sustainable \\
\hline 4 & $\begin{array}{l}\text { The budgets are a bit more modest } \\
\text { than they were a few years ago... }\end{array}$ & $\begin{array}{l}\text { than a few years } \\
\text { ago }\end{array}$ & $\begin{array}{l}\text { budgets more } \\
\text { modest }\end{array}$ & Challenge- budget & Sustainable \\
\hline 4 & $\begin{array}{l}\ldots, \text { but the need for sustainable } \\
\text { innovation is very much alive. }\end{array}$ & $\begin{array}{l}\text { need for } \\
\text { sustainable } \\
\text { innovation is alive }\end{array}$ & $\begin{array}{l}\text { need for } \\
\text { sustainability is } \\
\text { alive }\end{array}$ & $\begin{array}{l}\text { Sustainability is } \\
\text { relevant }\end{array}$ & Sustainable \\
\hline 4 & $\begin{array}{l}\text { But it [sustainability] does often } \\
\text { require patience to see the impact. }\end{array}$ & $\begin{array}{l}\text { require patience to } \\
\text { see the impact }\end{array}$ & $\begin{array}{l}\text { require patience } \\
\text { to see impact }\end{array}$ & $\begin{array}{l}\text { Challenges- more } \\
\text { time }\end{array}$ & Sustainable \\
\hline 7 & $\begin{array}{l}\text { The other challenge [sustainability] } \\
\text { is the time necessary to research } \\
\text { various materials and processes, a } \\
\text { process we often liken to } \\
\text { investigative journalism. }\end{array}$ & $\begin{array}{l}\text { challenge is time } \\
\text { research materials } \\
\text { and processes, } \\
\text { investigative } \\
\text { journalism. }\end{array}$ & $\begin{array}{l}\text { challenge time to } \\
\text { research } \\
\text { materials and } \\
\text { processes }\end{array}$ & $\begin{array}{l}\text { Challenges - more } \\
\text { time }\end{array}$ & Sustainable \\
\hline 60 & $\begin{array}{l}\text { The Living Principle for Design were } \\
\text { borne out of the design profession's } \\
\text { need for an aspirational and } \\
\text { actionable framework for integrated } \\
\text { sustainability-a common point of } \\
\text { reference to which all designers can } \\
\text { refer. }\end{array}$ & $\begin{array}{l}\text { design profession's } \\
\text { need for an } \\
\text { aspirational and } \\
\text { actionable } \\
\text { framework for } \\
\text { integrated } \\
\text { sustainability. }\end{array}$ & $\begin{array}{l}\text { design } \\
\text { profession's } \\
\text { need for an } \\
\text { actionable } \\
\text { integrated } \\
\text { sustainability }\end{array}$ & $\begin{array}{l}\text { Sustainability is } \\
\text { relevant }\end{array}$ & Sustainable \\
\hline
\end{tabular}


Table 5 Cont.

In Vivo Coding Method- Process

\begin{tabular}{lllll}
\hline Unit & \multicolumn{1}{c}{ Quotes } & In Vivo Code 1. & In Vivo Code 2. & Focused Code \\
\hline 69 & $\begin{array}{l}\text { Organizations are actively seeking } \\
\text { new problem-solving approaches } \\
\text { that respond to escalating business, } \\
\text { social, and environmental } \\
\text { challenges. }\end{array}$ & $\begin{array}{l}\text { Organizations are } \\
\text { actively seeking } \\
\text { problem solving } \\
\text { approaches to } \\
\text { [sustainability three } \\
\text { pillars] challenges }\end{array}$ & $\begin{array}{l}\text { organizations } \\
\text { are actively } \\
\text { seeking }\end{array}$ & $\begin{array}{l}\text { Sustainability is } \\
\text { relevant }\end{array}$ \\
& & & \\
& & & \\
& & & \\
\end{tabular}




\section{Verification}

I applied five approaches to secure validity in this research. First, the dissertation research faculty committee members were consulted on a regular basis when codes were to be established and analyzed. The researcher made sure that the critical lens of sustainability was systematically and consistently applied when coding, analyzing, and "themeing" (Saldaña, 2016, p. 68) the data. Please note that according to Saldaña (2016) "themeing" (p. 68) means to organize the analysis into main themes. Second, peer-review was used to ensure consistency and create trustworthiness within the analysis. Third, bracketing was also utilized to remain conscious of biases and assumptions. Fourth, "analytic memos" (p. 54) tracked decision making processes and rationale when coding and "themeing" (p. 68) the data. Lastly, a reflective journal was kept during this study. The reflective journal helped me to surface pre-assumptions in regards to the analysis of the data.

\section{Ethical Consideration}

In this study the researcher did not personally or financially benefit from this research. All data analyzed in this research were public records and were published in print or online. Therefore, there was no need to protect the identities of individuals or institutions. The dissertation proposal protocol was submitted to the West Virginia University Institutional Review Board (IRB) on November 14, 2017. IRB determined that this study did not meet the definition of human subject research and therefore, for this study, an IRB full review was not required. 


\section{CHAPTER 4: FINDINGS}

The literature review indicated a lack of consensus of what the term sustainability means in the graphic design industry. As a result, I examined the selected datasets for evidence of how sustainability is represented and in what way the three pillars are portrayed. This chapter also examines the balance and hierarchy of the three pillars of sustainability throughout the dataset. All sections provide a chart to visually demonstrate the findings.

Chapter four provides analysis of my findings in four sections. The first section identifies three main themes that appear in datasets 1-4, which were the four analyzed graphic design trade magazines. This section addresses my first research question (RQ1). The second section identifies three main themes found in dataset 5, which was the AIGA website textual content and addresses my second research question (RQ2). Section three provides insight to the three prevailing themes found in dataset 6 , which were the top ten graphic design academic programs' mission statements. This section addresses my third research question (RQ3). Section four explores the relationship and hierarchy between the three pillars of sustainability (social, environmental, and economic) within the entire data (RQ4).

\section{Graphic Design Trade Magazines}

In this section, I examined the main themes emerging from the data for the question: (RQ1) How have contemporary mainstream graphic design trade magazines articulated the concept of sustainability? Three main themes emerged from my analysis of the trade magazine data: challenge at 51 percent, design for 
2).

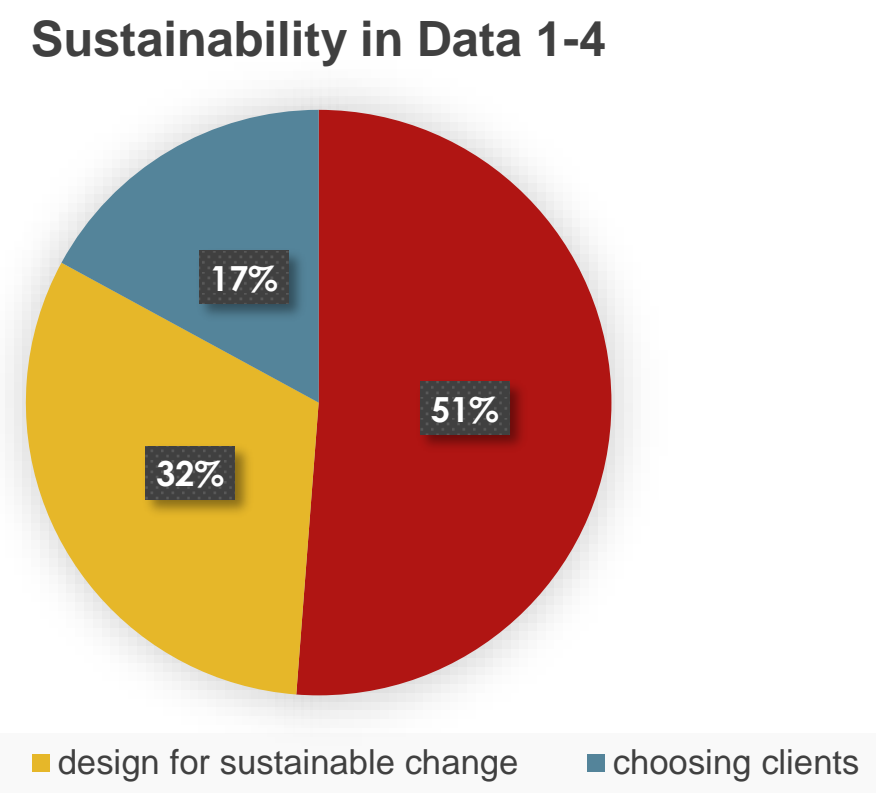

Figure 2. Sustainability in Data 1-4. This chart shows the three main themes of sustainability within the graphic design trade magazines (Data 1-4).

First theme. Of all the themes, the largest one, at 51 percent, was challenge. In this category, designers mentioned the challenges they faced while practicing sustainable graphic design, such as (a) the lack of standardized sustainable operational systems in place; (b) the higher cost of sustainable materials, which results in budgetary constraints; (c) the amount of time it takes to find sustainable materials and processes, due to the lack of sustainable resources available for designers; and (d) the current political climate. Each challenge is explored in more detail below.

Designers pointed out a lack of standardized sustainable operational systems in place that exist in the entire supply chain, beyond the graphic design 
profession. A sustainable designer argued that the sustainable packaging system is segmented and it needs to be fixed to design sustainably:

Within our specific niche of consumer packaging goods, there are pervasive problems if we ever want to be a truly sustainable society. One example is the disjointed material recovery system in the U.S. that has different processes and abilities for recycling and composting in each city and state, making it impossible to distribute truly sustainable CPG packaging nationally. (Unit 3)

However, this argument also revealed that sustainable graphic designers view their services as part of a larger holistic and multidisciplinary production chain system, rather than an isolated entity providing only visual services. Sustainable designers indicated that one designer cannot solve the problem by themselves; an interdisciplinary and collaborative design community including manufacturers must come together and create a standardized common approach for how to effectively operationalize each sector in a unified sustainable production chain. Because this common language does not yet exist, it will take some time and effort to create products and services that are truly sustainable.

Another challenge found in the data concerning sustainability was budgetary stress and concerns. Because the triple bottom line of sustainability includes the economic pillar, sustainable products and services must be economically profitable. A graphic designer pointed out that it is a significant problem, then, that "greener materials ... are more expensive than their conventional counterparts" (Unit 7). The higher manufacturing costs of 
sustainable products drive up the cost of sustainable solutions, leaving designers with less negotiating power to offer sustainable solutions to their clients: "overall one reason clients may be hesitant to commit could be the stigma that sustainability is inherently more expensive" (Unit 47). In addition, some designers referred to decreasing federal funding to support sustainable projects: "With state budget shortages and changing federal policies, we're thinking about ways to replace the potential loss of grant funding for several community projects and NPO clients that we work with" (Unit 16).

Many designers therefore indicated that they work pro-bono to help nonprofit organizations with good causes to subsidize the higher expenses of green practices. However, a designer acknowledged "Pro-bono work, while admirable, is not sustainable over the long term" (Unit 9). The way some designers try to compensate for the monetary loss was to "choose our corporate for-profit clients based on their willingness to support non-profit ventures...our selection criteria [for for-profit clients] in accepting businesses [includes] their willingness to pull alongside through their corporate responsibility policies" (Unit 17). This suggests that a graphic designer today needs to have a business strategy to mitigate the higher costs affiliated with sustainable manufacturing. One strategy mentioned in the data was to convince commercial clients to absorb some of the extra costs that the designer might lose while working for other clients that may prefer sustainable solutions.

Many designers indicated that designing sustainably is time consuming because there are no available resources on which designers can rely. A 
designer used the metaphor of "investigative journalism" to describe sustainable graphic design: "we read MSDS sheets [Material Safety Data Sheet], have conference calls with technicians and chemists, and ask vendors extremely specific questions they're often annoyed by" (Unit 7). This statement also connects to the previous challenge of the lack of a reliable sustainable supply chain. However, another designer voiced that despite the extra efforts and monetary investments that sustainable design needs, the benefits are not immediate and thus "it does often require patience to see the impact" (Unit 4).

Another challenge that graphic designers indicated was the "current political climate." As one designer noted, "federal environmental policies have changed for the worse." Another designer contended that the lack of federal environmental policies has caused less than ideal conditions for sustainability: "Since President Trump pulled the U.S. from the Paris Climate Accords and denies the reality of climate change, it's an uphill battle to achieve our mission" (Unit 15). Unless the government supports holistic initiatives toward sustainability, a common societal consensus toward sustainability is unlikely. Therefore, current efforts leading to sustainability, including for-profit and probono initiatives, are not enough to allow this vision to thrive. It requires collective action, including legislation and the federal government, to steer regulation toward creating a sustainable supply chain and marketplace where all three pillars of sustainability are considered. When this new system, operations, and regulations are fully established, new governments will be less likely to regress to unsustainable practices. 
All four challenges described in the data have a common emphasis on the lack of affordable and measurable sustainable systems for graphic designers. This gap can cause difficulties in providing consistent and reliable sustainable services to clients and customers. These challenges may not only cause a delaying effect on current sustainable efforts, but also may discourage potential designers from pursuing sustainable practices because of the additional uphill battles they may face.

Second theme. Design for sustainable change was the second most prevalent theme at 32 percent. Designers indicated that they saw the potential for the profession to be a force for changing public perception by incorporating design to advance sustainable lifestyles. A designer mentioned, "I believe design has the power to lead the way for positive change, to shift consumer behavior and lifestyle aspirations toward a healthier and sustainable future" (Unit 8). Designers not only want to avoid designs that may cause harm or "help sell products on a lie" to the public and the environment, but want also to be an engine that drives current mainstream culture to be more sustainable (Unit 47). Another graphic designer mentioned "graphic design has power. It's an incredible tool, and when wielded properly, it really can change the world" (Unit 45). A group of socially conscious and environmentally responsible graphic designers declared, "2017 is an incredible time and opportunity to use design for change" (Unit 5). These designers believe they can change how people behave through the conceptual power of their work. Designers have come to the realization that even though they may work on a single image, this image likely will be mass- 
produced. Therefore, their work will be interwoven into the collective fabric of the cultural consciousness.

It is important to note that designers turned to sustainable design out of a sense of moral obligation, which drew them away from traditional practice. In general, traditional practice has primarily concerned itself with aesthetics and functionality rather than morality. The data suggested that for sustainable designers it was important to produce work in which they find meaning by having a positive impact on the larger society and the environment. Some designers prefer to produce work that matters, work that adds a moral value to the commercial aspects of the profession. These sustainable graphic designers reported that they found little fulfillment in their commercial design work, thus causing them to seek out work that has a positive impact on the public and can actually change society for the better. According to one of the articles, "After a decade running a traditional firm, James felt like there had to be more to design... [therefore he transitioned] his company and career to focus on designing for social impact" (Unit 16). Another designer reported that "We are trying to give back to society from a profession where it's sometimes difficult to feel like you're bringing anything good to the group" (Unit 47).

Designers also contended that the power of graphic design rests within its mass-communicational quality. Because graphic designers work for the citizens of the world, graphic design has enormous power to change society for the better. One article featured a designer who said, "graphic designers have been branded by the establishment as the day laborers of the fine art world... the 
bastard of our creative craft... the boots-on-the ground" (Unit 45). But the source continued that precisely because graphic designers are serving the greater public, they are the artists who can actually impact people's lives the most:

[A]s the boots-on-the-ground, we're the ones who can use our skills to try to fix the bent and broken around us. Graphic design has power. In fact, it has a hell of a lot of power. It's an incredible tool, and when wielded properly, it really can change the world- or at least start to chip away at its archaic foundations. (Unit 45)

The emotional tone of this quote demonstrates the strong sense of moral purpose that guides graphic designers to work more sustainably.

Graphic designers believe they have enormous potential for achieving positive impact through their designs. For example, one designer mentioned, "we need to come to terms with the power and impact of our profession. We need to help mindfully bring a sustainable world into existence" (Unit 56). As another designer indicated, their mission was "to leverage the power of design to create social, environmental, and economic change" (Unit 17b). Graphic designers wield substantial power. After all, traditional designers operating on a non-sustainable paradigm allowed un-sustainable ideologies to perpetuate in the media in the first place. A graphic designer admitted that

[W]e unwittingly find ourselves as some of the chief architects of that denial [about the state of the world]...Don't belittle the power of graphic design. Don't rationalize your design contribution as a drop in the bucket 
or merely the result of your day job. Don't deflect blame to other industries.... Don't roll your eyes. And don't groan. (Unit 56)

The writer continued to say that "social norms have enabled such [unsustainable] behaviors, and reflecting and amplifying societal norms is a graphic designer's stock in trade" (Unit 56). If graphic designers have the power to modify social norms, they can also then consciously change and endorse more sustainable ideologies. In the words of one designer, "why can't the human footprint be a positive one?" (Unit 56). The author of this unit clearly called for a collective action rather than one-off sustainable initiatives. The author believed that only a unified community of designers could thus change perceptions of the future for a global audience. A common mission for designers can be to "not just solveproblems, but create sustainable solutions and systematic change for the global, social, environmental, and economic challenges we face" (Unit 8). Through the power of their work and with conscious design decisions, designers can perpetuate new ideologies leading toward a more sustainable future.

Third theme. At 17 percent, the second most commonly discussed theme was choosing clients. The code choosing clients indicated that the prevailing way to work sustainably for graphic designers was to choose their clients based on the client's sustainable values and work culture. Sustainable graphic designers "try to align [them]selves with likeminded clients who want to make their business more sustainable" (Unit 7). Many graphic designers mentioned that because there is still no affordable and reliable sustainable infrastructure in place, some graphic designers may feel little autonomy in negotiating with non-sustainable 
clients to choose sustainable solutions. Therefore, one of the few sources of control they have is through choosing their clients. To accomplish this, the data suggested that graphic designers are more likely to select sustainable companies and clients, when there are enough sustainable clients to keep their businesses alive:

We can make a living now in design without wreaking overconsumption havoc. We can choose our clients not simply based on how much money can be made, but on how promoting more of what they're selling contributes to or detracts from a healthy global environment and a robust social equity. (Unit 56)

Choosing likeminded clients who reflect their efforts and are aligned with their sustainable values gives graphic designers a sense of control. Therefore, the sustainable strategy that graphic designers embrace is working with clients who desire value and mission-driven projects such as: "[working with] mission-centric organic and natural product companies...cause-related projects within mental and physical health [and the] social and economic impact realm" (Unit 3).

In choosing clients, a sustainable graphic designer pointed out "One of the biggest in the industry involves the aforementioned greenwashing, and knowing how to take on the right clients-differentiating between the companies that are truly committed to a cause, and those who are not" (Unit 47). Therefore, another designer suggested to carefully "research the lifestyle impacts of their [clients] offerings" along with their "labor practices" (Unit 56). A sustainable project could 
include a numerous range of possibilities such as "art education, the environment, and women's issues" (Unit 43).

To remain productive and efficient in the current political climate, most graphic designers choose clients that are non-governmental and non-profit organizations: "At the start of 2017 all of my clients were social and environmental justice npo's," (Unit 11). However, many designers within the data noted that this work is still mostly pro-bono. This situation is problematic because to consider graphic design work sustainable, it needs to be economically feasible as well. This may suggest a lingering problem within the graphic design profession in establishing the balance between the three pillars of sustainability.

Conclusion. After examining the four most broadly circulated graphic design trade magazines, little substance emerged in how these institutions suggest realizing sustainable practices. The level of discourse within the magazines remained superficial compared to the detail offered in books on the topic of sustainable graphic design (Benson \& Perullo, 2017; Dougherty 2008; Dritz 2014; Gavos, 2012; Jedlička 2009a, b; and Sherin, 2013). For instance, though the magazines featured interviews (Unit 4, 15) with several experts in sustainable graphic design such as Eric Benson, Yvette Perullo, and Dougherty, the interview questions and editorial presentation of their work did not reflect the most important and incisive content and resources of their books. As the collective voice, the magazines missed the opportunity to introduce to their audience the resources and knowledge that the featured sustainable graphic designers accumulated. Instead, the dominating trends within these magazines 
emphasized challenges, design for sustainable change, and choosing clients. These intuitions steered the discourse toward highlighting the challenges that sustainable designers face, rather than their successes with sustainable design. The discourse within these institutions therefore, limited the conversation to what were their obstacles instead of what worked, and how to move forward. Their suggested strategy to use client selection to achieve sustainability is troublesome, because that indicates unwillingness on the part of the designer to implement sustainable practices on their own. This strategy of choosing clients as a mean for sustainability, puts the responsibility on the client, and leaves the designer in denial of their own culpabilities.

\section{American Institute of Graphic Arts}

In this section, I posit and then share the findings for the question: (RQ2) How has the American Institute of Graphic Arts (AIGA) communicated the concept of sustainability to their members? This section identifies the three major themes on the AIGA website to understand the textual implications of AIGA's current stances on sustainability. Sustainability was communicated through the AIGA website most frequently through and alongside three themes. Holistic emerged as the main theme of the examined AIGA's textual content at 45 percent. The theme Relevant and Actionable occurred at 33 percent within the AIGA website, similarly to the graphic design magazines. Design for sustainable change appeared at 22 percent (see Figure 3). In the following section these main themes are explored in more detail. 


\section{SUSTAINABILITY IN DATA 5}

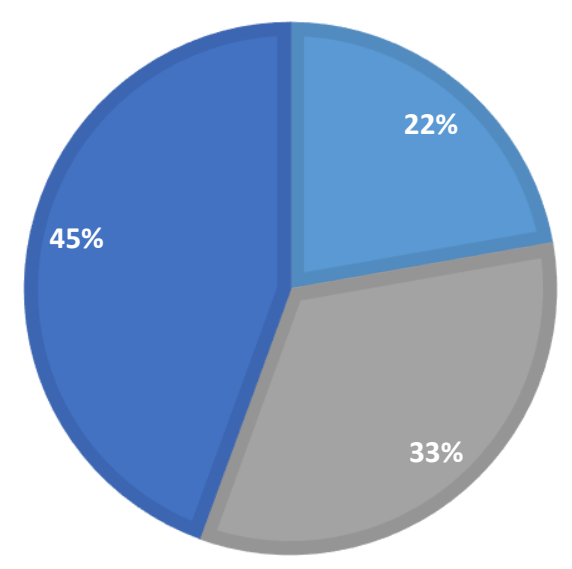

- design for a sustainable change $\quad$ relevant and actionable $\quad$ holistic

Figure 3. Sustainability in Data 5. This chart shows the main themes found within the online AIGA communication platform (Data 5).

First theme. The holistic theme surfaced as the most dominant theme in this data. The term holistic within the data emphasized the system thinking approach and the interconnected nature of sustainability. The theme, therefore, connects with Jedlička's $(2009$ a,b) sustainable design model, in which sustainability's three pillars (social, environmental, and economic) is perceived as interconnected spheres. The code holistic was given when the text highlighted the importance of multidisciplinary work and depicted the graphic design profession as part of the larger system rather than an isolated entity. The analysis suggested that the AIGA recognized the holistic approach of sustainable graphic design, arguing that designers cannot act alone as one-off operations within the production chain, and graphic designers may a need multidisciplinary skillset to operationalize sustainable practices. AIGA also emphasized the 
importance of achieving balance between the three pillars of sustainability, including social, environmental, and economic responsibilities (Unit 59).

Furthermore, the AIGA's Living Principle for Design provided a sustainable framework that added a fourth dimension to sustainability: culture. The AIGA added this category as they recognize the potential graphic designers have to influence large-scale cultural change. The AIGA's Living Principles for Design sought to "distill the four streams of sustainability [along with four streams of integrated sustainability] environment, people, economy, and culture" (Unit 59).

The AIGA thus recognized the importance of acting holistically in a systematic way so that graphic design may become a sustainable profession. For this end, the Living Principles for Design website offered comprehensive questions for designers to ask themselves when creating their designs. For instance, the AIGA asked designers to consider "How can you use this project to promote actions that protect and restore the environment? [and] as you consider your project from creation to end user, what materials are you using, and what potential intended or unintended ecological consequences can you foresee, including air quality and water?" (Unit 59). The AIGA website asked their readers to think about the entire life span of the product and ways to expand it. Also, they added, "how does the project affect various individuals and communities throughout its life, from makers to users and those involved in its disposal?" (Unit 59). The questions regarding waste were another example of the holistic nature AIGA framed sustainability to their members: "How can waste be eliminated? When your product's life span is completed, how can you 'close the loop' i.e. 
facilitate the use of materials in a continuous cycle?" (Unit 59). However, they do not offer any links to the resources mentioned in the literature review (pp. 49-63) to help designers put sustainability into practice.

The data also indicated that because sustainability's emphasis on the holistic would take complex planning and a paradigm shift from current practices, this monumental social change would take a significant amount of time to implement. The AIGA suggested graphic designers could, in the meantime, make informed decisions by choosing clientele that display sustainable values. Although choosing clients was an alternative method suggested to designers to work sustainably, this theme still did not make it to the main three themes at this dataset. The holistic aspect of sustainability surfaced as the dominant ethical responsibility of graphic designers. For instance, AIGA stated that designers should take a "responsible role in the visual portrayal of people, consumption of resources, and the protection of animals and the environment" (Unit 58). They should also ask themselves what emotional reactions do designs have on the customers and "what attitudes and values does your project promote both in its intention and its execution?" (Unit 59), which ties back to the idea of promoting one-off initiatives rather than a collective action taken toward sustainability. Thus, according to AIGA, designers must understand what philosophical lenses and ideologies they project to their audiences, along with what meanings their audiences might create from these works.

Second theme. The AIGA presented sustainability as relevant and actionable, and the organization emphasized the importance of taking immediate 
action to create sustainable change. On the Living Principles of Design webpage, the editors mentioned that the site was "born out of the design profession's need for an "aspirational" and "actionable framework for integrated sustainability" (Unit $60)$, which suggests that there is a demand and interest to learn about sustainable design within the graphic design profession. This statement therefore confirms Gavos's (2012) survey's findings. Gavos (2012) found that graphic designers showed an overwhelming interest in a proposed sustainable design certification. AIGA also wrote that "integrated sustainability [should be] accessible, relevant and ready to [be] put into action" (Unit 60). The AIGA stressed the urgency for creating designs with holistic and sustainable paradigms so that designers can take ethical responsibility of their work.

Third theme. This theme from the AIGA also was emphasized in graphic design magazines. However, this is the third category on AIGA's website at 22 percent while it was the second most emphasized factor in the magazines at 32 percent. Both media agree that graphic designers have significant power in shaping public perceptions of sustainability while making positive changes to the greater society. AIGA stated on their website that:

Design is a powerful conduit for change. As the message, artifacts and experiences we create pass through the hands, minds, and hearts of people, we have the opportunity to weave sustainability into the broader fabric of culture and to shift consumption and lifestyle aspirations to a more sustainable basis for living. (Unit 59) 
This quote indicates that graphic designers are gradually recognizing and coming to terms with the ideological impact of their work; therefore, they show eagerness to learn more about the way they can benefit and impact society for the better. The importance of this immediate action is integral, as graphic designers must be "a catalyst for driving positive cultural change" (Unit 60). The quote uses the pronoun "we" to emphasize the collective responsibility of all graphic designers to consider questions of sustainability in their work. The AIGA promoted and advocated for designers to investigate social and environmental issues to create a positive impact.

Conclusion. The examined AIGA platform focused on a different set of significant themes. While the AIGA also emphasized design for sustainable change, the next two most common themes stressed sustainability as holistic, along with relevant and actionable. Although the platform did not go into sufficient details or examples following their suggestions, it did acknowledge the need for a holistic system approach to achieve sustainability in the graphic design field. This was aligned with sustainability found in literature, and it is a distinct difference from the client selection strategy that was found within the previous dataset of the magazines, which shifts the responsibility from the designer to the client. This platform also illustrated sustainable graphic design as a relevant and actionable practice. AIGA provided a list of questions that sustainable practitioners could ask themselves, their clients, and their audience. These questions were promoted as a gateway to a more informed and realizable sustainable design practice. In this dataset, therefore, sustainable design was described as an 
urgent and simple process, which designers can easily incorporate into their practice.

\section{Graphic Design Higher Educational Programs}

In this section, I composed my findings for the third research question: (RQ3) How have the mission statements and web textual content of graphic design higher education departments conceived of sustainability? This section identifies the three major themes that emerged from analyzing the mission statements and web content of ten university programs' websites to understand the textual implications of their collective attitudes toward sustainability. The most prominent three themes were: (a) holistic at 60 percent (b) sustainable design education at 20 percent, and (c) relevant and actionable at 20 percent (see Figure 4). 


\section{Sustainability in Data 6}

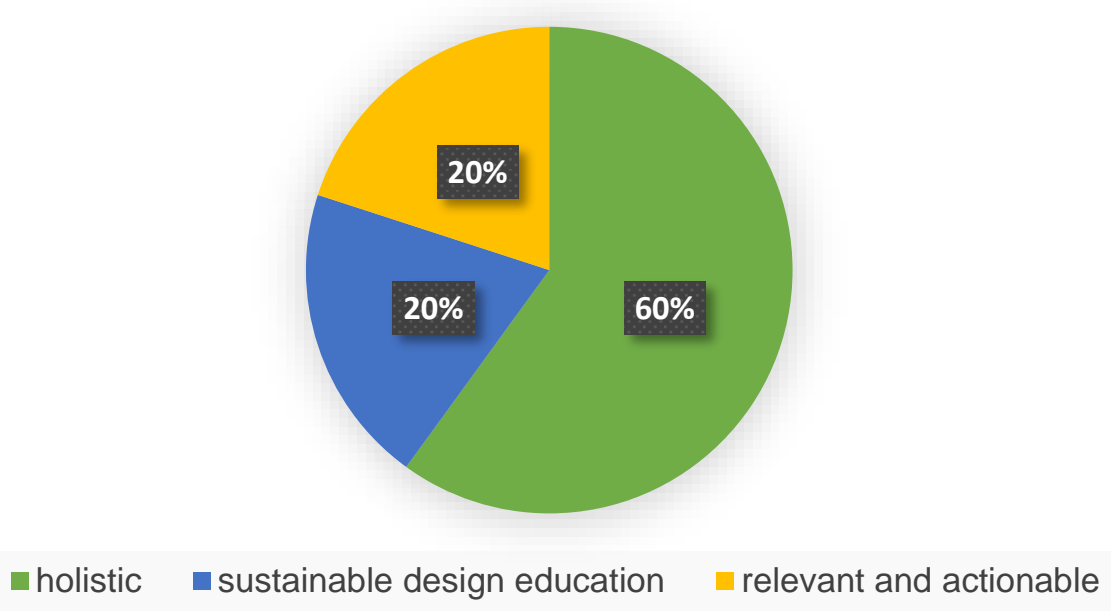

Figure 4. Sustainability in Data 6. This chart illustrates the three main themes that emerged in the textual content of ten graphic design university programs (Data 6).

In Figure 5, I demonstrate the frequency of emerging codes regarding sustainability. Please note that this type of comparison may only be relevant in this dataset, due to the proximately equal structure and length of each unit. This comparison shows that there were significant differences in the focus on sustainability of these best graphic design programs. Most of the analysis therefore came from Units 63, 66 and 69. However, the low sustainable initiative in the top graphic design school is part of the significance of my findings. This finding therefore indicated that currently sustainability is not the top priority for most of the leading programs. However, it also indicated that two schools within the ten graphic design programs in the United States do believe sustainability is one of its main foci. 


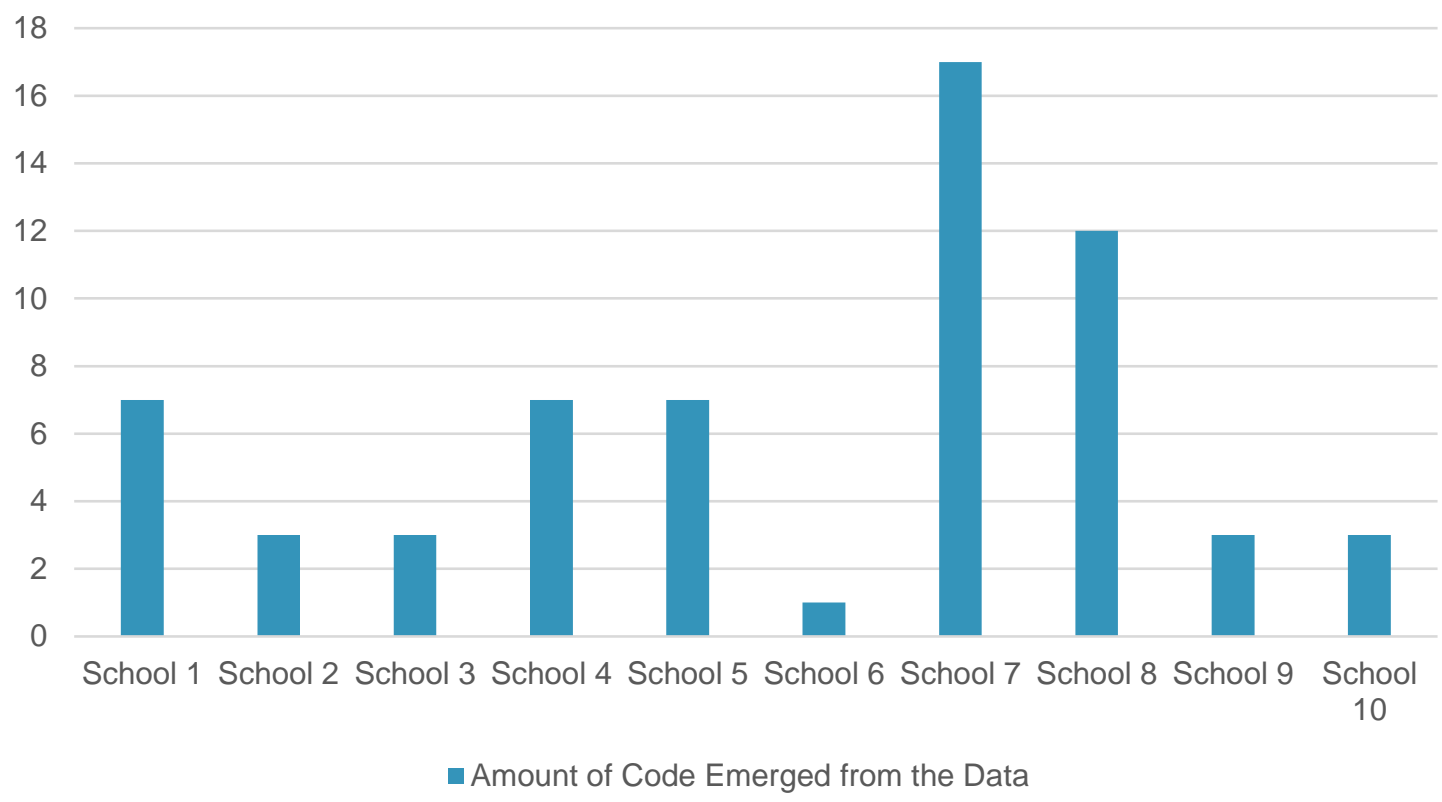

Figure 5. Distribution of Codes within the Academic Programs. This chart shows the amount if sustainable codes that emerged from the data distributed per university (each university was a separate unit).

The analysis of dataset 7 showed that although many of the examined higher educational graphic design programs showed some efforts to include sustainability in their mission statement and program description, in most cases the examined programs were demonstrating a strong ethical stance for the profession rather than focusing specifically on sustainability. Only two of the ten university programs showed specific focus on integrating sustainability with their curriculum. For example, a higher educational statement noted "We're also one of the first programs to integrate topics of sustainability and social innovation into the core of our research and curriculum" (Unit 69).

First theme. The most noticeable theme among the 10 graphic design programs regarding sustainability was focusing on its holistic quality, putting emphasis beyond the economic value of design: 
Our approach acknowledges the social and natural worlds as the greater context for all design problems. Designers can no longer think about products or communications in isolation; to practice ethically and effectively, they must also consider interactions within broader social and environmental context. (Unit 69)

The examined university programs emphasized the need of whole-system thinking when mentioning sustainability. Whole-system thinking is a key component of the concept of sustainability: "Our students become system thinkers able to see and solve complex problems in a globally connected and interdependent world...They are comfortable working collaboratively in transdisciplinary teams...that helps them stand out among their peers" (Unit 69). This quote illustrated that sustainability requires a whole-system thinking approach to be successful, but it also indicated that this holistic and transdisciplinary method sets future graphic designers apart from the current mainstream educational trends. Currently, in graphic design system, students not only lack the ability to work collaboratively but also lack the training to work outside their own disciplinary apparatus to communicate with other disciplines. The majority consensus among these universities is that because graphic design is a service provider, it requires a multidisciplinary approach to solve sustainable challenges.

Second theme. Both the sustainable design education and relevant and actionable codes were equally presented at 20 percent each. I will start discussing the sustainable design education first. The sustainable design 
education code revealed that universities stressed the importance of sustainable design education as a key strategy to shift the graphic design industry into a sustainable one. These institutions illustrated a need to implement the concepts of sustainability into the foundational training of graphic designers. However, due to the nature of the short mission statements, these platforms did not offer specifics on what sustainable education is. This may become more apparent through an analysis of their course offerings and curriculum, but their definition of sustainable education is not explicit in the examined data. An educator noted that "we are one of the first programs to integrate the topics of sustainability and social innovation into the core of our research and curriculum" (Unit 69). The aim of these universities was to implant a new generation of holistic and multidisciplinary thinkers and makers to be the future innovators of the field.

Third theme. Graphic design higher education programs also found it integral to emphasize what they term the relevant and actionable nature of sustainability. These programs use this term to emphasis sustainability as an achievable and realistic aim of graphic design, but one that requires urgency. This theme occurred on the AIGA's website; although there, it was the second largest theme occupying 33 percent, whereas educators only place it at 20 percent. The educator from one of the universities mentioned that "organizations are actively seeking new problem-solving approaches that respond to escalating business, social, and environmental challenges" (Unit 69). This quote suggested that a market exists for sustainable graphic designers. Therefore, future designers can no longer be trained in the old-fashioned way as isolated entities 
focusing only on aesthetic problems. These universities encourage their students to be "active creators for a better future" (Unit 69).

Other educators indicated that finding meaning and fulfillment is important in design education; therefore, they turn to sustainability. Finding meaning and fulfillment in sustainable education today requires students to not only master "the rigors of the craft" but also to "challenge the status quo" (Unit 66). One academic institution argued a sustainable university program prepares students "for meaningful creative life by developing their intellectual capacity to create art, shift perspective, think broadly, and master skills relevant to the twenty-first century" (Unit 66). This quote points back to thinking broadly, which is the holistic nature of sustainability. It also talks about shifting perspective, which refers to a design for change, in order to stay relevant.

Conclusion. When analyzing the mission statements and web textual content of the top graphic design higher education departments, the study revealed that there was little sustainable focus within these graphic design educational programs. All ten schools mentioned the need to follow the ethical guidelines, and this dataset obtained the most accurate alignment with the sustainability literature. This dataset conceived sustainability as a holistic, relevant and actionable, and suggested that more sustainable education was needed. 


\section{Three Pillars of Sustainability}

In section four, I address the research question: (RQ4) In what ways were the three pillars of sustainability (social, environmental, and economic) presented within the data? I also examine how the frequency of the different pillars of sustainability emerged in the data. Because the hierarchy of the three pillars is important for understanding how the profession conceives sustainability, this section analyzes which of the three pillars were the most dominant and popular, or whether the pillars were equally emphasized.

The social pillar. My analysis of the three pillars indicated that the discussions around sustainability within the selected data had a social focus (see Figure 6).

\section{Three Pillars of Sustainability}

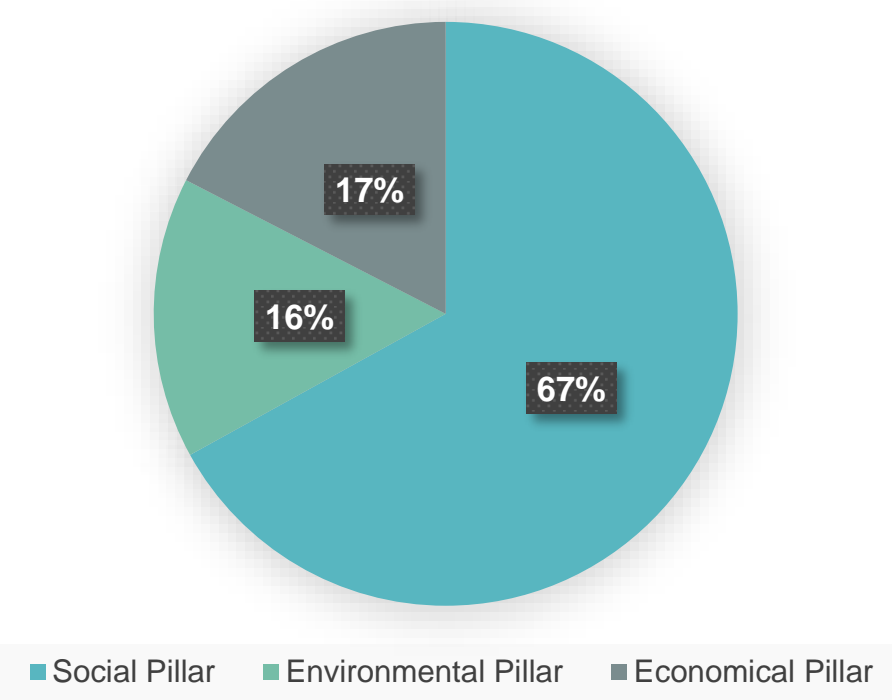

Figure 6. Three Pillars of Sustainability. This chart shows the distribution of the three pillars of sustainability within the entire examined data. 
This finding suggested that graphic design institutions perceive sustainability from a social aspect, which can be associated with the human-centered design and socially conscious design (Buchanan, 2001; Heller \& Vienne, 2003; Resnick, 2016; Scalin, 2012; Shea, 2012; and Simmons, 2011). Even when the institutions were talking about protecting the environment, they approached the issue from a social perspective. For example, the AIGA pointed out that sustainability is not "for trees or frogs or polar bears, but for human lives. And livelihoods. This we know: the planet will go on without us. But we cannot go on without it. At its core, sustainability is about people" (Unit 59). Furthermore, this finding also showed that not only were graphic design institutions more likely to approach environmental protection issues from a human-centered perspective but also, they chose sustainable materials because they felt a strong social responsibility to other human beings as opposed to the natural environment. The spirit that unifies this pillar is the humanist point of view of designers: designers view sustainability as a long-term benefit to humanity.

The environmental and economic pillars received significantly less attention in the dataset. Mentions of green or environmentally friendly materials were scarce within the data. During the few times sustainable materials or processes were mentioned, the emphasis was on the challenges such as the higher cost associated with these sustainable materials and their manufacturing processes. The economic pillar was the least significant within the data when mentioning sustainability. Most institutions within this data reported that graphic designers worked pro-bono and subsidized their sustainable projects with grant 
money and commercial sponsors. The challenges of the economic pillar appeared together with the lack of a sustainable supply chain, which drove up the costs of sustainable manufacturing.

Conclusion. After my analysis of the data, I propose a model that reflects the current view of the examined institutions' views on sustainability. This model (Figure 7) depicts how graphic design institutions perceived sustainability within this specific data. In this model, sustainable graphic design is projected from a social lens, in which these institutions believe that the mission of design is to empower society to change its social perceptions and behaviors by advocating for the ideology of sustainability.

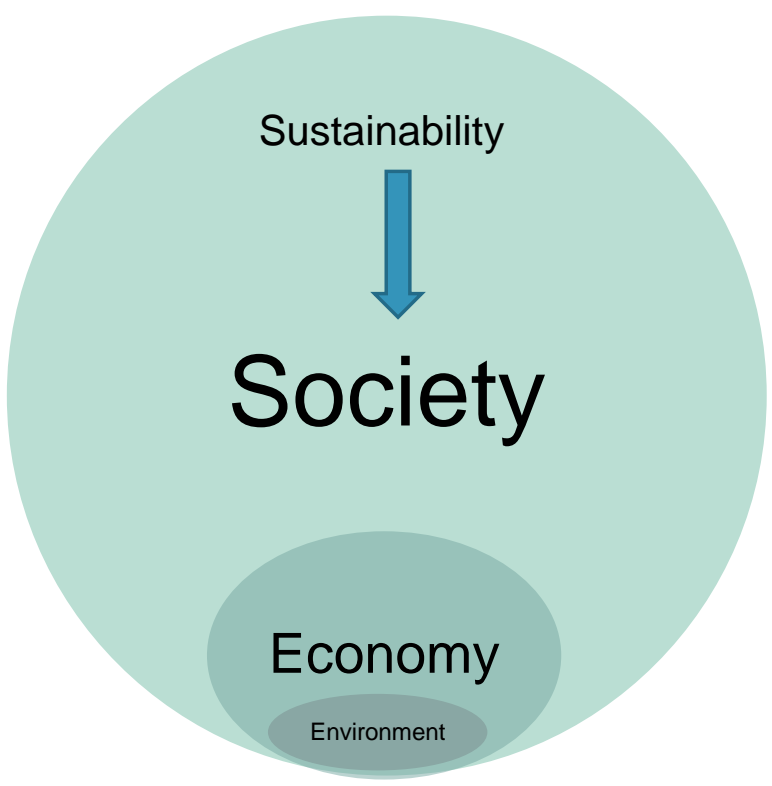

Figure 7. Model of Sustainability within the Data. This chart shows how sustainability was perceived within the data.

Another significance in the finding was that the analyzed institutions perceived the environment as a necessity of society's well-being, in which the society contained or controlled the environment. This model (Figure 7), therefore, 
is the exact opposite of Jedlička's sustainable design model. The emerging model (Figure 7) is linked to the institutions' arguments that if human behavior, propagated by graphic designers was the cause of the environmental depletion, graphic designers can also fix it. Graphic design institutions thus feel that their mission is to empower individual designers to take action for a more sustainable future. The following quote is an example that describes this phenomena: "We [graphic designers] created a new epoch on this planet. A dubious accomplishment as it stands today. ...Since we've started the Anthropocene, let's make damn sure it's an epic epoch" (Unit 56). These institutions suggested that more focus on the environment would inevitably benefit society. Graphic designers/advertising professionals are trained to sell a product promising benefits for the consumer. Graphic design institutions thus suggest the question: what greater benefit for society could there be than the well-being of the environment-i.e., the society controls the environment and thus the environment is contained within society.

The new model emerged from the data showed that the environment and the economy are two variables that both impact the well-being of a prosperous society. However the society was depicted as the dominant pillar that controls both the environment and the economy. Because graphic designers were presented within these institutional platforms as adamantly believing in their role to impact society, they can thus do so by perpetuating their work that will benefit the society, economy and the environment. 


\section{Overview and Discussion of Sustainability within the Data}

This final section provides an overview of the prevalence of the three main themes found within the entire data. In this analysis, I included only codes that were tagged sustainable, and examined them throughout the entire dataset. Section five thus offers a discussion about sustainability as an explicit term used within the data. My findings in this chapter link the three themes to the theories introduced in the literature review.

This research finding strengthened the results of the pilot study (Kadas \& Britten, 2017) that was conducted on a smaller scale, the single issue of GD USA 2016 October graphic design trade magazine. The ambiguity of the undefined concept of sustainability remained a concern through the current larger dataset. GD USA described the socially and environmentally conscious design as "wellmeaning but narrow." In lieu of "sustainable," they called it "responsible design," a term that substituted for "sustainable design" (p. 28). Within the current dataset I found that responsible design was many times used as a synonym for sustainable, socially, and environmentally conscious or ethical design.

This study revealed the three main themes concerning sustainability were: challenges at 46 percent of the data, design for change at 36 percent, and relevant and actionable at 18 percent (Figure 8). In the following I provide an overview of the prevalence of the three main themes throughout the entire data. 


\section{Concept of Sustainability within the Data}

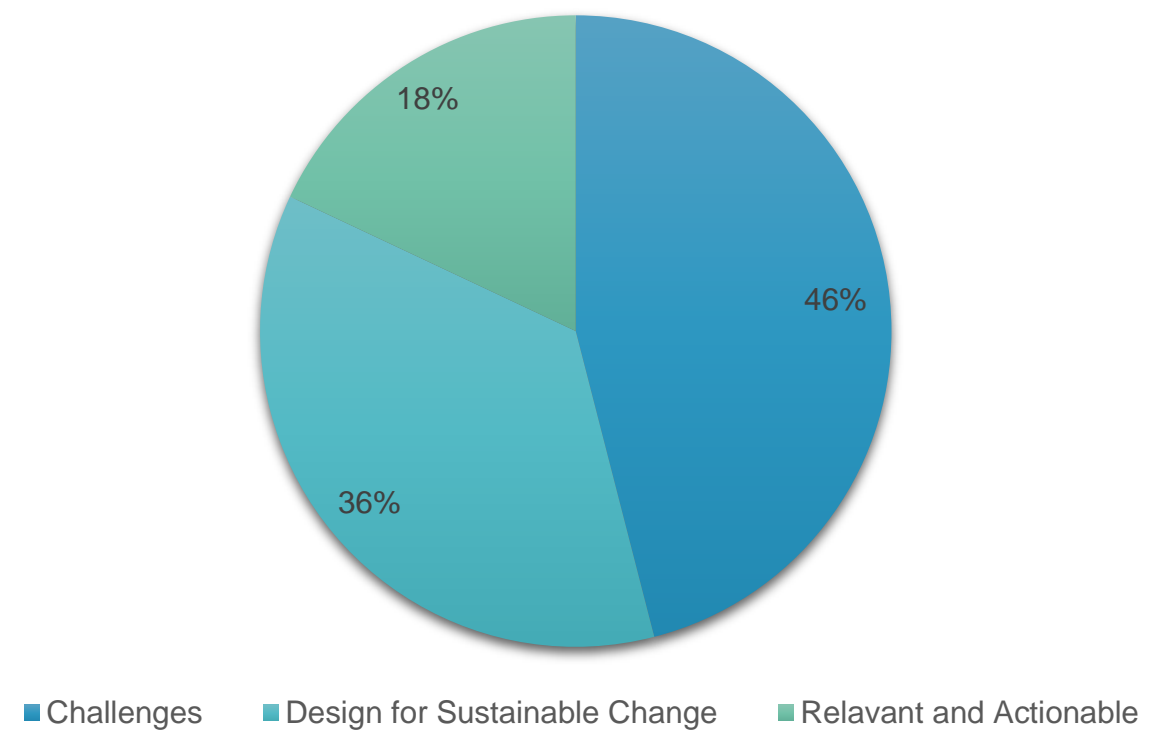

Figure 8: Concept of Sustainability within the Data. This chart documents the three dominant themes that surfaced across the entire data

First theme. The first most common theme was challenges. All institutions explored frequently mentioned a lack of sustainable systems in place, the lack of clear guidelines, and the amount of time it takes to research new sustainable avenues. This theme surfaced in 46 percent of the entire analyzed data, which made it the most prevalent theme of sustainable graphic design. This indicated that sustainability was overall presented in the three selected graphic design institutions as a struggle and an "uphill battle" (Unit 15). These challenges were focusing on various gaps in the field of graphic design regarding sustainability, such as efficiency, profitability, the absence of reliable sustainable systems in place, and the lack of standards. In most cases, sustainable design was depicted as a pro-bono activity, and designers had to find other income to support their moral calling. Also, the current 2017 political climate was mentioned as a setback 
for sustainable initiatives. These institutions described the year 2017 as a difficult time to maintain a sustainable business. Because challenge was the main theme in the discourse of sustainability, overall the data projected a weak motivation toward pursuing a sustainable graphic design career.

Although sustainability was featured within the data, it did not give the impression of a collectively approved and rationalized concept, but rather an emotionally charged argument. Sustainability was described mainly as a passion project, apart from the commercial day job of a graphic design. These challenges were contrasted with an optimistic tone of the power of design that can change the world for the better. The claims that graphic designers can help overhaul the current unsustainable system were coded as design for sustainable change.

Second theme. The second most common theme found was design for sustainable change, meaning that institutions conceptualized design as a conduit for change. The data showed many claims of the power of graphic design to create change in the behaviors and attitudes of consumers, users, and the public. These institutions depicted graphic design as a creative activity that "has enormous power for change... strong design can move people and get results" (Unit 5). Within all examined institutions there was a clear advocacy for social equality and environmental causes. Furthermore, there was an underlying belief that graphic design has the power to change public perception and behavior for the better. This was the second most frequent theme; it occupied 36 percent of the analyzed data. 
This analysis found that throughout the data, the arguments for sustainable design remained shallow and artificial with dominantly empty phrases. Also, all sustainable units lacked specific examples of how to create sustainable graphic design. The next quote is an example of how the superficiality of sustainable graphic design was framed within these datasets:

[Design Studio] is more than just socially conscious and environmentally responsible graphic designers, they are a community of passionate thinkers and doers who share beliefs and invest their energies in ethical organizations that are working together to make a positive and significant impact in our world. (Unit 5)

Although this quote included key words such as "socially conscious, environmentally responsible, and ethical," it did not discuss how the institution plans to bring those effects about, nor included any examples of sustainable design work. This created an overall feeling of empty phrases, as sustainable design was shown only in words and not in action. In the next quote we can detect this common pattern:

[N]ever believe that your desire to make a living and do right by the world is naïve. Instead, ask them what they've been doing while the world's been coming apart at the seams.... The only option we have now is to make it great-ecologically regenerative, socially equitable and prosperous for all. As graphic designers we can revel in the irony that much of our future work, while as ephemeral as always, will encourage notions of permanence—of lovingly built on adaptability, resilience, 
collaboration and respect for diversity in all matters - that the vessels of our present design work will scarcely comprehend. (Unit 56)

This quote is an example of a sustainable designer that did not mention any specifics on how they plan to create a better world. The designer was building his arguments on emotions rather than facts. The writer of this unit defended his sustainability argument solely with subjective phrases such as "great, resilience, and respect," while missing the opportunity to support his sustainability argument with examples and ideas of how to operationalize these concepts. However, this quote also indicated another lingering issue that was present within the data. These institutions presented sustainable designers as outsiders, cast out from the commercial graphic design world due to their moral callings. From the entire data only one of the university programs pronounced sustainability as an actual and realizable concept that would add value to their graduates. This academic program (Unit 69) used concrete and accurate language in its mission statement and that was aligned with the concept of sustainability as presented in the literature review.

Third theme. The third most frequent theme was relevant and actionable. This theme resided in 18 percent of the entire analyzed data. This theme embraced the urgency of taking immediate action toward sustainable design that can impact a global sustainable change. Sustainability was described as an ambitious but relevant practice. AIGA was the only platform that presented efforts to compose a set of questions that would help designers combat the ambiguity of 
sustainability. However, the rest of the data did not show any evidence or suggestion of how to realize sustainability within the graphic design field.

The higher education programs also presented sustainability as relevant and actionable. It is necessary to mention, that although the data depicted sustainable design as a highly demanded service for the market, there were also several remarks that sustainable design was not profitable, leading many designers to do the work pro-bono. This theme indicated that addressing sustainable design is not only appropriate for the market and the client, but also it is key for graphic designers who have good intentions and desire to have a positive impact and create meaningful work. However, when clients' desires are at odds with sustainable design ethics, clear and objective standards are needed to support designers' negotiations. Therefore, sustainable design allows designers to have the meaning and significance that they feel is lost when working traditionally. Comments such as "After 15 years of running a traditional graphic design studio, I was searching for something more" illustrate the need for designers for sustainability for their own personal fulfillment as well (Unit 5). This theme can be tied to the philosophical argument of Kant and Schiller (Tolstoy, 1995) of the moral obligation of art. Also, this theme can be connected with Findeli's (1994) Space of Artifacts model, in which it is necessary to have threshold of significance for an object to be called design or art. The threshold of significance includes the social and environmental and other moral obligations of an artifact. 


\section{Visual Representation of Sustainability}

Although this analysis was limited to the textual content of the selected institutions, a prominent pattern was detected within the visual presentation of the text; the data lacked evidence of specific examples of sustainably designed work. Most of the images that the three examined institutions demonstrated as sustainable design work were profile pictures introducing the designers themselves, rather than showcasing images of their actual designs. This deviated from patterns found elsewhere in traditional, non-sustainable units, where the content was dominated by images of designers' work. This may signify that sustainability appeared only on the surface rather than establishing exceptional sustainable design precedents.

Even when institutions did display examples of sustainable work, there is no means of measuring or confirming the extent to which any given design project is sustainable. Because there is a lack of regulation, accountability, and assessment within the graphic design profession, whether internally or from thirdparties, it is difficult to establish a sustainable profile for displayed work. This may be mitigated somewhat through provision of more detailed description. There is often a lack of descriptive notes next to images, where materials and methods of the design may be communicated. Lacking such information, sustainable work may not be distinguished visually. Further, this problem may contribute to the institutional belief that graphic designers are not responsible for the negative impact of the media through which they are using to convey their messages. 
To conclude, the entire data focused primarily on the significant challenges faced by graphic designers interested in pursuing sustainable practices, yet also that performing such design for change is an important task relevant to the entire industry and deserving of further sustained action. 


\section{CHAPTER 5: CONCLUSION}

The aim of this research was to understand the meaning of sustainability within selected institutions that comprise the graphic design profession. The overarching research question was: How does the collective voice of selected graphic design institutions conceptualize sustainability? To assess this question, this research was divided into three sub-questions, which I answered in Chapter 4. This chapter offers concluding remarks as to what sustainability meant overall in the entire data.

\section{The Meaning of Sustainability}

When looking at the collective articulation of the emerging themes, some underlying values came to the surface. The preliminary claim drawn from literature was that there was a lack of standards and consensus about the definition of sustainable graphic design (Chick \& Micklethwaite, 2011; Dritz 2014; Gavos, 2012; Jedlička et al., 2009; and Perkins, 2006), which was evident within this data. Many graphic designers showcased by the examined institutions believed that working for a good cause is sufficient to be called a sustainable designer. As many corporate businesses are incorporating sustainable efforts into their business model (Verghese, Lewis, \& Fitzpatrick, 2012; Kiron, Unruh, \& Kruschwitz, et. al., 2017), graphic designers may be left behind in offering a reliable and consistent sustainable graphic design service.

While the study showed that there was sustainable discourse present within the examined data, there was a lack of consistency in its definition; 
therefore, the concept of sustainability was presented as vague. As there are still no criteria and assessment in the graphic design field for sustainability, the concept of sustainability becomes equivocal. Because sustainability in graphic design can mean many things, the result was that it became meaningless. The analysis found that the examined institutions sold sustainability as an ideology, and projected sustainability as a vehicle to change the world for the better. For instance, statements such as "if designers are willing to convincingly bring visions of more sustainable realities into existence, more people will embrace their inherent possibilities" set the tone of the examined data (Unit 56). The projected sustainable graphic design ideology was based on the moral judgment of the designer, and was often described as an idealistic and naïve aim that was increasingly challenging to achieve. This better world was often described as transparent, ethical, and socially and environmentally conscious; however, there were no displayed examples or explanation of the details of sustainable practices.

Although in many cases sustainability was described as relevant and actionable, there were no examples or criteria to follow. Often, the examined institutions portrayed sustainability as a means to fill the designers' practice with meaning and purpose. The examined institutions depicted sustainability as a fulfilling activity from which designers may draw meaning and satisfaction. In this way, sustainable design was often contrasted with traditional graphic design activities, which according to the units tagged as sustainable lacked any moral purpose. Overall, within the examined data, sustainability was presented as a 
flexible concept with no specific guidelines, nor images of the successful sustainable work to illustrate the institutions' commitment to sustainability.

My findings highlight that sustainable graphic design was framed as a powerful tool to change society for the better. However, my findings also suggest that graphic designers currently lack the tools and resources to measure their impact on society and the environment, and their communication principles are often based on intuitions rather than information. Furthermore, sustainability was depicted from a social perspective, focusing on the way sustainable design ultimately benefited the people.

\section{Discussion}

This study found that there are potentially many factors delaying the adoption of sustainable practices in the graphic design field. The findings indicated a connection with the literature, which pointed out that graphic designers are "service providers" (Cramsie, 2010). Cramsie's claim can be associated with the choosing clients theme found in the data. Most graphic designers showcased in the examined institutions reported that choosing clients—based on value alignment—was their only option to work sustainably.

This theme is a manifestation of the projected beliefs that graphic designers have limited sovereign decision-making opportunity as service providers. But the phenomenon of the inherent dependence on clients' values is juxtaposed against the promoted slogan that graphic designers can change the society for the better. Therefore, a contradiction surfaced, which reflected both the power and powerlessness of the graphic design profession. 
This contradiction recognizes that graphic designers exist between the realm of the high arts or the symbolic arts and the realm of functionality. Design practice has to have both symbolic and functional drives in order to fully realize its potential. The status of sustainable graphic design as leaders rather than service providers could be established by teaching graphic design in conjunction with different majors, such as communication, media, science, and technology. Graphic design is still taught and conceived as an artistic craft that is occupied with aesthetics of form and composition; however, graphic design is also conceived as a commercial visual communication tool applied to the media, affecting a global audience, with the objective to sell and inform. When this duality is addressed, new innovative platforms and multidisciplinary collaborations may take place to fill the void of sustainable graphic design. As such, the NASAD guidelines clearly stated the need for a comprehensive design education that includes the core principles of sustainable design; now it needs to be actualized within the constraints of the relationship between symbolism and functionality.

\section{Contribution}

This study built on the premise that the way institutions project ideas shape the beliefs and behaviors of its members and the industry. Therefore, this study was the first step to understand the larger discourse of sustainability in the graphic design field. By conducting textual analysis of documents published by the three representative institutions of graphic design, (a) the American Institute of Graphic Arts (AIGA), (b) professional trade publications, and (c) academic 
graphic design departments, I was able to identify the main themes that are most dominant in today's representation of sustainability within its core institutions. This research also detected lingering gaps in the selected institutions that may indicate directions for future research. Such research can help the field move toward a consensus about what sustainability is as well as how it is discussed and projected to current and future graphic design professionals. It is necessary to reiterate that this research finding cannot be generalized. These findings are relevant only within the specific context of the examined data. As such, this empirical study may signal directions for future research and indicate gaps and discrepancies that may need to be overcome to move toward a sustainable graphic design industry.

The significance of this research study was to provide a foundation about how sustainability was communicated to graphic design professionals through the three selected institutions to move toward establishing clear standards for sustainable best practices. This study can also serve as a model to motivate graphic designers to conduct research that would help integrate sustainable graphic design practices into the commercial graphic design industry.

\section{Opportunities for Future Research}

The next steps could be to expand this study by conducting interviews with graphic design professionals to include the voice of individual designers into the equation. This expansion would increase the variety of point of views and would aim to understand how the institutional promotion of sustainability infiltrates into beliefs of the individual designers. It also would be vital to 
systematically examine the actual work of sustainable graphic designers and see underlying similarities and trends with what the designers say and do. This larger data collection set would expand understanding of the meaning of sustainability in order to move towards a consensus of how to practice sustainability within the graphic design field.

Because graphic design in most cases mass produced and targeting mass audiences, I argue that it would be essential to establish strong ethical conduct toward its public responsibility. Although there is an abundance of literature on sustainable graphic design, it is essential to stress the need to incorporate social research into the graphic design field. Social research methods could add value to graphic designers work and elevate its significance. This additional method tool may help graphic designers understand the scope and complexities of their profession and mitigate the negative impact on society and the environment. New methods may be applied from other design disciplines besides social research as well. It may include borrowing communication and business strategies to learn how to incorporate sustainable graphic design methods into the profession.

Because graphic designers may work in multidisciplinary teams within the supply chain, this study suggests that further multidisciplinary research is needed to examine how to operationalize a sustainable supply chain that includes graphic design services. A future multidisciplinary research would be crucial to map out and standardize the best sustainable design practices relevant to the supply chain. It is fair to conclude that sustainable graphic design can only be 
established when perceived holistically and as a system affected by and affecting other connected areas and disciplines.

A first step toward sustainability is to increase the graphic designers' interest and motivation in participating in multidisciplinary empirical and scholarly research. Packaging design is one of the areas in which much research has been done concerning sustainability—predominantly by engineers and product designers. However, it may be an effective collaboration if graphic designers would join the conversation and be part of these research teams. In fact, this can be true for many closely related fields where sustainability has been adopted.

\section{Researcher Reflection}

It is necessary to acknowledge the inherent biases which shaped the outcome of this research. As a practicing graphic designer, I learned that combining my artistic intuitions with empirical research furthered my growth as a sustainable designer. The most challenging aspect of the analysis for me was to find the right methodology and coding method. I started off my data analysis with different analytical approaches (Descriptive coding and Concept coding) but soon I realized these coding methods did not yield useful information to answer my research questions. However, when I began coding with In Vivo coding technique, my data crystalized. Another positive experience that I recall with In Vivo coding method was that after conducting the analysis the codes organically connected with my literature review. All units related together and confirmed the major problems that the literature review pointed out about the delay in sustainability in the field of graphic design. I found that expanding my research to 
three selected institutions helped triangulate my findings and enriched the data source for my study. I believe that the textual document analysis of these institutions provided sufficient data to find the patterns and links that helped to further the understanding of the delay in the shift toward sustainable practices in the graphic design profession. 


\section{REFERENCES}

Abendroth, L. M., Bell, B., \& Ebrary, I. (2016). Public interest design practice guidebook: SEED methodology, case studies, and critical issues. New York, NY: Routledge.

Abramovitz, J.N. \& Mattoon, A. T. (1999). Paper cuts: Recovering the paper landscape. Danvers, MA: The Worldwatch Institute.

Adams, S. (2014). "Learning Graphic Design History." Lynda.com. Retrieved from https://www.lynda.com/Graphic-Design-tutorials/Learning-GraphicDesign-History/166781-2.html

Alexander, E. R. (2006). Institutional design for sustainable development. The Town Planning Review, 77(1), 1-27.

Almudhaf, S. (2017). Design for a sustainable future: An autoethnographic examination of practical applications of sustainability for design education (Order No. 10286703). Available from ProQuest Dissertations \& Theses Full Text. (1935613048). Retrieved from https://search.proquest.com/docview/1935613048?accountid=2837

Altheide, D. L. (1996). Qualitative media analysis (Vol. 38). Thousand Oaks, CA: Sage Publications.

Altheide, D. L. (2000). Tracking discourse and qualitative document analysis. Poetics, 27(4), 287-299.

American Institute of Graphic Arts (AIGA). (2010). AIGA Standards of professional practice. Retrieved from https://www.aiga.org/standardsprofessional-practice.

American Institute of Graphic Arts (AIGA). (2015). Retrieved from http://www.aiga.org/

Anderson, E. H., \& Spencer, M. H. (2002). Cognitive representations of AIDS; A phenomenological study. Qualitative Health Research, 12, 1338-1352.

Anderson, J. L., Jolly, L. D., \& Fairhurst, A. E. (2007). Customer relationship management in retailing: A content analysis of retail trade journals. Journal of Retailing and Consumer Services, 14(6), 394-399. 
Armstrong, H. (2012). Graphic design theory: Readings from the field. New York: Princeton Architectural Press.

Ary, D, Jacobs, L.C, \& Sorensen, C. (2006). Introduction to research in education ( $8^{\text {th }}$ Ed.). Belmont, CA: Wadsworth Cengage Learning.

Assadourian, E. (2010). The Rise and fall of consumer cultures. In L. Starke \& Mastny (Eds.), State of the World: Transforming cultures from consumerism to sustainability. (pp. 3-23). New York, NY: W. W. Norton \& Company.

Bennett, A. (2006). Design studies: Theory and research in graphic design. New York: Princeton Architectural Press.

Benson, E. \& Perullo Y. (2017). Design to renourish- Sustainable graphic design in practice. FL: CRC Press, Taylor \& Francis.

Benyus, J. M. (1997). Biomimicry: Innovation inspired by nature ( $1^{\text {st }} \mathrm{Ed}$.). New York, NY: Morrow.

Berger, P., \& Kellner, H. (1981). Sociology reinterpreted: An essay on method and vocation ( $1^{\text {st }}$ Ed.). Garden City, NY: Doubleday Anchor Press.

Bierut, M. (1994). Looking closer: Critical writings on graphic design. New York, NY: Allworth Press.

Bogdan, R. C., \& Biklen, S. K. (1998). Qualitative research for education: An introduction to theory and methods. Boston: Allyn and Bacon.

Boylston, S. (2009). Designing sustainable packaging. London: Laurence King.

Bowen, G. A. (2009). Document analysis as a qualitative research method. Qualitative Research Journal, 9(2), 27-40.

Brown, P., \& Schmidt, J. (2014). Living in the Anthropocene: Business as usual, or compassionate retreat? In R. Orr (Ed.) State of the world: Governing for sustainability (pp. 63-71). Washington, D.C.: Island Press.

Bucci, D. Z., \& Forcellini, F. A. (2007). Sustainable packaging design model. In G. Loureiro \& R. Curran (Ed.), Complex systems concurrent engineering: Collaboration, technology, innovation, and sustainability (pp. 363-370). London: Springer-Verlag. 
Buell, L. (2005). The future of environmental criticism: Environmental crisis and literary imagination. Malden, MA: Blackwell Pub.

Carnegie Classification of Institutions of Higher Education (2017). Institution Lookup. Retrieved from http://carnegieclassifications.iu.edu/lookup/lookup.php.

Carr, E. (2009). Applying LEED principles to graphic design. AIGA Center for Sustainable Design. 10/1.

Carroll, J. (2012). Foreward. In K. Verghese, H. Lewis, \& L. Fitzpatrick (Ed.), Packaging for sustainability. (pp. v-vi). London: Springer.

Carson, D., \& Blackwell, L. (1996). The end of print: The graphic design of David Carson. San Francisco, CA: Chronicle Books.

Celery Design Collaborative. (2015). Retrieved from http://www.celerydesign.com/eco-tools.

Chan, J. (2016, June). Afterthought to precondition re-engaging design ethics from Technology Sustainability and Responsibility. 2016 Design Research Society Conference. Brighton, England.

Chase, S. (1966). The tyranny of words. San Diego, CA: Harcourt Brace Jovanovich.

Chiapponi, M. (1998). Environmental design and industrial design: Integrating knowledge around urgent issues. Design Issues, 14(3), 74-84.

Chick, A. \& Micklethwaite, P. (2011). Design for sustainable change: How design and designers can drive the sustainability agenda. New York, NY: Bloomsbury Academic Publishing.

Chick, A. (2012). Design for social innovation: emerging principles and approaches. Iridescent, 2 (1), 52-64.

Communication Arts. (2016). 57/1.

Cook N. (2008). Design and responsibility: The interdependence of natural, artificial, and human systems. In Philosophy and design: From engineering to architecture. (259-269). Dordrecht, NL: Springer.

Cramsie, P. (2010). The story of graphic design: From the invention of writing to the birth of digital design. New York: Abrams. 
Cezzar, J. (2015). What is graphic design? AIGA. Retrieved from http://www.aiga.org/guide-whatisgraphicdesign.

Chafetz, J. S., Lorence, J., \& Larosa, C. (1993). Gender depictions of the professionally employed: A content analysis of trade publications, 19601990. Sociological Perspectives, 36(1), 63-82.

Coffey, A. (2013). Analyzing documents. In U. Flick ( $1^{\text {st }}$ Ed.), The Sage handbook of qualitative data analysis. (367-379). Thousand Oaks, CA: Sage Publications.

Crawford, T. (2005). The Graphic Design Business Book. New York: Allworth Press.

Creswell, J. (2013). Qualitative Inquiry \& Research Design. (3 ${ }^{\text {rd }}$ Ed.). Thousand Oaks, CA: Sage Publications.

Crotty, M. (1998). The foundations of social research: Meaning and perspective in the research process. Thousand Oaks, CA: Sage Publications.

D’Andrade, G. (1984). Cultural meaning systems, In Shweder and R. LeVine (Ed.) Culture theory: Essays on mind, self and emotion. (88-119). Cambridge, England: Cambridge University Press.

Davis, M. (2012). Graphic design theory. New York: Thames \& Hudson Inc.

Denzin, N., \& Lincoln, Y. (2013). Collecting and interpreting qualitative materials (4 $4^{\text {th }}$ Ed.). Thousand Oaks, CA: Sage Publications.

Dresner, S. (2002). The principles of sustainability. Abingdon, Oxon: Routledge.

Dritz, A. (2014). Closing the Sustainability Gap: The Emerging Role of Sustainable Graphic Designer (Master thesis Minneapolis College of Art and Design). Retrieved from http://amydritz.prosite.com/

Dominic, C.A.S., Östlund, S., Buffington, J., \& Masoud, M. M. (2015). Towards a conceptual sustainable packaging development model: a corrugated box case study packaging technology and science. Packaging Technology and Science, 28, 397-413.

Dougherty, B. (2008). Green graphic design. New York, NY: Allworth Press. Edwards, A. (2005). The sustainability revolution - portrait of a paradigm shift. Gabriola, BC, Canada: New Society Publishers. 
Elkington, J. (1998). Cannibals with forks: The triple bottom line of 21st-century business. Gabriola Island, BC, Canada: New Society Publishers.

Ensure sustainable consumption and production patterns. Retrieved from http://www.un.org/sustainabledevelopment/sustainable-consumptionproduction/

Eskilson, S. (2012). Graphic design: A new history. New Haven, CT: Tale University Press.

Esslinger, H. (2012). Design forward: Creative strategies for sustainable change. Stuttgart, Germany: Arnoldsche Verlagsanstalt.

Field, C. B., \& Intergovernmental Panel on Climate Change. Working Group II. (2014). Climate change 2014: Impacts, adaptation, and vulnerability. Cambridge, England: Cambridge University Press.

Findeli, A. (2001). Rethinking design education for the 21st century: Theoretical, methodological, and ethical discussion. Design Issues, 17(1), 5-17.

Findeli, A. (1994). Ethics, aesthetics, and design. Design Issues, 10(2), 49-68.

Fine, P. C. (2016). Sustainable graphic design: Principles and practices. New York, NY: Bloomsbury Academic Publishing.

Fisher, T. (2010). Designing for re-use: The Life of consumer packaging. London, England: Earthscan.

Florman, S. (1987). The civilized engineer (1 ${ }^{\text {st }}$ Ed.). New York, NY: St. Martin's Press.

Frascara, J. (2004). Communication Design-Principles, Methods, and Practice. New York, NY: Allworth Press.

Frascara, J. (2006). "Graphic Design: Fine Art or Social Science?" Design Studies: Theory and Research in Graphic Design. Bennett, A. (Ed.). New York, NY: Princeton Architectural Press.

Fry, T. (2009). Design futuring: Sustainability, ethics, and new practice. New York, NY: Berg.

Fuad-Luke, A. (2009). Design activism: Beautiful strangeness for a sustainable world. London: Earthscan. 
Gadamer, H.G. (1976). Philosophical hermeneutics. Berkley, CA: University of California Press.

Gadamer, H.G. (1984). The hermeneutics of suspicion. In G. Shapiro \& A. Sica (Eds.), Hermeneutics: Questions and prospects (pp. 54-65). Amherst, MA: University of Massachusetts Press.

Gavos, R. (2012). The sustainable design office: leed-type certification (Master thesis Texas A\&M University-Commerce).

Garland, K. (1964). First things first: A Manifesto. London, England: Goodwin Press Ltd.

Garland, K. (1966). Graphics handbook. New York, NY: Studio Vista.

Gibboney, R. K. (2013). Community as client: Defining social design as a means of designing for good.

Gibson, B., (2009). Working with qualitative data. Thousand Oaks, CA: Sage Publications.

Glaser, M. (2002). The Road to Hell. Metropolis.

Gomez-Palacio, B. (2009). Graphic design, referenced: A visual guide to the language, applications, and history of graphic design. Beverly, MA: Rockport Publishers.

Gowdy, J. (2014). Governance, sustainability, and evolution. In R. Orr (Ed.), State of the World: Governing for Sustainability (pp.31-39). Washington, D.C.: Island Press.

Graphic Design USA (2016, September/October) 31/4.

Graphic Design USA (2017, April). Highest honors: 2017 top design schools. 3542.

Greenwood, J. (1994). Action research and action researchers: Some introductory considerations. Contemporary Nurse (3)2, 84-91.

Grigsby, K. A., \& Megel, M. E. (1995). Caring experiences of nurse educators. Journal of Nursing Education 34, 411-418.

Groenewald, T., (2004). A Phenomenological Research Design Illustrated. International Journal of Qualitative Methods, (3)1, 42-55. 
Groth, C. (2006). Exploring packaging design. Clifton Park, NY: Thomson Delmar Learning.

Gupta, A. E., Zimmerman, T. S., \& Fruhauf, C. A. (2008). Relationship advice in the top selling women's magazine, Cosmopolitan: A content analysis. Journal of Couple \& Relationship Therapy, 7(3), 248-266.

Hawken, P., Lovins, A. B., \& Lovins, L. H. (1999). Natural capitalism: Creating the next Industrial Revolution. Boston, MA: Little, Brown and Co.

Heidegger, M., \& Dahlstrom, D. (2005). Introduction to phenomenological research (Studies in continental thought). Bloomington, IN: Indiana University Press.

Heller, S. \& Vienne, V. (2003). Citizen designer: Perspectives on design responsibility. New York, NY: Allworth Press.

Heller, S., \& llić, M. (2012). Stop think go, do: How typography \& graphic design influence behavior. Beverly, MA: Rockport Publishers.

Heller, S. (2014). Design literacy: Understanding graphic design. New York, NY: Allworth Press.

Hickle G. (2009).The Changing landscape: Laws and regulations. In Jedlička, W. (Eds.), Packaging sustainability: Tools, systems, and strategies for innovative package design (pp. 107-115). Hoboken, NJ: John Wiley \& Sons.

Holland D. (2001). Design Issues: How Graphic Design Informs Society. New York, NY: Allworth Press.

Jonas, W. (2001). A Scenario for design. Design Issues, 17(2), 64-80.

Jedlička, W., Amel E., \& Baumeister D. (2009a). Packaging sustainability: Tools, systems, and strategies for innovative package design. Hoboken, $\mathrm{NJ}$ : John Wiley \& Sons.

Jedlička, W. (2009b). Sustainable graphic design: Tools, systems and strategies for innovative print design. Hoboken, N.J: John Wiley \& Sons.

Jobling, P. (2003). Lavin, Maud. Clean new world: Culture, politics and graphic design. (MIT press, 2001). Journal of Design History, 16(3), 260-262.

Johnson, A. (2014). Packaging for sustainability. Hoboken, NJ: Wiley-Blackwell. 
Kadas, S., Britten, B. (2017). Exploring the concept of sustainability within the GD USA magazine. Unpublished manuscript.

Kiron, D., Unruh, G., Reeves, M., Kruschwitz, N., Rubel, H., \& ZumFelde, A. M. (2017). Corporate sustainability at a crossroads. MIT Sloan Management Review, 58(4)

Klöpffer, W.; \& Grahl, B. (2014). Life cycle assessment: A Guide to Best Practice. Hoboken, NJ: John Wiley \& Sons.

Laszlo, C. (2003). The Sustainable company: How to create lasting value through social and environmental performance. Chicago, IL: Shearwater Books.

Laszlo, C. (2008). Sustainable values: How the world's leading companies are doing well by doing good. Stanford, CA: Stanford business books.

Lavin M. (2001). Clean new world - culture, politics, and graphic design. Cambridge, MA: MIT Press.

Lee, G. (2002). Selling the internet: An analysis of advertisements for the internet and related products in "Time" magazine, 1995-2000. (Doctoral dissertation). Retrieved from ProQuest. http://search.proquest.com/docview/305508516?accountid=2837.

Lupton, E., Phillips, J. (2008). Graphic design: The new basics. Baltimore; NY: Princeton Architectural Press.

Maclntyre, A. J. (2003). The power of institutions: Political architecture and governance. Ithaca, NY: Cornell University Press.

Madge, P. (1993). Design, ecology, technology: A historiographical review. Journal of design history, 6(3), 149-166.

Madge, P. (1997). Ecological design: A new critique. Design Issues, 13(2), 4454.

Maniates, M. (2010). Editing out unsustainable behavior. In L. Starke \& Mastny (Eds.), State of the World: Transforming cultures from consumerism to sustainability. (pp. 119-126). New York, NY: W. Norton \& Company.

Manion, M. A. (2010). The Wiley encyclopedia of packaging technology. Middletown, CT: American Library Association. 
Manzini, E. (1992). Prometheus of the everyday: The Ecology of the artificial and the designers' responsibility. Design Issues, 9(1), 5-20.

Manzini, E. (1994). Design, environment and social quality: from "existenzminimum" to "quality maximum". Design Issues, 10(1), 37-43.

Manzini, E. (2003). Hong Kong as "laboratory of the future". Design Issues, 19(3), 59-70.

Manzini, E. (2014). Making Things Happen: Social innovation and design. Design Issues, 30(1), 57-66.

Margolin, V. (1998). Design for a sustainable world. Design Issues, 14(2), 83-92.

May, T. (2011). Documentary research: excavation and evidence. In Social research: Issues, methods and process. (191-218). Maidenhead, England: McGraw-Hill Education.

McGee T., Baumeister D. (2009). Biomimicry. In Jedlička, W. (Eds.), Packaging sustainability: Tools, systems, and strategies for innovative package design (pp.158-223). Hoboken, NJ: John Wiley \& Sons.

McDonough, W., \& Braungart, M. (2002). Cradle to cradle: Remaking the way we make things (1st Ed.). New York, NY: North Point Press.

McLuhan, M. (1964). Understanding media: The extensions of man. New York, NY: McGraw-Hill.

McLuhan, M., \& Fiore, Q. (1967). The medium is the massage. New York: Bantam Books.

McNamara, C. (2009). System Thinking. In Jedlička, W. (Eds.), Packaging sustainability: Tools, systems, and strategies for innovative package design (pp. 133-140). Hoboken, NJ: John Wiley \& Sons.

Meggs, P. B. (1998). A history of graphic design (3rd Ed.). New York, NY: John Wiley.

Merriam, S. (2002). Qualitative research in practice: Examples for discussion and analysis ( $1^{\text {st }}$ Ed.). San Francisco, CA: Jossey-Bass.

Merriam, S. (2009). Qualitative research: A guide to design and implementation. San Francisco, CA: Jossey-Bass, 139-163. 
Meyer, J. M. (2015). Engaging the everyday: Environmental social criticism and the resonance dilemma. Cambridge, MA: The MIT Press.

Micklethwaite, P., \& Chick, A. (2005). Remarkable pencils Itd: Breaking out of the green niche. Design Management Review, 16, 23-28.

MIT Sloan Management Review and Boston Consulting Group (2012).

Environment; nearly a third of companies say sustainability is contributing to their profits, says MIT sloan management review-Boston consulting group report. Business \& Finance Week, 798.

Mitchell, W. J.T. (2002). Showing seeing: A critique of visual culture. Journal of Visual Culture, 1(2), 165-181.

Mitchell, W. J.T. (2005). What do pictures want: the lives and loves of images? Chicago, IL: University of Chicago Press.

Molleda, J. C., \& Laskin, A. V. (2005). Global, international, comparative and regional public relations knowledge from 1990 to 2005: A quantitative content analysis of academic and trade publications.

Morton, T. (2007). Ecology without nature: Rethinking environmental aesthetics. Cambridge, MA: Harvard University Press.

Moustakas, C. (1994). Phenomenological research. Thousand Oaks, CA: Sage Publications.

Nair, S. (2014). Handbook of research on higher education in the MENA region. In Ethics in higher education (pp. 230-260). Hershey, PA: IGA Global

NASAD Handbook. (2018). NASAD. Retrieved from https://nasad.artsaccredit.org/accreditation/standards-guidelines/handbook/.

Nederhof, A.J. and Meijer, R.F. (1995). Development of bibliometric indicators for utility of research to users in society: Measurement of external knowledge transfer via publications in trade journals. Scientometrics 32 (1), 37-48.

Nordin, N., \& Selke, S. (2010). Social aspect of sustainable packaging. Packaging Technology and Science, 23, 317-326.

Northwest Product Stewardship Council (NWPSC). (2015). The Problem: volume, waste, cost, design. Retrieved from http://productstewardship.net/products/packaging. 
O2 International Network for Sustainable Design. (2015). Retrieved from http://www.o2.org/

Oki, Y., \& Sasaki, H. (2000). Social and environmental impacts of packaging (LCA and assessment of packaging functions). Packaging Technology and Science, 13, 45-53.

Orr, D. W. (2002). The nature of design: Ecology, culture, and human intention. New York, NY: Oxford University Press.

Oxford English Dictionary (OED), (2017). Retrieved from https://en.oxforddictionaries.com/definition/us/sustainability

Pantzar, M. (1997). Domestication of everyday life technology: Dynamic views on the social histories of artifacts. Design Issues, 13(3), 52-65.

Pantzar, M. (2000). Consumption as work, play, and art: Representation of the consumer in future scenarios. Design Issues, 16(3), 3-18.

Parsons, T. (1977). The Institutionalization of Belief. Sociological Analysis, 38(2), 137-139. doi: $10.2307 / 3710175$

Patrick, I. (Ed.). (1998). Social constructionism, discourse and realism. Retrieved from http://ebookcentral.proquest.com

Perkins, S. (2006). Ethics and Social Responsibility. The Professional Association for Design Retrieved from www.aiga.org/ethics-and-socialresponsibility/.

Polanyi, M., \& Prosch, H. (2014). Meaning. Retrieved from http://ebookcentral.proquest.com

Poynor, R. (1999). The First Things First Revisited. Émigré, 51.

Ram, K., \& Houston, C. (2015). Phenomenology in anthropology: a sense of perspective. Retrieved from https://ebookcentral.proquest.com

Renner, M., \& Prugh, T. (2014). Failing governance, unsustainable planet. In R. Orr (Ed.) State of the world: Governing for sustainability (pp.320).Washington, D.C: Island Press.

Re-nourish (2015). Retrieved from http://www.re-nourish.com/?l=home "Responsible Design" (2016) Graphic Design USA. October, 2016, 4, 28-47. 
Resnick, E. (2016). Developing citizen designers. New York, NY: Bloomsbury Academic.

Robertson, M. (2014). Sustainability principles and practice. Abingdon, Oxon: Routledge.

Rowledge, L. R., Barton, R. S., \& Brady, K. S. (1999). Mapping the journey: Case studies in strategy and action toward sustainable development. Sheffield: Greenleaf.

Russ, T. H. (2010). Sustainability and design ethics. Boca Raton, FL: CRC Press, Taylor \& Francis Group.

Saldaña, J. (2016). The coding manual for qualitative researchers (no. 14). Thousand Oaks, CA: Sage Publications.

Scalin, N. (2012). The Design activist's handbook - How to change the world (or at least your part of it) with socially conscious design. Cincinnati, $\mathrm{OH}$ : How Books

Scalin, N. (2017). Forward In Design to renourish- Sustainable graphic design in practice (vii-viii). Boca Raton, FL: CRC Press, Taylor \& Francis Group.

Schreier, M. (2012). Qualitative content analysis in practice. Thousand Oaks, CA: Sage Publications.

Scott, W. R. (1995). Institutions and organizations. Thousand Oaks, CA: Sage Publications.

Selke, S. (1994). Packaging and the environment. Lancaster, PA: Techonomic Publishing Company, Inc.

Seyle, C., Wilburg, K. (2014). Understanding Governance. In R. Orr (Ed.) State of the world: Governing for sustainability (pp. 20-30).Washington, D.C: Island Press.

Shaughnessy, A. (2005). How to be a graphic designer, without losing your soul. New York, NY: Princeton Architectural Press.

Shea, A. (2012). Designing for social change: Strategies for community-based graphic design (1st Ed.). New York, NY: Princeton Architectural Press.

Sherin, A. (2008). SustainAble: A handbook of materials and applications for graphic designers and their clients. Beverly, MA: Rockport Publishers. 
Sherin, A. (2013). Sustainable thinking: Ethical approaches to design and design management. New York, NY: Bloomsbury Academic Publishing.

Simmons, C. (2011). Just design - Socially conscious design for critical causes. Cincinnati, OH: How Books.

Singer, P. (2002). One world: The Ethics of globalism. New Haven, MA: Yale University Press.

SRDS. (n.d.). Communication Arts [Publication Profile]. Retrieved March 11, 2017, from SRDS Media Solutions Database.

Strauss, A. \& Corbin, J. (1998). Basic of qualitative research: Techniques and procedures for developing grounded theory ( $2^{\text {nd }}$ ed.). Thousand Oaks, CA: Sage.

Sustainable Packaging Coalition® (SPC). (2015). Retrieved from http://www.sustainablepackaging.org/

"Sustainable Design Dictionary" (2017). Retrieved from http://www.aiga.org/sustainable-design-dictionary/

Sweeney, S., \& Hollifield, C. A. (2000). Influence of agricultural trade publications on the news agendas of national newspapers and news magazines. Journal of Applied Communications, 84(1), 23-45.

Szenasy, S. S. (2012). Reflections on Sustainable Design. Journal of Interior Design, (37)7, 10.

"The Copenhagen Letter." (2017). Retrieved from https://copenhagenletter.org/

The Living Principles: Creative Action for a Collective Good (AIGA). (2015). Retrieved from http://ivingprinciples.aiga.org/

Tolstoy, L. (1995). What is art? London, England: Penguin Books.

Triggs, T. (2002). [Review of Clean New World: Culture, Politics and, Graphic Design]. Design Issues, 18(3), 93-95. Retrieved from http://www.jstor.org/stable/1512071

Triggs, T. (2009). Designing graphic design history. Journal of Design History, 22(4), 325-340.

Triggs, T. (2010). Graphic design history: Past, present, and future. Design Issues, 27(1), 3-6. 
United Nations Environment Programme, (UNEP), Global partnership on waste management. (2015). Retrieved from http://www.unep.org/gpwm/Background/tabid/56401/Default.aspx United Nations Framework Convention on Climate Change. (2016). Retrieved from www.unfccc.com.

United Nations World Commission. Our common future. (1987). Retrieved from http://www.un-documents.net/our-common-future.pdf

United States Department of Labor. (2018). "Graphic Design," Occupational Outlook Handbook. U.S. Bureau of Labor Statistics. Retrieved from https://www.bls.gov/ooh/arts-and-design/graphic-designers.htm\#tab-1. United States Environmental Protection Agency (EPA). (2015). Retrieved from http://www.epa.gov

United States Environmental Protection Agency (EPA). (2016). Advancing Sustainable Materials Management: 2014 Fact Sheet. Retrieved from http://www.epa.gov

van Manen, M. (2007). Phenomenology of practice: Meaning-giving methods in phenomenological research and writing. Phenomenology \& Practice, 1(1), 11- 30.

van Manen, M. (1990). Researching lived experience: Human science for an action sensitive pedagogy. Albany, NY: State University of New York Press.

Verghese, K., Lewis, H., \& Fitzpatrick, L. (2012). Packaging for sustainability. London, England: Springer.

Vermaas, P. (2008). Philosophy and design: From engineering to architecture. Dordrecht, NL: Springer.

Vitell, S., \& Singhapakdi, A. (2008). The Role of Ethics Institutionalization in Influencing Organizational Commitment, Job Satisfaction, and Esprit de Corps. Journal of Business Ethics, 81(2), 343-353.

Walker, S., \& Giard, J. (2013). The handbook of design for sustainability. New York, NY: Bloomsbury Academic. 
Waste Management, International Journal of Integrated Waste Management, Science and Technology. (2015). Retrieved from http://www.journals.elsevier.com/waste-management/

World Commission on Environment and Development. (1987). Our common future. Oxford; NY: Oxford University Press.

Worthington, R. (2014). Digitization and Sustainability. In R. Orr (Ed.) State of the world: Governing for sustainability (pp. 53-63).Washington, D.C: Island Press.

Young, O. R., King, L. A., \& Schroeder, H. (2014). Institutions and environmental change: principal findings, applications, and research frontiers. Cambridge, MA: MIT Press

Ytre-Arne, B. (January 01, 2011). 'I want to hold it in my hands': readers' experiences of the phenomenological differences between women's magazines online and in print. Media, Culture and Society, (33)3, 467-477.

Zanna, M. P. (2011). While waiting for nature to take her course: There's nothing so practical as a good...design. Journal of Social Issues, 67(3), 651-662.

Zucker, L. (1977). The Role of Institutionalization in Cultural Persistence. American Sociological Review, 42(5), 726-743. 


\section{VITA}

Szilvia Kadas is a practicing graphic designer, researcher, and educator. In 2008, Kadas earned a Bachelor of Design degree in visual communication from Bezalel Academy of Art and Design and she earned her Master of Fine Arts (MFA) degree in graphic design and printmaking from the University of Arkansas in 2011. In addition to her MFA, Kadas also completed her Master of Arts in art history at West Virginia University (WVU). Kadas will complete a multidisciplinary doctoral program and she will earn her Doctor of Philosophy degree in human and community development at the School of Design and Community Development at WVU in August 2018. Overall, Kadas's theoretical research explores the social, environmental, historical context, and ramifications of design. 